Aus der Klinik für Psychiatrie und Psychotherapie

(Prof. Dr. med. J. Wiltfang)

der Medizinischen Fakultät der Universität Göttingen

\title{
Der Einfluss von (-)- $\Delta$ 9-trans- Tetrahydrocannabinol und Cannabidiol auf die Alzheimer-Pathologie im 5XFAD-Mausmodell
}

\author{
INAUGURAL-DISSERTATION \\ zur Erlangung des Doktorgrades \\ der Medizinischen Fakultät der \\ Georg-August-Universität zu Göttingen
}

vorgelegt von

Eva Maria Schleicher

aus

Schwetzingen

Göttingen 2021 
Dekan:

\section{Betreuungsausschuss}

Betreuer/in:

Ko-Betreuer/in:

\section{Prüfungskommission}

Referentin:

Ko-Referent:

Drittreferent:

Datum der mündlichen Prüfung:
Prof. Dr. med. W. Brück

PD Dr. rer. nat. Y. Bouter

Prof. Dr. rer. nat. T. Dresbach

PD Dr. rer. nat. Y. Bouter

Prof. Dr. rer. nat. T. Dresbach

Prof. Dr. rer. nat. A. Fischer 
Hiermit erkläre ich, die Dissertation mit dem Titel "Der Einfluss von (-)- $\Delta$ 9-trans-Tetrahydrocannabinol und Cannabidiol auf die Alzheimer-Pathologie im 5XFADMausmodell" eigenständig angefertigt und keine anderen als die von mir angegebenen Quellen und Hilfsmittel verwendet zu haben.

Göttingen, den 
Die Daten, auf denen die vorliegende Arbeit beruht, wurden teilweise publiziert:

Schleicher EM, Ott FW, Müller M, Silcher B, Sichler ME, Löw MJ, Wagner JM, Bouter Y (2019): Prolonged cannabidiol treatment lacks on detrimental effects on memory, motor performance and anxiety in C57BL/6J mice. Front Behav Neurosci $\underline{13}, 196$

Wagner JM, Sichler ME, Schleicher EM, Franke TN, Irwin C, Löw MJ, Beindorff N, Bouter C, Bayer TA, Bouter Y (2019): Analysis of motor function in the Tg4-42 mouse model of Alzheimer's disease. Front Behav Neurosci 13, 107

Sichler ME, Löw MJ, Schleicher EM, Bayer TA, Bouter Y (2019): Reduced acoustic startle response and prepulse inhibition in the Tg4-42 model of Alzheimer's disease. J Alzheimers Dis Rep $\underline{3}, 269-278$

Die Daten, auf denen die vorliegende Arbeit beruht, wurden im Rahmen von Posterpräsentationen vorgestellt:

Schleicher EM, Bayer TA, Wiltfang J, Bouter Y (2018): Prolonged Tetrahydrocannabinol (THC) treatment improves memory deficits in a familiar mouse model of Alzheimer's disease. Posterpräsentation im Rahmen des 11. FENS Forum of Neuroscience, Berlin, Deutschland, 7.07. - 11.07.2018

Schleicher EM, Bayer TA, Wiltfang J, Bouter Y (2018): Improvement of memory deficits in a familial mouse model of Alzheimer's disease due to prolonged treatment with Tetrahydrocannabinol (THC). Posterpräsentation im Rahmen des International Annual Congress on Controversies on Cannabis-Based Medicines, Wien, Österreich, $25.06-$ 26.06.2018 


\section{Inhaltsverzeichnis}

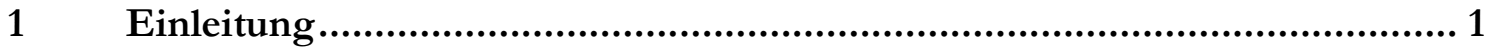

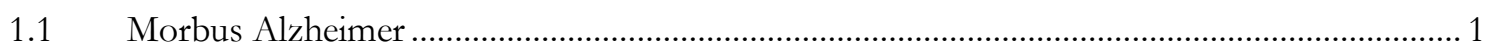

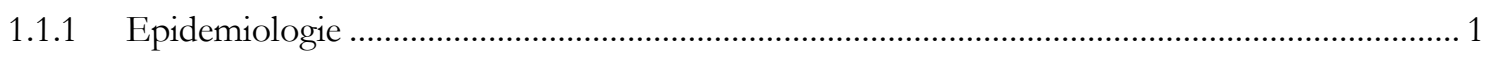

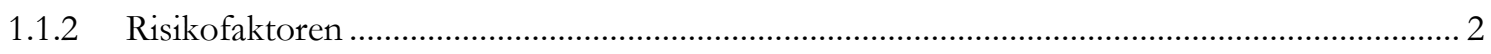

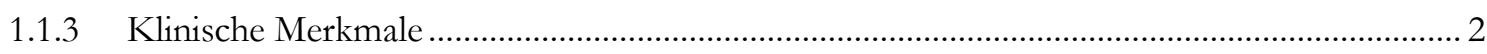

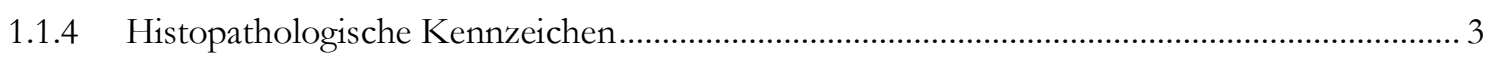

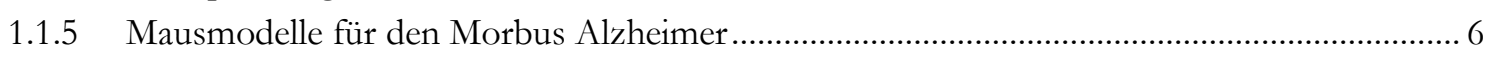

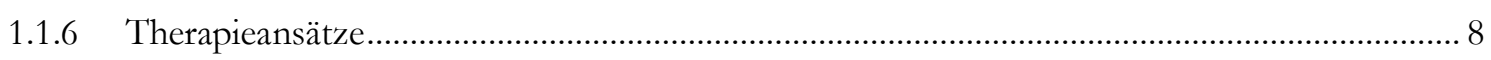

1.2 Cannabis, Cannabinoide und das Endocannabinoidsystem .................................................. 9

1.2.1 Kulturelle und historische Aspekte medizinischen Cannabis ${ }^{c}$................................................. 9

1.2.2 Aufbau und Funktion des Endocannabinoidsystems..........................................................

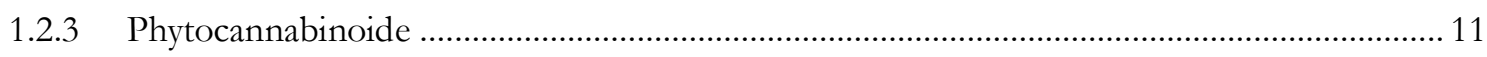

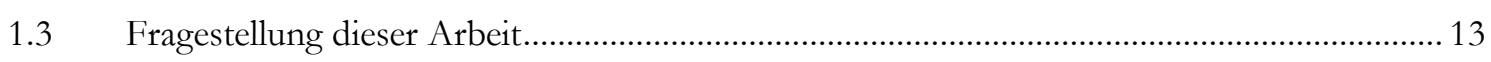

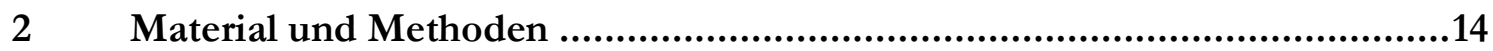

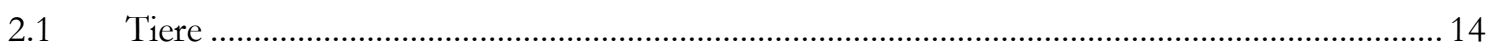

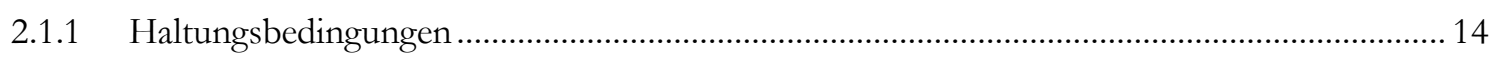

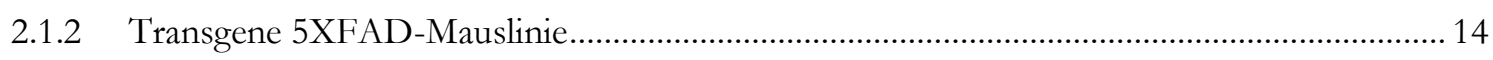

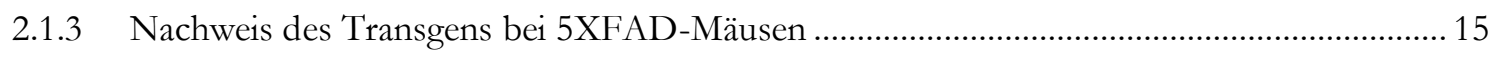

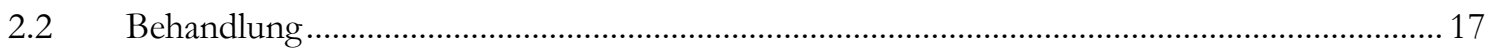

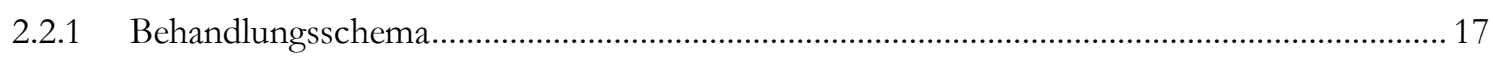

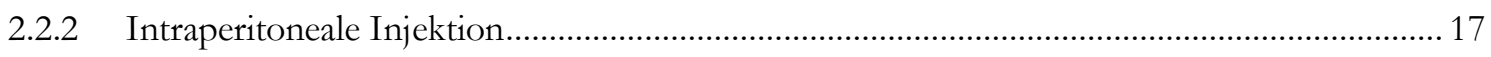

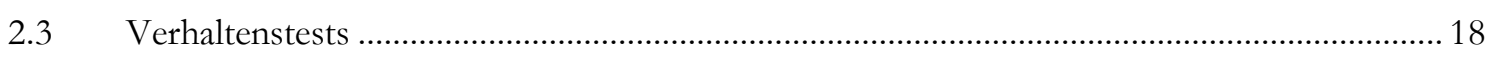

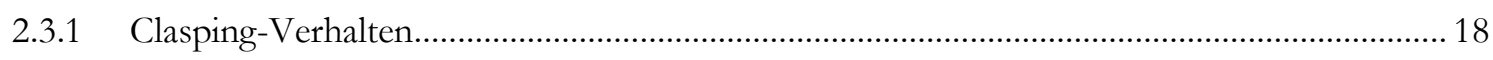

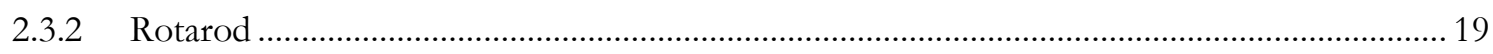

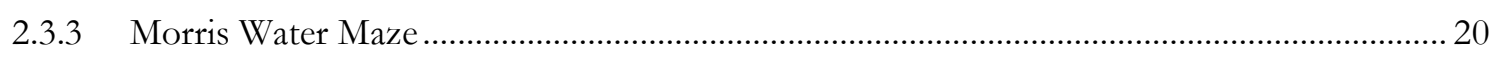

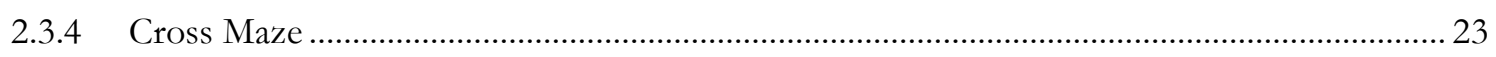

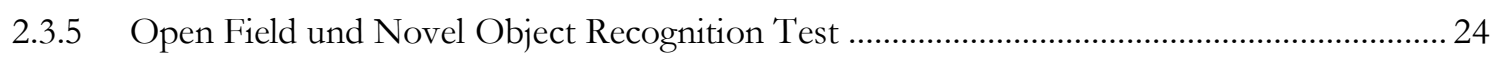

2.3.6 Elevated Plus Maze...................................................................................................... 25

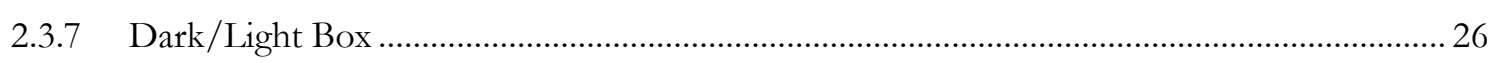

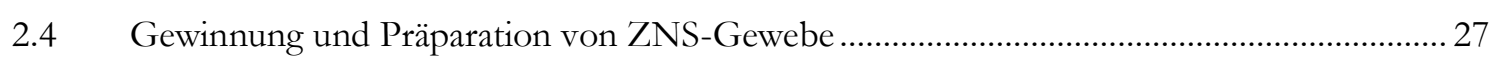

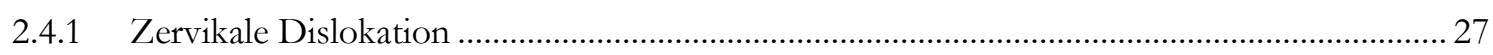

2.5 Quantifizierung der Expression von Beta-Amyloid, Neuroinflammationsmarkern und

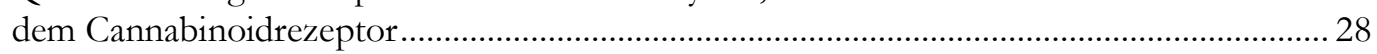

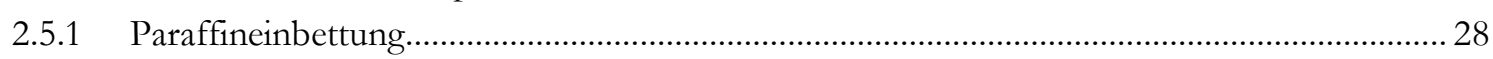

2.5.2 Schnittgewinnung durch Arbeit am Mikrotom ................................................................... 28

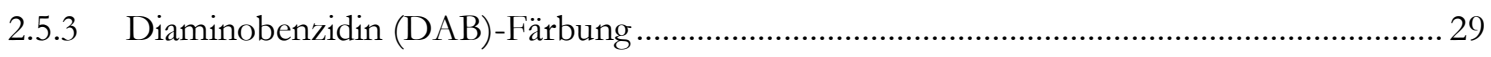

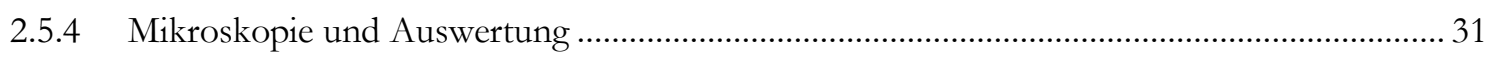

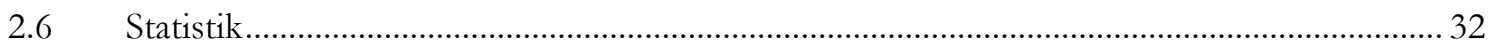

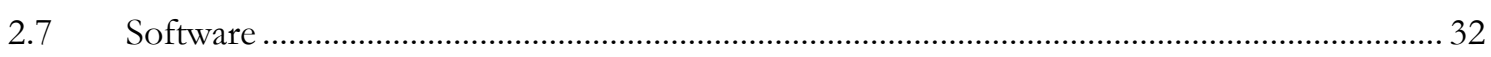

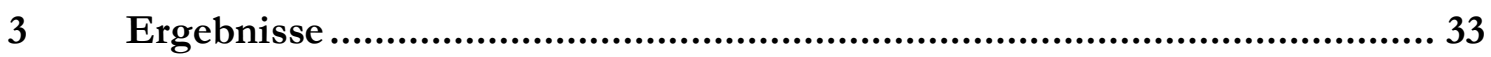




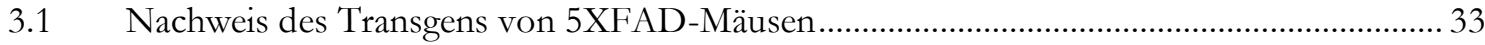

3.2 Auswirkungen von THC und CBD auf das Verhalten von 5XFAD-Mäusen.......................... 33

3.2.1 Auswirkungen von THC und CBD auf das Gewicht von 5XFAD-Mäusen ........................... 34

3.2.2 Auswirkungen von THC und CBD auf das Clasping-Verhalten von 5XFAD-Mäusen........ 34

3.2.3 Auswirkungen von THC und CBD auf die Motorik von 5XFAD-Mäusen im Rotarod...... 35

3.2.4 Auswirkungen von THC und CBD auf das Lernverhalten von 5XFAD-Mäusen im

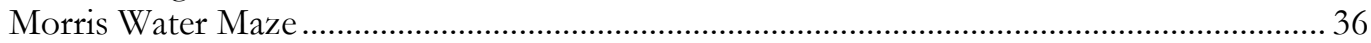

3.2.5 Auswirkungen von THC und CBD auf das Lernverhalten von 5XFAD-Mäusen im Novel Object Recognition Test.

3.2.6 Auswirkungen von THC und CBD auf das Lernverhalten von 5XFAD-Mäusen im Cross Maze

3.2.7 Auswirkungen von THC oder CBD auf das Angstverhalten von 5XFAD-Mäusen im Open Field

3.2.8 Auswirkungen von THC und CBD auf das Angstverhalten von 5XFAD-Mäusen im

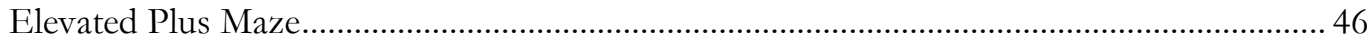

3.2.9 Auswirkungen von THC und CBD auf das Angstverhalten von 5XFAD-Mäusen in der Dark/Light Box.

3.3 Auswirkungen von THC und CBD auf die Expression von Beta-Amyloid, Neuroinflammationsmarkern und dem Cannabinoidrezeptor in 5XFAD-Mäusen

3.3.1 Auswirkungen von THC und CBD auf den Beta-Amyloid Plaqueload in 5XFADMäusen.

3.3.2 Auswirkungen von THC und CBD auf die Expression des Astrozytenmarkers GFAP in 5XFAD-Mäusen

3.3.3 Auswirkungen von THC und CBD auf die Expression des Mikrogliamarkers IBA1 in 5XFAD-Mäusen...

3.3.4 Auswirkung von THC und CBD auf die Expression des CB1-Rezeptors in 5XFADMäusen.

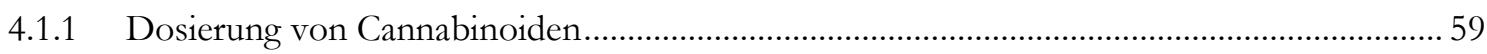

4.1.2 Geschlechterunterschiede hinsichtlich des Endocannabinoidsystems und der Krankheitsentstehung von Morbus Alzheimer.

4.1.3 Auswirkungen von THC und CBD auf die CB1-Rezeptorexpression von 5XFADMäusen.

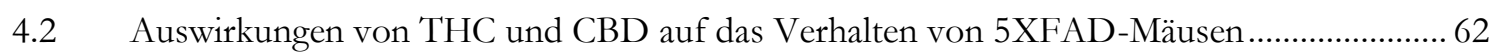

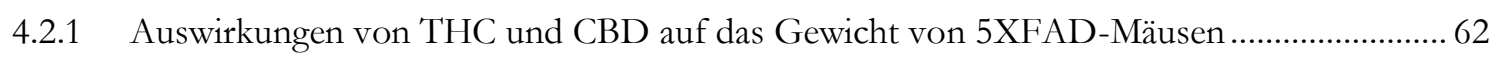

4.2.2 Auswirkungen von THC und CBD auf motorische Fähigkeiten von 5XFAD-Mäusen ...... 63

4.2.3 Auswirkungen von THC und CBD auf das Lernverhalten von 5XFAD-Mäusen..................... 64

4.2.4 Auswirkungen von THC und CBD auf das Angstverhalten von 5XFAD-Mäusen................ 67

4.3 Auswirkungen von THC und CBD auf histopathologische Aspekte der Alzheimer-

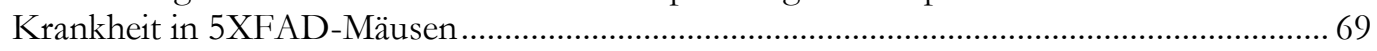

4.3.1 Auswirkungen von THC und CBD auf die Plaque-Pathologie von 5XFAD-Mäusen .......... 69

4.3.2 Auswirkungen von THC und CBD auf die Neuroinflammation von 5XFAD-Mäusen ...... 70

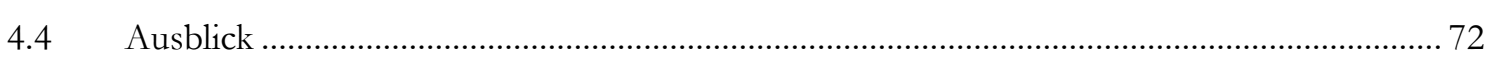

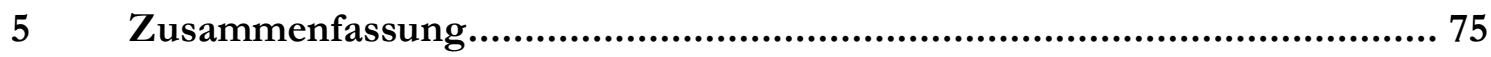

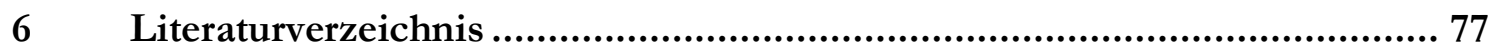




\section{Abbildungsverzeichnis}

Abbildung 1: Schematische Darstellung der histopathologischen Kennzeichen der AlzheimerKrankheit

Abbildung 2: 5XFAD-Transgene......

Abbildung 3: Charakterisierung des 5XFAD-Mausmodells ........................................................... 8

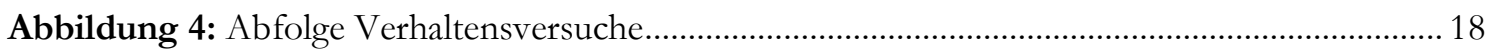

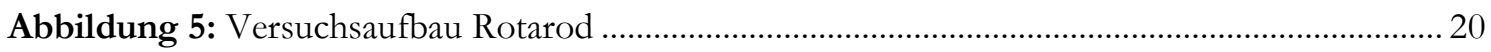

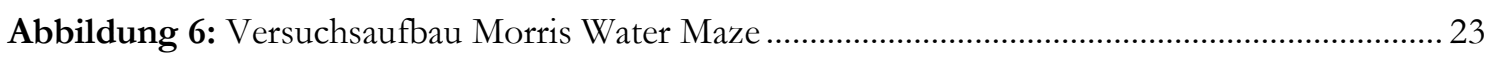

Abbildung 7: Versuchsaufbau Cross Maze ..................................................................................... 24

Abbildung 8: Versuchsaufbau Open Field und Novel Object Recognition Test............................. 25

Abbildung 9: Versuchsaufbau Elevated Plus Maze......................................................................... 26

Abbildung 10: Versuchsaufbau Dark/Light Box....................................................................... 27

Abbildung 11: Schematische Darstellung eines Ausschnitts von Cortex und Hippocampus eines Mausehirns im Sagittalschnitt ............................................................................. 31

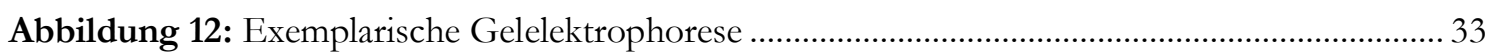

Abbildung 13: Unbeeinträchtigtes Gewicht von 5XFAD-Mäusen während des

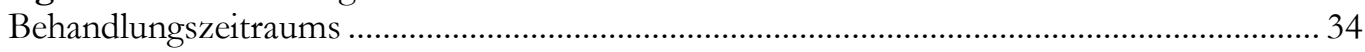

Abbildung 14: Aufschluss über motorische Defizite als Zeichen von Neurodegeneration in 5XFAD-Mäusen mithilfe des Clasping-Verhaltens....................................................... 35

Abbildung 15: Unauffällige motorische Fähigkeiten im Rotarod ..................................................36

Abbildung 16: Ausschluss motorischer und visueller Defizite weiblicher THC- und vehikelbehandelter 5XFAD-Mäuse mittels des Cued Trainings......................................... 37

Abbildung 17: Ausschluss motorischer und visueller Defizite männlicher CBD- und vehikelbehandelter 5XFAD-Mäuse mittels des Cued Trainings......................................... 37

Abbildung 18: THC hat keinen Einfluss auf das räumlichen Gedächtnis von weiblichen THC- und vehikelbehandelten 5XFAD-Mäusen im Acquisition Training ......................... 38

Abbildung 19: CBD hat keinen Einfluss auf das räumliche Gedächtnis von männlichen CBDund vehikelbehandelten 5XFAD-Mäusen im Acquisition Training................................... 39

Abbildung 20: Intaktes räumliches Gedächtnis bei weiblichen THC-behandelten 5XFADMäusen im Probe Trial .....

Abbildung 21: Unbeeinträchtigtes räumliches Gedächtnis von männlichen CBD- und vehikelbehandelten 5XFAD-Mäusen im Probe Trial...

Abbildung 22: Unbeeinträchtigtes Lernverhalten von weiblichen 5XFAD-Mäusen im NORTest nach THC-Behandlung....

Abbildung 23: Unbeeinträchtigtes Lernverhalten von 5XFAD-Mäusen im NOR-Test nach CBD-Behandlung

Abbildung 24: Kein Behandlungseffekt von THC auf das Arbeitsgedächtnis von weiblichen 5XFAD-Mäusen im Cross Maze

Abbildung 25: Unverändertes Arbeitsgedächnis von männlichen CBD- und vehikelbehandelten 5XFAD-Mäusen im Cross Maze...

Abbildung 26: Unbeeinträchtigtes Erkundungs- und Angstverhalten von weiblichen 5XFADMäusen im Open Field nach THC-Behandlung

Abbildung 27: Unbeeinträchtigtes Erkundungs- und Angstverhalten von männlichen 5XFAD-Mäusen im Open Field nach CBD-Behandlung....

Abbildung 28: Normalisierung des Angstverhaltens von weiblichen 5XFAD-Mäusen nach THC-Behandlung......

Abbildung 29: Unbeeinträchtigtes Angstverhalten von männlichen 5XFAD-Mäusen und WTMäusen im Elevated Plus Maze nach CBD-Behandlung . 
Abbildung 30: Unbeeinträchtigtes Angstverhalten von weiblichen 5XFAD-Mäusen in der Dark/Light Box nach THC-Behandlung.

Abbildung 31: Unbeeinträchtigtes Angstverhalten von 5XFAD-Mäusen in der Dark/Light Box nach CBD-Behandlung.... 50

Abbildung 32: Signifikante Reduktion des Beta-Amyloid Plaqueloads im Cortex von weiblichen 5XFAD-Mäusen nach THC-Behandlung..

Abbildung 33: Signifikante Reduktion der Beta-Amyloid Expression in männlichen 5XFADMäusen nach CBD-Behandlung im Hippocampus

Abbildung 34: Gesteigerte Expression des Astrozytenmarkers GFAP im Cortex von weiblichen 5XFAD-Mäusen nach THC-Behandlung

Abbildung 35: Gesteigerte Expression des Astrozytenmarkers GFAP im Hippocampus von männlichen 5XFAD-Mäusen nach CBD-Behandlung

Abbildung 36: Verringerte Expression von IBA1 im Cortex von weiblichen 5XFAD-Mäusen nach THC-Behandlung.....

Abbildung 37: Verringerte Expression des Mikrogliamarkers IBA1 im Hippocampus von männlichen 5XFAD-Mäusen nach CBD-Behandlung 56

Abbildung 38: Signifikant geringere CB1-Rezeptorexpression nach THC-Behandlung von weiblichen 5XFAD-Mäusen..

Abbildung 39: Unbeeinträchtigte CB1-Rezeptorexpression von männlichen 5XFAD-Mäusen nach CBD-Behandlung. 


\section{Tabellenverzeichnis}

Tabelle 1: PCR-Zyklen-Protokoll des Lab Cyclers für Nukleinsäure-Amplifikation 16

Tabelle 2: Punkteschlüssel Clasping-Verhalten............................................................................ 19

Tabelle 3: Start- und Zielpositionen im Cued Training.................................................................. 21

Tabelle 4: Start- und Zielpositionen im Acquisition Training ...................................................... 22

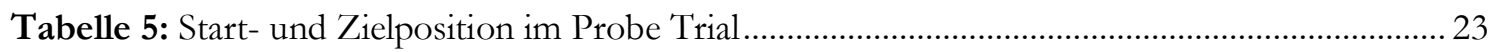

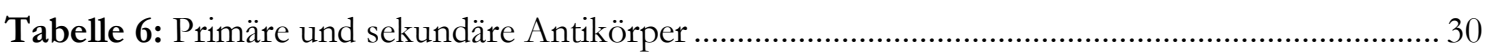




\section{Abkürzungsverzeichnis}

\begin{tabular}{|c|c|}
\hline $2-A G$ & 2-Arachidonylglycerol \\
\hline AEA & Arachidonsäurederivate Anandamid \\
\hline ApoE4 & Apolipoprotein E4 \\
\hline $\mathrm{APP}$ & amyloid precursor protein, Amyloid-Vorläufer-Protein \\
\hline$A \beta$ & Beta-Amyloid \\
\hline CB1 & Cannabinoidrezeptor 1 \\
\hline CB2 & Cannabinoidrezeptor 2 \\
\hline CBD & Cannabidiol \\
\hline CBG & Cannabigernol \\
\hline ddNTP & Didesoxynukleosidtriphosphat \\
\hline $\mathrm{dH}_{2} \mathrm{O}$ & Destilliertes Wasser \\
\hline DNA & Desoxyribonukleinsäure \\
\hline dNTPs & Desoxynukleosidtriphosphate \\
\hline ECS & Endocannabinoidsystem \\
\hline EDTA & Ethylendiamintetraacetat \\
\hline EPM & Elevated Plus Maze \\
\hline FAD & familial Alzheimer's Disease, familiäres Alzheimer \\
\hline FCS & fetal calf serum, fetales Kälberserum \\
\hline GFAP & glial fibrially acid protein, saures Gliafaserprotein \\
\hline IBA1 & $\begin{array}{l}\text { ionized calcium-binding adaptor molecule 1, ionisiertes calciumbindendes } \\
\text { Protein }\end{array}$ \\
\hline KG & Körpergewicht \\
\hline LD50 & Letale Dosis 50 \\
\hline MCI & mild cognitive impairment \\
\hline MWM & Morris Water Maze \\
\hline NFTs & neurofibrillary tangles, Neurofibrillenbündel \\
\hline NOR & Novel Object Recognition \\
\hline PCR & polymerase chain reaction, Polymerase-Kettenreaktion \\
\hline PET & Positronen-Emissions-Tomographie \\
\hline PHF & paired helical filaments, gepaarte fadenförmig, helikale Filamente \\
\hline $\operatorname{PPAR} \gamma$ & Peroxisomen-Proliferator-aktivierte Rezeptor- $\gamma$ \\
\hline $\operatorname{Pr} \mathrm{P}$ & Prion Protein Promotor \\
\hline PSEN & presenilin protein, Präsenilin Proteine \\
\hline THC & $(-)-\Delta 9$-trans-Tetrahydrocannabinol \\
\hline TRPV1 & transient receptor potential vanilloid receptor type 1 \\
\hline WHO & World Health Organization \\
\hline WT & Wildtyp \\
\hline ZNS & Zentrales Nervensystem \\
\hline
\end{tabular}




\section{$1 \quad$ Einleitung}

\subsection{Morbus Alzheimer}

Der Morbus Alzheimer oder die Alzheimer-Krankheit wurde Anfang des 20. Jahrhunderts das erste Mal von dem deutschen Psychiater und Neurologen Alois Alzheimer beschrieben und ist die bis heute häufigste Form von Demenzerkrankungen in Deutschland. Als Herr Alzheimer 1901 der Patientin Auguste Deter begegnete, konnte er noch nicht ahnen, dass deren Tod und die nachfolgenden Untersuchungen ihres Gehirns und dessen Beschreibungen ihn später zum Namensgeber der Alzheimer-Krankheit machen sollten. In seiner Veröffentlichung des Falles beschrieb er die folgenden neurologischen Charakteristika: Gedächtnisstörungen, Neuronenverlust, Amyloid-Plaques und Neurofibrillen (Alzheimer 1907; Alzheimer et al. 1995), die bis heute zur Diagnosestellung genutzt werden. Die Ätiologie ist bis heute nicht hinreichend geklärt, auch wenn Alzheimers Erkenntnisse die Basis der heutigen Forschung bildeten. Seitdem wird intensiv an der Alzheimer-Krankheit geforscht, bislang gibt es jedoch keine den Krankheitsprozess aufhaltende Therapie.

\subsubsection{Epidemiologie}

In Deutschland leben gegenwärtig ca. 1,7 Millionen Menschen mit Demenz. Weltweit schätzt die World Health Organization (WHO) und die Alzheimer's Disease International Organization die Zahl der Betroffenen auf bis zu 50 Millionen (WHO 2017). 50 - 70 \% davon sind nach klinischen Kriterien der Alzheimer-Demenz zuzuordnen. Die Zahl der Neuerkrankungen nimmt rapide zu, wobei Frauen häufiger erkranken als Männer, sodass die Statistik einen Frauenanteil von knapp zwei Drittel annimmt (Alzheimer's Association 2019). Hinsichtlich der Inzidenz der Alzheimer-Krankheit zeigen sich deutliche Geschlechterunterschiede. Frauen haben besonders im Alter über 85 Jahren eine höhere Inzidenz der Alzheimer-Krankheit als Männer (Andersen et al. 1999; Fratiglioni et al. 2000). Das Lebenszeitrisiko für Frauen an der Alzheimer-Krankheit zu erkranken liegt bei $20 \%$, bei Männern bei $10 \%$ (Chêne et al. 2015). Diskutiert werden grundsätzliche Unterschiede zwischen männlichen und weiblichen Gehirnen, die sich auch deutlich histopathologisch zeigen. Weibliche Gehirne weisen insgesamt mehr alzheimertypische Veränderungen hinsichtlich einer vermehrten Zahl von Neurofibrillen und AmyloidPlaques als Männer auf (Barnes et al. 2005; Oveisgharan et al. 2018). 


\subsubsection{Risikofaktoren}

Der bedeutendste Risikofaktor für die Entwicklung der Alzheimer-Krankheit ist das Alter (Blennow et al. 2006; Hebert et al. 2013). Das Ausbilden der Alzheimer-Krankheit gehört jedoch nicht zum physiologischen Alterungsprozess (Nelson et al. 2011). Wahrscheinlich ist die Ursache der Krankheit multifaktoriell, sodass eine Kombination aus genetischen Faktoren und Umwelteinflüssen anzunehmen ist (Mayeux und Stern 2012). Eine Lebensstiländerung bezüglich des Rauchverzichts, gesunder Ernährung, des Verzichts auf exzessiven Alkoholkonsum und eine gute Blutdruckeinstellung können das Erkrankungsrisiko verringern. Als Risikofaktoren zur Entstehung der Alzheimer-Krankheit gelten neben dem Altern oder genetischer Disposition kardiovaskuläre Faktoren wie Diabetes mellitus, Hypercholesterinämie, arterieller Hypertonus und arteriosklerotische Veränderungen sowie bereits stattgefundene Schlaganfälle (Roher et al. 2011; Toledo et al. 2013; De Oliveira Lanna et al. 2014; Duncombe et al. 2017).

Diskutiert wird außerdem der Einfluss von Prionen und Schädel-Hirn-Traumata als Auslöser der Alzheimer-Krankheit (Iba et al. 2013; Tolppanen et al. 2017; Weiner et al. 2017).

Genetische Faktoren spielen eine wichtige Rolle für die Entstehung der AlzheimerErkrankung, sind aber durchschnittlich nur in 3\% der Fälle als alleiniger Auslöser der Krankheit verantwortlich. Mutationen in den Genen des Amyloid-Vorläufer-Proteins (amyloid precursor protein, APP) und des Präsenilins (presenilin protein, PSEN) steigern die Produktion von Beta-Amyloid (A $\beta$ ) und verursachen dadurch familiäres Alzheimer (familial Alzheimer's Disease; FAD; Oakley et al. 2006). Als weiterer genetischer Risikofaktor werden Genotyp-Varianten des Apolipoprotein E4 (ApoE4) angesehen. Dies wird gehäuft im zentralen Nervensystem (ZNS) exprimiert und ist am Fett- und Beta-Amyloid-Abbau beteiligt (Giacobini und Becker 1994; Strittmatter et al. 1994; Raber et al. 2004; Jiang et al. 2008). Außerdem haben Menschen mit der Chromosomenaberration Trisomie 21 fast 90 \% Wahrscheinlichkeit an der Alzheimer-Krankheit zu erkranken (Colacurcio et al. 2018; Zis und Strydom 2018).

\subsubsection{Klinische Merkmale}

Die Alzheimer-Krankheit beginnt oft schleichend und entwickelt sich langsam aber stetig über einen Zeitraum von mehreren Jahren (ICD-10 Definition). Meist werden drei Stadien der Krankheit durchlaufen, die aber nicht immer sicher voneinander abgrenzbar sind. Die Dauer der Erkrankungsverläufe ist sehr variabel.

Im präklinischen Stadium ist die Krankheit klinisch nicht manifest, zeichnet sich aber im histopathologischen Korrelat durch Ablagerungen von Amyloid-Plaques und Neurodegeneration aus, die bis zu 20 Jahre vor Beginn der Krankheit schon vorhanden sein können (Blennow et al. 2006). Nicht alle Erkrankten mit nachgewiesenen Biomarker (Phospho-Tauprotein, Gesamt-Tauprotein und Beta-Amyloid) im Blut und Liquor gehen 
in das nächste Erkrankungsstadium über oder entwickeln eine Demenz (Knopman et al. 2003; Bennett et al. 2006).

Im Stadium des mild cognitive impairment (MCI) zeigen sich leichte kognitive Auffälligkeiten, zum Beispiel eine verminderte Fähigkeit neue Dinge zu lernen oder zu erkennen. Neben der Beeinträchtigung des Gedächtnisses können auch folgende Gebiete betroffen sein: Sprache, Aufmerksamkeit, räumlich-visuelle Wahrnehmung und Orientierung. Die Geschwindigkeit, Effizienz und Fehlerlosigkeit komplexer funktioneller Abläufe im Alltag sind gestört. Die Betroffenen bleiben jedoch weiterhin im sozialen und beruflichen Leben unabhängig (Albert et al. 2011). Innerhalb dieses Stadiums zeigt sich ein hohes Risiko für die Entwicklung des Vollbildes einer Demenz (Petersen et al. 2018).

Die Eigenständigkeit der Erkrankten verliert sich im finalen Stadium, in der manifesten Phase der Alzheimer-Krankheit. Neben kognitiven Störungen kommt es auch zu vegetativen Störungen wie Inkontinenz und Stummheit. Grundlegende motorische Beeinträchtigungen führen zur Bettlägerigkeit und damit zur vollständigen Pflegebedürftigkeit (McKhann et al. 2011; Holtzman et al. 2011; Alzheimer's Association 2019). Außerdem kann die Entwicklung einer Aspirationspneumonie deutlich zur Verminderung der Lebenserwartung beitragen (Wada et al. 2001).

Insgesamt lässt sich feststellen, dass die Alzheimer-Krankheit keine determinierten, den Erkrankungsbeginn voraussagende Symptome hat (Albert et al. 2011). Eine Differenzierung zwischen frühem und spätem Beginn der Krankheit anhand neurobiologischer oder klinischer Charakteristika sowie anhand der Pathologie ist derzeit nicht möglich.

Während in der Vergangenheit eine definitive Diagnosestellung ausschließlich post mortem, also nach dem Tod mit dem Beweis einer pathologischen Ansammlung von AmyloidPlaques und Neurofibrillenbündeln im Gehirn erfolgte, wird heute ein komplexer diagnostischer Prozess durchgeführt (Montine et al. 2012; Weller und Budson 2018). Neue Diagnosekriterien des National Institute of Aging und der Alzheimer's Association definieren zunächst allgemeine und klinische Kriterien, die auf eine mögliche oder wahrscheinliche Alzheimer-Demenz hinweisen. Wenn diese Kriterien erfüllt sind, erfolgt die Diagnosestellung mithilfe von laborchemischen Blut- und Liquoruntersuchungen sowie einer zerebralen Bildgebung zur ätiologischen Differenzierung der Symptomatik. Insbesondere die Darstellung des zerebralen Amyloids mittels Positronen-EmissionsTomographie (PET) kann die Diagnostik ergänzen (Mantzavinos und Alexiou 2017; Jack et al. 2018).

\subsubsection{Histopathologische Kennzeichen}

Die Präsenz von alzheimertypischen Pathologien zeigt sich einige Jahre vor der symptomatischen, klinischen Manifestation (Blennow et al. 2006; Holtzman et al. 2011). Makroskopisch lässt sich eine globale Hirnatrophie erkennen. Mikroskopisch zeigen sich 
die Hauptkennzeichen der Krankheit: Amyloid-Plaques, Neuronenverlust, neurofibrilläre Bündel aus Tau-Protein und Entzündungsreaktionen im Sinne einer Neuroinflammation. Nachfolgend ist ein Überblick über die wichtigsten und für diese Arbeit relevantesten Pathologien dargestellt.

\subsubsection{Amyloid-Plaques}

Senile Amyloid-Plaques sind Ansammlungen bzw. Ablagerungen von Fragmenten von Proteinen im Extrazellularraum des Gehirns. Diese bestehen hauptsächlich aus BetaAmyloid, ein aus 36 - 42 Aminosäuren bestehendes Peptid, das aus dem Vorläuferprotein APP entsteht (Kang et al. 1987; Holtzman et al. 2011). APP ist ein natürlich vorkommendes membranständiges Protein der Neuronen. Zunächst zeigt sich die PlaquePathologie im Neocortex und breitet sich über den Hippocampus, die Basalganglien und das Kleinhirn bis über das gesamte Gehirn aus (Serrano-Pozo et al. 2011). Eine Korrelation zwischen der Ausbreitung der Amyloid-Plaques und der klinischen Symptomatik besteht nicht (Billings et al. 2005; Schaeffer et al. 2011; Villemagne et al. 2011). Unterteilen lassen sich die Amyloid-Plaques in diffuse und neuritische Formen. Erstere besitzen eine amorphe Struktur, während neuritische Plaques von dystrophen Neuriten sowie Astro- und Mikrogliose umgeben sind (Selkoe 2011; Holtzman et al. 2011). Interessanterweise befinden sich diffuse Plaques auch im Cortex älterer, kognitiv gesunder Menschen (Serrano-Pozo et al. 2011), während neuritische Plaques eher typisch für die AlzheimerErkrankung sind (Dickson et al. 1988; Tekirian et al. 1996).

\subsubsection{Neurofibrilläre Bündel aus dem Tau-Protein}

Ein weiteres typisches Merkmal sind intraneuronal gelegene Neurofibrillenbündel (neurofibrillary tangles, NFTs) bestehend aus dem Tau-Protein. Dieses formt Teile von Mirkotubuli zum Transport von Nährstoffen und anderen Substanzen von Nervenzellen mit Stützfunktion (Weingarten et al. 1975). Bei der Alzheimer-Pathologie liegt das TauProtein in veränderter, hyperphosphorylierter Form vor (Castellani et al. 2008; Hanger et al. 2009; Alonso et al. 2018). Das veränderte, hyperphosphorylierte Tau-Protein führt zur Zerstörung und Auflösung des Zytoskeletts der Neuronen. Die löslichen Proteine lagern sich zu gepaarten fadenförmig, helikalen Filamenten (paired belical filaments, PHF) zusammen, die den Hauptbestandteil von intrazellulären NFTs ausmachen (Alonso et al. 2018). Tau-Fibrillen bilden sich zunächst im Hippocampus und breiten sich mit Fortschreiten der Krankheit über das gesamte Gehirn aus. Als Tauopathien bezeichnet man verschiedene neurodegenerative Erkrankungen, die mit einer Akkumulation des TauProteins einhergehen. Die Alzheimer-Krankheit ist der wichtigste Vertreter der Tauopathien. Die Bedeutung von NFTs für die Alzheimer-Pathologie ist bis heute ungeklärt, jedoch korreliert das Auftreten von NFTs stärker mit der Schwere der Alzheimer-Krankheit als die Amyloid-Plaques (Holtzman et al. 2011). 


\subsubsection{Neuroinflammation}

Die Entzündungsreaktion des ZNS ist ein wichtiger Bestandteil der Alzheimer-Pathologie und wird auch als Neuroinflammation bezeichnet. Sie ist einer der wichtigsten Mechanismen zur Bekämpfung von Beta-Amyloid. Die exakte Bedeutung des Immunsystems in der Alzheimer-Pathologie ist noch nicht geklärt und wird kontrovers diskutiert (Vázquez et al. 2015; Borgonetti et al. 2019). Entzündungsvorgänge wie die Aktivierung und Ausschüttung von Zytokinen, Akute-Phase-Proteinen und Komplementfaktoren sind die Immunantwort auf das Absterben von Neuronen. Das Zusammenspiel aus Amyloid-Plaques, NFTs und geschädigter Neurone wirkt proinflammatorisch (Akiyama et al. 2000). Aktivierte Astrozyten und Mikroglia als Immunzellen des ZNS siedeln sich in direkter Nachbarschaft zu Amyloid-Plaques an (Abbildung 1). Es wird davon ausgegangen, dass Beta-Amyloid die Aktivierung der Zellen triggert (Itagaki et al. 1989; Edison et al. 2008; Edison et al. 2018). Außerdem gibt es Indizien, dass eine anfängliche Aktivierung von Mikroglia in der frühen Phase der Krankheit aufrechterhalten wird, selbst wenn sich die Anzahl der Amyloid-Plaques verringert. Dies deutet auf eine chronische Aktivierung von Mikroglia hin (Fan et al. 2017). Diese führt zu einer morphologischen Änderung und Proliferation von Mikrogliazellen, die daraufhin den typischen Marker, das ionized calcium-binding adaptor molecule 1 (IBA1) exprimieren (Ito et al. 1998; Hirasawa et al. 2005). Das saure Gliafaserprotein (glial fibrially acid protein, GFAP) ist der Marker für aktivierte Astrozyten. Diese sind ebenfalls wichtiger Bestandteil der Neuroinflammation. Ihnen wird eine Wirkung auf die neuronale Signalübertragung sowie auf die synaptische Plastizität zugesprochen (Pittà et al. 2016).

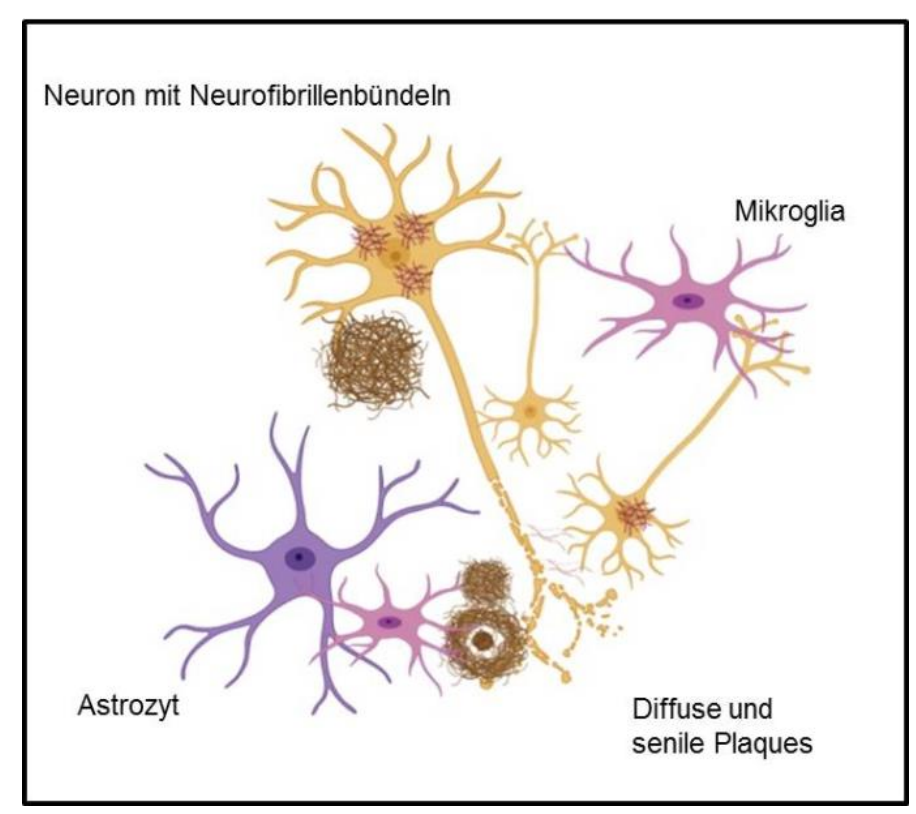

Abbildung 1: Schematische Darstellung der histopathologischen Kennzeichen der AlzheimerKrankheit Erstellt nach Masters et al. (2015). 


\subsubsection{Mausmodelle für den Morbus Alzheimer}

Die Generierung der Mausmodelle basiert auf den Hypothesen zur Entstehung des Morbus Alzheimer und auf den mutierten Genen in Personen mit familiärem Alzheimer. Folglich gibt es große Gruppen transgener APP-Tiermodelle, transgener PräsenilinTiermodelle sowie Tau-Modelle (Esquerda-Canals et al. 2017). Obwohl die Überexpression von APP in Mausmodellen die Alzheimer-Pathologie imitieren kann, stellt sie nur einen kleinen Teil der Gesamtpathologie dar (Games et al. 1995; Hsiao et al. 1996). Die Kombination von Präsenilin-Modellen (Duff et al. 1996; Gómez-Isla et al. 1999) mit mutierten APP-Genen führt zu einer schnell ausgeprägten Pathologie der AlzheimerKrankheit (Holcomb et al. 1998). Trotzdem lassen sie einige wichtige Beiträge zur Pathologie aus, unter anderem die Bildung von NFTs. Um diese Lücke zu schließen, wurde das dreifach-transgene Modell der 3xTg-Mauslinie generiert (Oddo et al. 2003).

Mausmodelle mit Kombinationen der Mutationen in APP-Genen und Präsenilin-Proteinen sind etablierte Beispiele für Modelle mit Neuronenverlust. Diese sind beispielsweise das 5XFAD-Modell (Oakley et al. 2006; Jawhar et al. 2012), APP751SL/PS1M146L-Mäuse (Casas et al. 2004) und die APP/PS1K1-Mauslinie (Schmitz et al. 2004). Durch diese Mausmodelle konnte eine Verbindung zwischen Neuronenverlust und intraneuronaler Beta-Amyloid Ansammlungen gefunden werden (Bayer und Wirths 2010).

Keines der transgenen Mausmodelle bildet die menschliche Pathologie exakt ab, jedoch konnte mit der Entwicklung verschiedener Mausmodelle ein enormer Fortschritt hinsichtlich des Verständnisses der Pathogenese und der daraus resultierenden therapeutischen Konsequenzen erlangt werden.

Die meisten Mausmodelle für die Alzheimer-Krankheit entwickeln Amyloid-Plaques sehr langsam. Sie benötigen im Durchschnitt ca. sechs bis zwölf Monate, um Amyloid-Plaques zu generieren (Spires und Hyman 2005). Das fünffach transgene Mausmodell der 5XFADMauslinie bietet ein breites Spektrum an Pathologien und bildet eine deutlich massivere und schnellere Plaque-Pathologie aus als andere Mausmodelle.

\subsubsection{5XFAD-Mausmodell}

Das 5XFAD-Mausmodell ist ein weit verbreitetes Modell für die familiäre Alzheimer Erkrankung und wurde 2006 von Oakley et al. das erste Mal beschrieben. Es bildet durch fünf Mutationen aus der FAD-Genfamilie eine hohe Akkumulation von intra- und extrazellulärem A $\beta_{42}$ und deren Varianten. Drei Mutationen befinden sich in der 695Isoform des humanen APP-Gens (Schweden- (K670N, M671L), Florida- (I716V) und London- (V717I) Mutationen) und zwei weitere im PSEN-1-Gen (M146L- und L286VMutationen). Kontrolliert werden die Mutationen allesamt durch den Murin-Thy1Promotor (Oakley et al. 2006, Abbildung 2). Es besteht eine stabile Keimbahnvererbung und damit eine Mitvererbung der Mutationen über viele Generationen. 
A

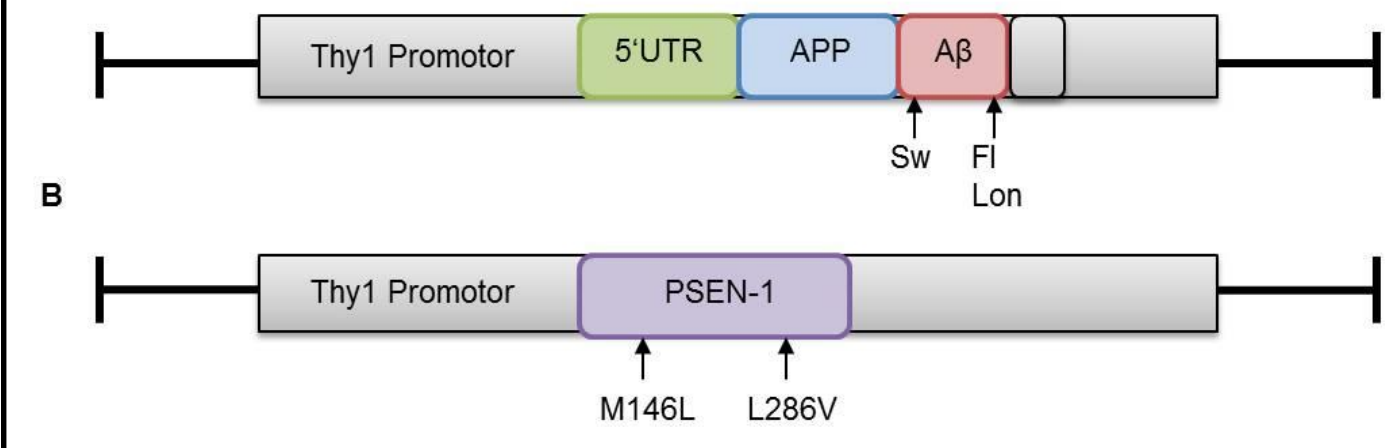

Abbildung 2: 5XFAD-Transgene Schematische Übersicht über (A) Thy1-APP- und (B) Thy-PSEN-1Transgene im 5XFAD-Mausmodell. Die Darstellung der Mutationen erfolgt mittels Pfeilen. Abkürzung: Sw = Schweden-Mutation; Fl = Florida-Mutation; Lon = London-Mutation. Übersicht erstellt nach Oakley et al. (2006).

Die Florida-, London- und die zwei PSEN-Mutationen führen zu einer erhöhten Produktion von $A \beta_{x}-42$, während die Schweden-Mutation den Gesamtanteil von BetaAmyloid erhöht. Die Plaque-Pathologie entwickelt sich mit ca. eineinhalb Monaten zunächst im Subiculum und der Lamina V des Cortex (Eimer und Vassar 2013). Diese wird von Astrozytose und Mikrogliose begleitet. Diese Eigenschaften verstärken sich drastisch mit zunehmendem Alter (Oakley et al. 2006). Außerdem konnten extrazelluläre AmyloidPlaques im Rückenmark von drei Monate alten 5XFAD-Mäusen nachgewiesen werden (Jawhar et al. 2012). Die 5XFAD-Mauslinie stellt ein anschauliches Modell für Neuronenverlust im Alter von neun Monaten in den pyramidalen Neuronen der Lamina V des Cortex und im Subiculum dar. Dies entspricht den Orten, wo sich intraneuronale Ansammlungen von Beta-Amyloid-Plaques besonders häufig bilden (Eimer und Vassar 2013). Auffallend ist jedoch, dass sich dieser Effekt nicht auf die CA1-Region des Hippocampus übertragen lässt, wo folglich also kein Neuronenverlust stattfindet (Jawhar et al. 2012). Des Weiteren zeigen sich signifikante Veränderungen an den Synapsen der Neuronen. Synaptische Marker wie Synaptophysin, Syntaxin und das postsynaptic densitiy protein 95 (PSD-95) nehmen mit zunehmendem Alter ab und sind im Alter von neun bis zwölf Monaten drastisch reduziert (Oakley et al. 2006). Die synaptische Plastizität ist im Alter von sechs Monaten beeinträchtigt, was eine Veränderung der Langzeit-Potenzierung und Langzeit-Depression (long-term potentiation; LTP; long-term depression; LTD) an der CA1Region des Hippocampus widerspiegelt und Auswirkungen auf das Lernen und das Gedächtnis der Mäuse haben kann (Kimura und Ohno 2009). Es zeigen sich kognitive Veränderungen in Form von Verhaltensdefiziten. Neben Defiziten im Arbeitsgedächtnis, im räumlichen Gedächtnis und im Langzeitgedächtnis weisen die Mäuse auch ein vermindertes Angstverhalten ab dem Alter von vier bis fünf Monaten auf. Motorische Einschränkungen stehen in Korrelation zur Plaque-Pathologie im Rückenmark der 
5XFAD-Mäuse und dessen altersbedingte, axonale Degeneration (Jawhar et al. 2012). Eine Übersicht des Phänotyps zeigt Abbildung 3.

Alter der Mäuse

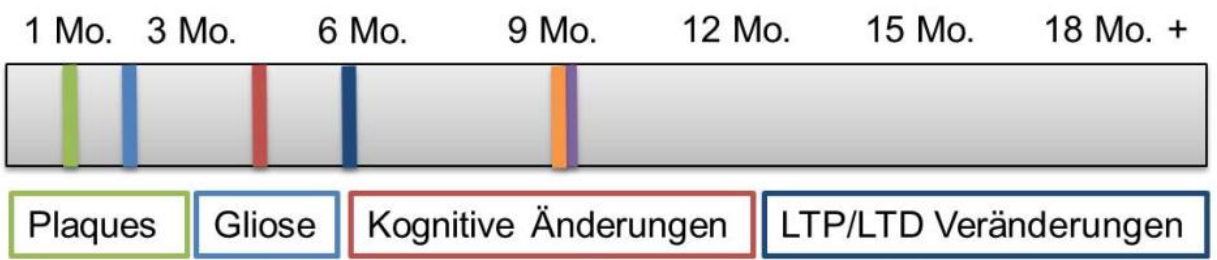

\begin{tabular}{|l|ll} 
Neuronenverlust & Veränderungen der Synapse \\
\hline
\end{tabular}

Abbildung 3: Charakterisierung des 5XFAD-Mausmodells Schematische Übersicht über die charakteristischen Pathologien des 5XFAD-Mausmodells im Altersverlauf. Abkürzung: Mo. = Monate. Übersicht erstellt nach Oakley et al. (2006); Jawhar et al. (2012); Eimer und Vassar (2013); Richard et al. (2015).

Weibliche 5XFAD-Mäuse haben ein höheres Beta-Amyloid-Level als männliche Mäuse. Auch Veränderungen wie Verhaltensdefizite und motorische Einschränkungen manifestieren sich $\mathrm{zu}$ unterschiedlichen Zeitpunkten bei weiblichen und männlichen 5XFAD-Mäusen. Dieser geschlechterspezifische Effekt wird mit zunehmendem Alter verstärkt (Oakley et al. 2006; Maarouf et al. 2013).

\subsubsection{Therapieansätze}

Derzeit gibt es keine Heilung für die Alzheimer-Krankheit. Die aktuellen Therapiemöglichkeiten beschränken sich auf rein symptomatische Ansätze, die in den aktuellen S3-Leitlinien der deutschen Gesellschaft für Neurologie (DGN) und der deutschen Gesellschaft für Psychiatrie und Psychotherapie, Psychosomatik und Nervenheilkunde (DGPPN) beschrieben werden. Außerdem bilden psychosoziale Interventionen für Erkrankte und deren Angehörige sowie eine pharmakologische Therapie die Grundbasis, um ein Fortschreiten der Krankheit zu verhindern. Die pharmakologische Therapie richtet sich je nach Schweregrad der Alzheimer-Krankheit nicht nur nach der Behandlung der Kernsymptomatik der Demenz, sondern auch nach Begleitsymptomen wie Verhaltensstörungen. Im Bereich der leichten bis mittelschweren Demenz werden Acetylcholinesterase-Hemmer wie Donzepezil, Galantamin und Rivastigmin eingesetzt, die in Studien einen verbesserten klinischen Gesamteindruck hervorbrachten (Kaduszkiewicz et al. 2005; Winblad et al. 2006). Für die schwere Alzheimer-Demenz ist der nicht-kompetitive NMDA-Antagonist Memantin zugelassen (Dysken et al. 2014). 
Die Wirksamkeit des Einsatzes von anderen Medikamentenklassen wie Ginkgo Biloba, Vitamin E oder nichtsteroidale Antiphlogistika ist bisher nicht sicher belegt (Martin et al. 2008; Ihl et al. 2012; Dysken et al. 2014). Insbesondere die oft nicht zufriedenstellende symptomatische Therapie führt zur erhöhten Nachfrage nach alternativen Wirkstoffen.

\subsection{Cannabis, Cannabinoide und das Endocannabinoidsystem}

\subsubsection{Kulturelle und historische Aspekte medizinischen Cannabis ${ }^{6}$}

Cannabis zählt zu den ältesten Zier- und Nutzpflanzen der Welt. Als Heilmittel wurden die Extrakte der Pflanze schon von den alten Ägyptern ca. 2350 v. Chr. therapeutisch genutzt. Auch in China und Indien besitzt die Präparation von Cannabis eine lange Tradition (Russo 2007; Friedman und Sirven 2017). Die Pflanze wurde schließlich durch Kreuzritter nach Europa gebracht, wo sie ein Teil der Volksmedizin wurde. Das etablierte CannabisPräparat wurde Ende des 19. Jahrhunderts unter anderem bei Schlafstörungen, Schmerzen, Depressionen und psychischen Erkrankungen eingesetzt (Grotenhermen und Häußermann 2017). Mit der Änderung des Opiumgesetzes 1929 wurde Cannabis verboten, sodass seine Bedeutung und sein Einsatz als Heilmittel stark abnahmen. Seit März 2017 können Ärzte in Deutschland Cannabisblüten und cannabishaltige Arzneimittel wieder verschreiben. Insbesondere als alternative Therapieform für diverse Erkrankungs- und Beschwerdebilder, die durch die bislang leitliniengerechte Therapie nicht adäquat versorgt werden können, besteht großes Interesse. Oft wird kritisiert, dass Cannabis als Arzneimittel zugelassen wurde, ohne dass die Wirksamkeit und Indikation ausreichend wissenschaftlich belegt wurden. Die üblichen Phasen von Arzneimittelstudien wurden nicht durchlaufen. Bislang liegen nur wenige Studien mit guter Evidenz vor, die die Wirksamkeit, Sicherheit und auch Verträglichkeit von Cannabinoiden testeten (Grotenhermen und Müller-Vahl 2012).

\subsubsection{Aufbau und Funktion des Endocannabinoidsystems}

Anfang der 1990er Jahre wurde das Endocannabinoidsystem (ECS), oder auch körpereigenes Cannabinoidsystem genannt, als Teil des menschlichen Nervensystems entdeckt (Kano et al. 2009). Als Namensgeber diente die Hanfpflanze Cannabis sativa, da das ECS als physiologisches Regulationssystem erst im Zusammenhang mit der Forschung über deren pflanzliche Inhaltsstoffe entdeckt wurde. Das ECS ist in seiner Komplexität trotz der rasant wachsenden Zahl an neuen Informationen zur Cannabisforschung nicht vollständig verstanden. Es dient der Erhaltung der Homöostase im Nervensystem durch seine Rolle als Neuromodulator und ist außerdem ein wichtiger Faktor für Neuroplastizität (Kano et al. 2009; Katona und Freund 2012; Lutz et al. 2015).

Nachfolgend ist ein Überblick über die Bestandteile des Systems dargestellt. 


\subsubsection{Cannabinoidrezeptoren}

Um die Wirkung von Cannabinoiden im ZNS entfalten zu können, müssen diese an bestimmten Bindungsstellen, den so genannten Cannabinoidrezeptoren (CB-Rezeptoren), binden. Bisher wurden nur zwei dieser Rezeptoren, CB1 und CB2, identifiziert und ausführlich charakterisiert (Lu und Mackie 2016). Beide Rezeptoren sind Gi/o-Proteingekoppelte Rezeptoren mit Transmembrandomänen (Petrocellis et al. 2011).

Der zunächst in der Ratte identifizierte CB1-Rezeptor (Devane et al. 1988) besteht aus 473 Aminosäuren. Das menschliche Homolog hingegen aus 472 Aminosäuren. Die Vergleichbarkeit der Sequenzen liegt bei ca. 97 - 99 \% (Kano et al. 2009). Hohe Dichten des Rezeptors finden sich insbesondere in den Basalganglien, der Substantia nigra, dem Hippocampus, dem Bulbus olfactorius und dem Kleinhirn. Vergleichsweise moderate Dichten von CB1 zeigen sich im Cortex und in Regionen des Vorderhirns. In Hirnarealen, die eine hohe Relevanz für lebenserhaltende Prozesse haben, finden sich sehr geringe Dichten des Rezeptors (Kano et al. 2009; Lu und Mackie 2016). Die Expressionsstärke des CB1-Rezeptors variiert nicht nur zwischen den Gehirnregionen, sondern auch zwischen den Zelltypen. Neben der Expression auf Neuronen konnten die Rezeptoren auch auf Astrozyten und Mikroglia nachgewiesen werden (Lutz et al. 2015; Lu und Mackie 2016; Busquets-Garcia et al. 2018a).

Ursprünglich wurde der CB2-Rezeptor auf Immunzellen entdeckt und deshalb lange Zeit als „peripherer Cannabinoidrezeptor“ gehandelt (Munro et al. 1993). Die Expression des CB2-Rezeptors im ZNS wurde lange diskutiert. Nachgewiesen wurde der CB2-Rezeptor in Mikroglia, den Immunzellen des Gehirns (Atwood und Mackie 2010), sowie in Nervenzellen des Zerebellum, Hippocampus, Hirnstamm und in der Thalamusregion (Atwood und Mackie 2010; Zhang et al. 2014; Stempel et al. 2016). Aufgrund der Verwendung von unspezifischen Antikörpern und einer geringeren Expressionsdichte im Vergleich zum CB1-Rezeptor, ergaben sich zunächst Unklarheiten über den Nachweis des CB2-Rezeptors (Marchalant et al. 2014). Der CB2-Rezeptor besteht aus 360 Aminosäuren und stimmt zu 44 \% mit der Sequenz des CB1-Rezeptors überein (Kano et al. 2009).

Neben CB1 und CB2 gibt es weitere Rezeptoren, deren Relevanz für das ECS nicht ausreichend belegt ist, die jedoch an den Effekten von endogenen und exogenen Cannabinoiden beteiligt sind. Diese sind unter anderem der transient receptor potential vanilloid receptor type 1 (TRPV1) und der Peroxisomen-Proliferator-aktivierte-Rezeptor- $\gamma$ (PPAR $\gamma$ ) (Zygmunt et al. 1999; Bouaboula et al. 2005; O'Sullivan 2007).

\subsubsection{Liganden}

Endocannabinoide sind körpereigene Liganden und sind unter anderem die Arachidonsäurederivate Anandamid (AEA) und 2-Arachidonylglycerol (2-AG). AEA ist ein voller Agonist für TRPV1 und ein partieller Agonist am CB1 - und CB2-Rezeptor. 2-AG ist ein voller Agonist für beide CB-Rezeptoren (Kano et al. 2009). Die pharmakologische 
Aktivität anderer Stoffe ist noch nicht abschließend geklärt, weshalb in der vorliegenden Arbeit nicht weiter auf sie eingegangen wird.

Pflanzliche Cannabinoide (Phytocannainoide) wie (-)- $\Delta$ 9-trans-Tetrahydrocannabinol (THC) und Cannabidiol (CBD) interagieren ebenfalls mit den oben genannten Rezeptoren und werden in Absatz 1.2.3 näher erläutert.

\subsubsection{Phytocannabinoide}

In der Hanfplanze Cannabis sativa L. sind vorrangig die pflanzlichen Inhaltsstoffe (-)- $\Delta$ 9trans-Tetrahydrocannabinol und Cannabidiol enthalten. Die Wirkweise dieser beiden bedeutendsten Cannabinoide spielt für den medizinischen Nutzen eine große Rolle und wird im Folgenden näher erläutert.

\subsubsection{1 (-)- $\Delta$ 9-trans-Tetrahydrocannabinol}

THC gilt seit seiner Isolierung 1964 (Gaoni und Mechoulam 1964) als wichtigstes psychoaktives Cannabinoid, dessen Wirkspektrum im Vergleich zu den über 100 anderen bislang bekannten Phytocannabinoiden am besten untersucht ist (Mechoulam et al. 2014). Neben seiner Wirkung als moderater, partieller Agonist an CB1- und CB2-Rezeptoren, reichen die Effekte von THC aber auch über die CB-Rezeptoren hinaus. Abhängig von den Zelltypen, deren Rezeptorexpression und der Anwesenheit anderer Endocannabinoide, interagiert es über ein gemischtes Agonist-/Antagonist-Profil unter anderem an den TRPV2-4-Kanälen, GPR55-Rezeptoren und 5-HT3A-Rezeptoren (Petrocellis et al. 2011; Bolognini et al. 2012; Morales et al. 2017).

THC wurde schon seit den 1980er Jahren für den klinischen Gebrauch gegen Übelkeit und Erbrechen bei Chemotherapie oder zur Appetitanregung bei an AIDS-Erkrankten verabreicht (Whiting et al. 2015). Es hat einen schmerzlindernden Effekt bei neuropathischen Schmerzen (Boychuk et al. 2015) und findet Anwendung bei TicStörungen (Müller-Vahl et al. 2003). Studien zeigen unterschiedliche Ergebnisse hinsichtlich der Wirkungsweise von THC bei Krankheiten wie Epilepsie und Angststörungen (Wallace et al. 2003; Schramm-Sapyta et al. 2007).

THC wird ein positiver Effekt auf den Alterungsprozess des Hirns sowie auf den Niedergang von Hirnzellen bei neurodegenerativen Erkrankungen wie der AlzheimerKrankheit, unter anderem durch eine Stimulation von intraneuronalem Beta-Amyloid, zugeschrieben (Eubanks et al. 2006; Cao et al. 2014; Currais et al. 2016). Es konnte außerdem gezeigt werden, dass THC den Alterungsprozess im Gehirn so verändert, dass die kognitiven Leistungen von 12- und 18-monatigen mit THC behandelten WT-Tieren denen von unbehandelten zweimonatigen Mäusen entsprach (Bilkei-Gorzo et al. 2017). Diese Eigenschaften suggerieren, dass THC eine maßgebliche Rolle in der Therapie der Alzheimer-Krankheit spielen könnte. 


\subsubsection{Cannabidiol (CBD)}

CBD wurde 1940 von Adams et al. erstmalig isoliert. Seine Struktur wurde jedoch erst 23 Jahre später identifiziert (Cunha et al. 1980). CBD hat ein komplexes Interaktionsmuster mit dem ECS. Es zeigt eine geringere Verdrängung von CB1- und CB2-Rezeptoren verglichen mit THC. Trotz der geringen Rezeptoraffinität konnte gezeigt werden, dass CBD als inverser Agonist an beiden Rezeptoren agieren kann. Dennoch ist das pharmakologische Wirkungsprofil nicht auf die CB-Rezeptoren beschränkt, denn für den therapeutischen Effekt wirkt es außerdem über TRPV1-, PPAR $\gamma$ - 5HT1A-, und GPR55Rezeptoren (Zygmunt et al. 1999; Bouaboula et al. 2005; Russo et al. 2005; O'Sullivan 2007; Ryberg et al. 2007). Die genauen Wirkmechanismen sind bislang nicht geklärt und zeigen die Komplexität hinsichtlich der pharmakologischen Eigenschaften (Petrocellis und Di Marzo 2010). CBD wurde als nicht psychoaktiv klassifiziert, da es keine typischen Verhaltenseffekte, die mit einer Aktivierung des CB1-Rezeptors einhergehen, hervorruft (Mechoulam et al. 2007). Das große Spektrum an Effekten hebt das Potential von CBD als multimodales Medikament hervor.

Es konnten günstige Auswirkungen von CBD auf die Pathogenese verschiedener Erkrankungen wie Multiple Sklerose (Mecha et al. 2013), Hirninfarkte (Schiavon et al. 2014; Mori et al. 2017) und Epilepsie (Patra et al. 2019) in Mausmodellen aufgezeigt werden. CBD findet auch zur Behandlung von neuropsychiatrischen Erkrankungen, insbesondere für Angststörungen, Depression und Schizophrenie, Anwendung (Micale et al. 2013; Kucerova et al. 2014; Blessing et al. 2015). Ein angstlösender Effekt zeigte sich auch in gesunden Menschen (Cunha et al. 1980). Kürzlich konnte gezeigt werden, dass eine frühere Behandlung mit CBD das Auftreten von Schizophrenie-ähnlichen Defiziten verhindert (Stark et al. 2019). Negative Effekte von CBD auf gesunde C57Bl/6J-Mäuse konnten nicht nachgewiesen werden (Schleicher et al. 2019).

Das in vivo Potential von CBD wurde in einigen pharmakologischen AlzheimerMausmodellen dargestellt, nachdem sich in vitro positive neuroprotektive und entzündungshemmende Effekte zeigten (Esposito et al. 2007; Mukhopadhyay et al. 2011). Des Weiteren wurde die Fähigkeit von CBD, die Neurodegeneration im Hippocampus und Cortex zu verhindern, beschrieben (Hamelink et al. 2005). Außerdem soll es die Migration von Mikrogliazellen regulieren (Martín-Moreno et al. 2011) und die Hyperphosphorylierung von Tau-Protein reduzieren (Esposito et al. 2007). Schließlich konnte nachgewiesen werden, dass CBD vor Beta-Amyloid- und Mikoglia-aktivierterNeurotoxizität schützt (Janefjord et al. 2014), die Beta-Amyloid-Produktion reduziert werden kann (Scuderi et al. 2014) und möglicherweise ein Schutz der Lebensfähigkeit von Zellen entsteht (Harvey et al. 2012). Ergänzend dazu führt CBD dazu, dass die synaptische Plastizität im Hippocampus geschützt wird und somit erhalten bleibt (Hughes und Herron 2019). Diese Eigenschaften suggerieren, dass CBD vielversprechend hinsichtlich des therapeutischen Potentials bei der Alzheimer-Krankheit ist. 


\subsection{Fragestellung dieser Arbeit}

Das Endocannabinoidsystem (ECS) ist ein körpereigenes, physiologisches Regulationssystem, das an verschiedenen Mechanismen zur Erhaltung der Homöostase des Nervensystems und Neuroplastizität beteiligt ist. Als Signalsystem dient es wichtigen physiologischen Funktionen wie Gedächtnisbildung, Kontrolle der Motorik und neuronaler Differenzierung (Kano et al. 2009; Katona und Freund 2012; Lutz et al. 2015). Bei der Alzheimer-Krankheit sind unter anderem diese kognitiven Funktionen gestört, was zu einer erheblichen Beeinträchtigung von Alltagsfunktionen und Lebensqualität führt (Millan et al. 2012). Eine Modulation des ECS könnte somit neue therapeutische Möglichkeiten zur Behandlung neurodegenerativer Erkrankungen wie der Alzheimer-Krankheit bieten.

Ziel der vorliegenden Arbeit ist es deshalb, die therapeutischen Effekte von pflanzlichen Cannabinoiden bzw. deren Hauptwirkstoffe THC und CBD in vivo auf die Alzheimerpathologie zu untersuchen. Hierzu erhielten adulte Mäuse des klassischen Mausmodells für familiäres Alzheimer, dem 5XFAD-Mausmodell, eine sechswöchige Behandlung mit THC bzw. CBD oder einer Trägerlösung (Vehikelsubstanz). Um den Einfluss auf kognitive sowie motorische Verhaltensweisen zu testen, wurde eine Reihe von Verhaltenstests durchgeführt. Hierbei wurden insbesondere das Lernen, die Motorik und das Angstverhalten getestet. Die Frage, inwieweit THC bzw. CBD die Beta-Amyloid Pathologie und die Neuroinflammation der 5XFAD-Mäuse beeinflussen kann, konnte mithilfe der Färbung von Beta-Amyloid und der immunhistochemischen Färbung gegen die Inflammationsmarker GFAP und IBA1 beantwortet werden. Um den Einfluss auf die Rezeptorexpression bei chronischer THC- und CBD-Gabe zu untersuchen, wurde eine Färbung des CB1-Rezeptors angefertigt, um so den Therapieeffekt der Substanzen zu evaluieren. 


\section{$2 \quad$ Material und Methoden}

\section{$2.1 \quad$ Tiere}

\subsubsection{Haltungsbedingungen}

Die Tiere, die in dieser Arbeit verwendet wurden, gehörten allesamt der Spezies der Hausmaus (mus musculus) an. Die Mäuse wurden unter spezifisch pathogenfreien Bedingungen (SPF) gehalten. Verpaart und ausgetragen wurden die Mäuse in der zentralen tierexperimentellen Einrichtung (ZTE) der Universitätsmedizin Göttingen (UMG). Dort trennte man sie nach Geschlechtern und teilte sie in Gruppen von bis zu sechs Tieren auf, wo sie in standardisierten, einzelbelüfteten IVC-Käfigen $(14,5 \mathrm{~cm} \times 32 \mathrm{~cm} \times 15 \mathrm{~cm})$ gehalten wurden. Wasser und Futter waren für die Tiere frei verfügbar. Für die Verhaltensexperimente wurden die Mäuse von der ZTE ins Labor überführt und dort in einem Schrank für die Haltung von Versuchstieren (Charles River Labaratories, Washington, MA, USA) untergebracht. Der von der ZTE festgelegte 12/12 Stunden TagNacht-Rhythmus wurde umgekehrt, sodass die Verhaltensexperimente und Injektionen in der wachen Phase der Tiere durchgeführt werden konnten. Ansonsten unterschieden sich die Haltungsbedingungen nicht von denen in der ZTE.

Die Mäuse wurden nach den Vorgaben der „Gesellschaft für Versuchstierkunde“ (GVSOLAS) und der „Federation of European Labaratory Animal Science Associations“ (FELASA) behandelt. Die Tierexperimente wurden vom Niedersächsischen Landesamt für Verbraucherschutz und Lebensmittelsicherheit genehmigt und von hierfür ausgebildeten Personen durchgeführt. Die Anzahl der verwendeten Tiere wurde so klein wie möglich gehalten. Zudem wurden Schmerzen minimiert sowie Leiden und Schäden der Tiere nach Möglichkeit vermieden.

\subsubsection{Transgene 5XFAD-Mauslinie}

In dieser Arbeit wurden Mäuse der transgenen 5XFAD-Mauslinie verwendet. Transgene 5XFAD-Mäuse exprimieren fünf Mutationen, die die familiäre Alzheimerkrankheit hervorrufen. Die Schweden- (K670N, M671L), Florida- (I716V) und London- (V717I) Mutationen betreffen die 695-Isoform des humanen APP, während sich die M146L- und L286V-Mutationen auf das PSEN-1 auswirken. Kontrolliert werden die Mutationen allesamt durch den Murin-Thy-1-Promotor (Oakley et al. 2006).

Die hemizygoten 5XFAD-Mäuse entstammen den Jackson Laboratories (Jackson Laboratories, Bar Habour, ME, USA). Die nicht-transgenen Geschwistertiere wurden als Wildtyp-Kontrollen verwendet. 


\subsubsection{Nachweis des Transgens bei 5XFAD-Mäusen}

Alle Mäuse, die in dieser Arbeit verwendet wurden, wurden anhand von isolierter DNA aus Schwanzbiopsien genotypisiert, sodass die Zugehörigkeit der Tiere zur transgenen 5XFAD-Linie nachgewiesen werden konnte.

\subsubsection{DNA- Isolierung aus Schwanzbiopsien}

Zunächst wurde das Gewebe mit $200 \mu$ Lysepuffer [200mM Tris/Hcl pH 8,5 (Carl Roth, Karlsruhe, Deutschland), $10 \mathrm{mM}$ EDTA (Carl Roth, Karlsruhe, Deutschland), 0,4\% Natriumdodecylsulfat (SDS, Biomol GmbH, Hamburg, Deutschland), $400 \mathrm{mM} \mathrm{NaCl}$ (Carl Roth, Karlsruhe, Deutschland)] mit $10 \mu$ Proteinase K [PeQlab GmbH (VWR Life Science Competence Center), Erlangen, Deutschland] in ein 1,5 $\mathrm{ml}$ Eppendorfgefäß gegeben. Es folgte die etwa 20 -stündige Inkubation bei $56{ }^{\circ} \mathrm{C}$ im Thermomixer Compact (Eppendorf AG, Hamburg, Deutschland) bei $350-450 \mathrm{U} / \mathrm{min}$, bis das Gewebe schließlich lysiert war. Anschließend erfolgte die Abzentrifugation bei $17.000 \mathrm{U} / \mathrm{min}$ bei $4{ }^{\circ} \mathrm{C}$ der Probe für 20 min (Heraeus Biofuge Stratos Zentrifuge, Thermo Fisher Scientific, Waltham, MA, USA).

In ein Eppendorfgefäß mit $200 \mu$ Isopropanol (Carl Roth GmbH, Karlsruhe, Deutschland) wurde der Überstand aus der Probe hineinpipettiert und durch Schwenken vermischt bis ein Präzipitat sichtbar war. Danach wurde die Probe für 10 min erneut zentrifugiert, diesmal bei $13.000 \mathrm{U} / \mathrm{min}$. Nachdem der Überstand vorsichtig abgegossen wurde, erfolgte die Waschung des entstandenen Pellets mit $200 \mu \mathrm{l} 70 \%$ Ethanol (Walter-CMP, Kiel, Deutschland) und wieder wurde die Probe bei $13.000 \mathrm{U} / \mathrm{min}$ für $10 \mathrm{~min}$ zentrifugiert. Die Überstände und Ethanolreste wurden abpipettiert und verworfen, während das Pellet eine Stunde lang bei $55^{\circ} \mathrm{C}$ auf dem UNO-Thermoblock (Biometra, Göttingen, Deutschland) getrocknet wurde. Schließlich folgte die Lösung der Pellets in $30 \mu$ Reinstwasser, Aqua (B.Braun, Melsungen, Deutschland) und die Inkubation über Nacht im Thermomixer bei $56{ }^{\circ} \mathrm{C}$.

\subsubsection{Nukleinsäure-Quantifizierung}

Die Konzentrationen der Nukleinsäuren wurden für den Einsatz der PolymeraseKettenreaktion (polymerase cain reaction, PCR) mithilfe eines Biophotometers (Nanodrop one, Thermo Fisher Scientific, Waltham, MA, USA) quantifiziert. Dazu wurde $1 \mu \mathrm{l}$ Aqua auf den gereinigten Messarm des Gerätes gegeben, um den Leerwert zu bestimmen. Um ein Anhaften der DNA in dem Eppendorf-Gefäß zu verhindern, wurde zunächst auf- und abpipettiert, um anschließend nach erneuter Reinigung $2 \mu \mathrm{l}$ der Probe auf den Messarm zu geben. Bei einem Extinktionskoeffizienten von 1,8 für A260/A280 und A260/230 konnte von einer ausreichenden Konzentration und Reinheit der Nukleinsäuren ausgegangen werden. Für den Einsatz der PCR konnte nun die Probenverdünnung von $20 \mathrm{ng} / \mu \mathrm{l}$ hergestellt werden. 


\subsubsection{Nukleinsäure-Amplifikation durch die Polymerase-Kettenreaktion}

Für die PCR wurden jeweils $2 \mu$ der DNA-Probenverdünnung (siehe Absatz 2.1.3.2) mit je $18 \mu$ leines PCR-Mastermixes [9,6 $\mu$ l aqua bidestillata (B.Braun, Melsungen, Deutschland), $2 \mu l 10$ x Reaktionspuffer (Axon Labortechnik GmbH, Kaiserslautern, Deutschland), 3,2 $\mu 1$ 25 mM MgCl2 (Axon Labortechnik GmbH, Kaiserslautern, Deutschland), $2 \mu$ dNTPs (peQlab GmbH (VWR Life Science Competence Center), Erlangen, Deutschland), 0,5 $\mu 1$ Primer 1 rev. 2 x (5'3'-Sequenz CATGACCTGGGACATTCTC) 0,5 $\mu$ l Primer 2 for. (5‘3Sequenz GTAGCAGAgGAgGAAGAAGTG), 0,2 $\mu$ l Taq-Polymerase (5 U/ $\mu \mathrm{l}$, Axon Labortechnik $\mathrm{GmbH}$, Kaiserslautern, Deutschland)] verdünnt. Anschließend wurden die DNA-Proben im Lab Cycler (SensoQuest GmbH, Göttingen, Deutschland) nach folgendem Protokoll amplifiziert (Tabelle 1).

Tabelle 1: PCR-Zyklen-Protokoll des Lab Cyclers für Nukleinsäure-Amplifikation

\begin{tabular}{c|c|c|c}
\hline Schritt & Zeit [s] & Temperatur $\left[{ }^{\circ} \mathbf{C}\right]$ & \\
\hline $\mathbf{1}$ & 180 & 94 & Denaturierung \\
\hline $\mathbf{2}$ & 45 & 94 & Denaturierung \\
\hline $\mathbf{3}$ & 60 & 58 & Hybridisierung \\
\hline $\mathbf{4}$ & 60 & 72 & Polymerisation \\
\hline $\mathbf{5}$ & \multicolumn{3}{|c}{35 x Schritt $2-4$ wiederholen } \\
\hline $\mathbf{6}$ & 300 & 72 & Polymerisation \\
\hline $\mathbf{7}$ & Kein Zeitlimit & 4 & Abkühlen \\
\hline
\end{tabular}

\subsubsection{Gel-Elektrophorese}

Die Herstellung des Agarose-Gels für die elektrophoretische Differenzierung der Nukleinsäuren erfolgte durch die Verdünnung von 1 x TBE-Puffer [54,5 g/1 Tris (Carl Roth, Karlsruhe, Deutschland), 27,8 g/l Borsäure (Carl Roth, Karlsruhe, Deutschland), $20 \mathrm{ml}$ 0,5 M Na2EDTA PH 8.0 (Carl Roth, Karlsruhe, Deutschland), aufgefüllt mit aqua bidest auf 1 Liter] mit $200 \mathrm{ml}$ Wasser (B.Braun, Melsungen, Deutschland). $35 \mathrm{ml}$ davon wurden mit 0,7 g Agarose (Biozym Scientific, Hess. Oldenburg, Deutschland) bei $200 \mathrm{~W}$ in der Mikrowelle aufgekocht. Nach Abkühlung der erwärmten Substanz auf $65{ }^{\circ} \mathrm{C}$ wurden $2 \mu \mathrm{l}$ des DNA-HD Green Plus Stain (Intas Science Imaging Instruments, Göttingen, Deutschland) der Lösung hinzugefügt. Mithilfe eines Probekamms entstanden zehn Probekammern in dem entstandenen Agarosegel. Dieses wurde nach dem Abkühlen in eine mit $240 \mathrm{ml} 1 \mathrm{x}$ TBE-Puffer gefüllte Elektrophoresekammer Blue Marine 100 (SERVA Electrophoresis, Heidelberg, Deutschland) gelegt. In die Kammern des Agarosegels wurden schließlich jeweils $10 \mu \mathrm{l}$ der DNA-Probe (siehe Absatz 2.1.3.3) mit $2 \mu \mathrm{l} 10 \mathrm{x}$ 
Ladepuffer [Life Technologies, Carlsbad, CA, USA (jetzt Thermo Fisher Scientific)] hineingefüllt. Als Referenz diente 100 bp DNA-Ladder (Bioron GmbH, Ludwigshafen, Deutschland) ergänzend zu je einer Positiv- und Negativ-Kontrolle. Als Positiv-Kontrolle diente ein bereits in vorherigen Studien verifiziertes 5XFAD-Tier. Ein Wildtyp-Tier wurde als Negativ-Kontrolle genutzt. Dann wurde eine Spannung von $120 \mathrm{~V}$ für 45 min angelegt. Im Blue Cube 300 (SERVA Electrophoresis, Heidelberg, Deutschland) wurde das Gel unter UV-Licht mit einer Wellenlänge von $366 \mathrm{~nm}$ analysiert, um das Transgen nachzuweisen.

\subsection{Behandlung}

Die jeweilige Menge des pulverförmigen CBD (THCPharm, Frankfurt, Deutschland) und harzförmigen THC (THCPharm, Frankfurt, Deutschland) wurde mit der Feinwaage bestimmt (CBD: 0,1 g; THC: 0,1 g). Das THC wurde zunächst im Wärmeschrank bei ca. $65{ }^{\circ} \mathrm{C}$ erwärmt, um ein einfacheres Lösen der Substanz aus der Ampulle zu gewährleisten. Die Herstellung der Substanzlösungen erfolgte durch Lösen von CBD und THC in jeweils 2,5 ml Tween 80 (Sigma-Aldrich, St. Louis, MO, USA) und $100 \%$ Ethanol (Carl Roth, Karlsruhe, Deutschland). Anschließend wurde das Gemisch in $45 \mathrm{ml}$ einer 0,9\% NaCLLösung verdünnt. Die Herstellung der Vehikellösung erfolgte ohne eine Zugabe von THC oder CBD.

\subsubsection{Behandlungsschema}

Vor Beginn der Behandlung wurden die fünf Monate alten Mäuse gewogen und die jeweilige Substanzdosis abhängig vom Körpergewicht (KG) gewählt (THC und CBD: $20 \mathrm{mg} / \mathrm{kg}$ KG). Das Gewicht der Mäuse wurde im Verlauf der sechswöchigen Behandlung alle sieben Tage dokumentiert und die Substanzdosis entsprechend angepasst. Das Injektionsvolumen betrug $10 \mathrm{ml} / \mathrm{kg} \mathrm{KG}$. Bei jeder Substanzapplikation wurde darauf geachtet, dabei für die Mäuse entstehenden Stress gering zu halten und mögliche Schmerzen zu minimieren.

\subsubsection{Intraperitoneale Injektion}

Die intraperitoneale Injektion der jeweiligen Substanzlösungen erfolgte mit EinmalFeindosierungsspritzen Omnican F $1 \mathrm{ml}$ (B.Braun, Melsungen, Deutschland). Beginnend im Alter von fünf Monaten wurden die Mäuse, je nach Einteilung in THC-, CBD- oder Vehikel-Gruppe, täglich und zur gleichen Uhrzeit $( \pm 2 \mathrm{~h}$ ) sechs Wochen lang behandelt. Die Applikation der Substanzlösung erfolgte auch während der Verhaltenstests, sodass die letzte intraperitoneale Injektion einen Tag vor dem Töten, also am letzten Verhaltenstag, erfolgte. 


\subsection{Verhaltenstests}

Um motorische und kognitive Defizite zu begutachten, wurden die Mäuse einer Reihe von Verhaltenstests unterzogen. Diese Testbatterie beinhaltete Angsttests (Dark/Light Box; Elevated Plus Maze, Open Field) und Lerntests (Novel Object Recognition Test, Cross Maze und Morris Water Maze). Um außerdem unabhängig von kognitiven Defiziten ein motorisches Defizit der Mäuse ausschließen zu können, erfolgte die Durchführung des Rotarod-Tests.

Der Startpunkt der Verhaltenstest wurde auf den Zeitpunkt einer bereits vierwöchigen Behandlung ( \pm 2 Tage) mit den oben beschriebenen Substanzlösungen gesetzt, nachdem sichergestellt wurde, dass keine Ausschlusskriterien erfüllt waren. Diese beinhalteten den Gewichtsverlust von $20 \%$ ihres Startgewichts oder andere Bedingungen, wie beispielsweise Blindheit oder motorische Verhaltensauffälligkeiten. Die Dauer der Testbatterie betrug 15 Tage ( \pm 2 Tage). Während der Verhaltensexperimente erfolgte die intraperitoneale Injektion in einem Mindestabstand von einer Stunde zum jeweiligen Experiment. Die Verhaltenstests wurden zwischen 7 und 19 Uhr durchgeführt. Dies entspricht der aktiven Phase der Mäuse bei einem umgekehrten 12/12 h Tag-Nacht-Rhythmus. Die Ausführung von mehreren Lern-und Angsttests wurde vermieden, sodass die Mäuse nur je einen Angstoder Motortest und einen Lerntest pro Tag ausführen mussten.

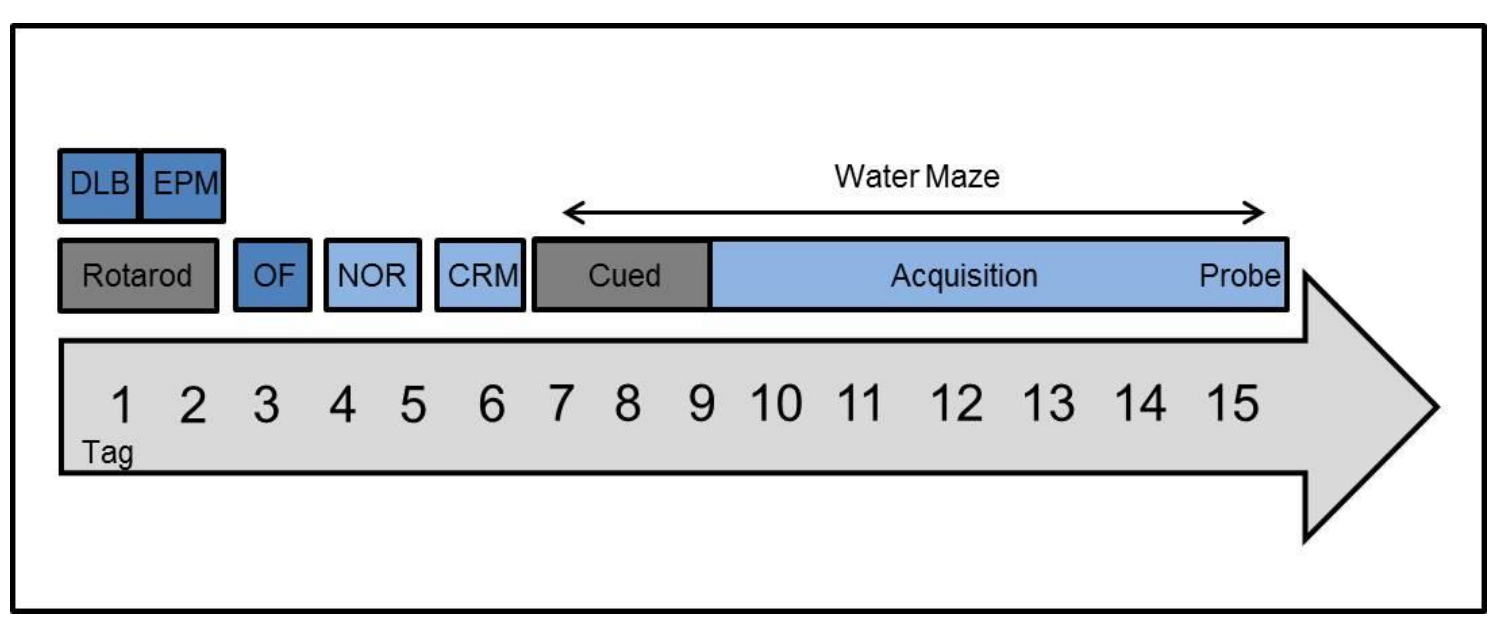

Abbildung 4: Abfolge Verhaltensversuche Schema der verschiedenen Verhaltenstests, die innerhalb der letzten 15 Tage ( \pm 2 Tage) der sechswöchigen Behandlung mit der jeweiligen Substanz durchgeführt wurden. Das Morris Water Maze wurde am Ende der Testbatterie ausgeführt. Außerdem wurde vermieden, dass gleichzeitig mehrere Angsttests bzw. motorische Tests an einem Tag stattfanden. Abkürzungen: DLB (Dark/Light Box); EPM (Elevated Plus Maze); Rotarod; OF (Open Field); NOR (Novel Object Recognition); CRM (Cross Maze); Morris Water Maze (Cued Training, Acquisition Training, Probe Trial).

\subsubsection{Clasping-Verhalten}

Das Clasping-Verhalten bietet eine einfache Möglichkeit, erste Hinweise über motorische Defizite in verschiedenen Mausmodellen neurodegenerativer Erkrankungen zu liefern (Jawhar et al. 2012). Hierzu wurden die Mäuse $10 \mathrm{~s}$ an der Schwanzbasis aus dem Käfig 
gehoben und kopfüber hängen gelassen. Die Reaktion gesunder Mäuse zeigte sich in dem Wegstrecken aller vier Extremitäten, Winden und Strampeln, wohingegen ein positives Clasping-Verhalten beobachtet wurde, wenn die Pfoten zum Körper gezogen wurden. Es erfolgte eine Bewertung mithilfe eines Punkteschlüssels von 0 bis 3 Punkten (Miller et al. 2008), der in Tabelle 2 gezeigt wird.

Tabelle 2: Punkteschlüssel Clasping-Verhalten

\begin{tabular}{c|l}
\hline Punktzahl & \multicolumn{1}{c}{ Erklärung } \\
\hline $\mathbf{0}$ & Kein Klammern \\
\hline $\mathbf{1}$ & Klammern mit den Vorderpfoten \\
\hline $\mathbf{2}$ & Klammern mit den Vorderpfoten und einer Hinterpfote \\
\hline $\mathbf{3}$ & Klammern mit Vorder- und Hinterpfoten \\
\hline
\end{tabular}

\subsubsection{Rotarod}

Der Rotarod-Test ist ein Test zur Bestimmung von motorischer Ausdauer, Koordination und Lernverhalten der Mäuse (Shiotsuki et al. 2010).

Beim Rotarod handelt es sich um einen motorischen Zylinder (Technical Scientific Equipment, Australien), der mit steigender Drehgeschwindigkeit rotiert und von einem mit dunklem Plastik ausgekleideten Käfig umgeben ist. $12 \mathrm{~cm}$ unterhalb des Zylinders befindet sich ein Gitter, hoch genug, um die Maus von einem vorzeitigen Absprung von dem Zylinder abzuhalten, dennoch ausreichend bodennah, um die Maus vor Verletzungen zu schützen (Abbildung 5). Die Maus wurde auf den Zylinder gesetzt, dessen Drehgeschwindigkeit nun stetig zunahm und innerhalb von einer Testdauer von maximal $300 \mathrm{~s}$ von $4-45 \mathrm{rpm}$ anstieg. Fiel die Maus vom Zylinder, wurde der Test abgebrochen und die Maus wurde zurück in den Käfig gesetzt. Erreichte die Maus die maximale Testdauer, wurde der Test nach $300 \mathrm{~s}$ beendet. Das Intervall zwischen den je vier Versuchen an beiden aufeinanderfolgenden Testtagen betrug 10 min.

Der Test wurde bei Rotlicht durchgeführt, sodass die Maus nicht durch visuelle Hinweise abgelenkt wurde. Für jede Maus wurde die Dauer bis zum Herabfallen von dem Zylinder registriert und als Maß ihrer motorischen Fähigkeiten ausgewertet. Nach jedem Durchlauf wurde der Versuchsaufbau mit Desomed ${ }^{\circledR}$ Rapid AF Tüchern (Desomed, Malsfeld, Deutschland) gereinigt, um mögliche Geruchsspuren zu beseitigen. 


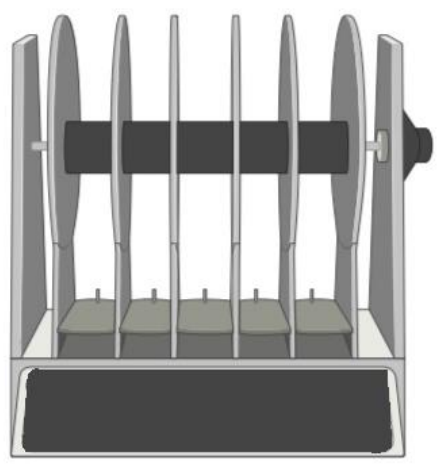

Abbildung 5: Versuchsaufbau Rotarod Motorische Fähigkeiten von Nagetieren können über den RotarodTest getestet werden. Die Maus wird auf einen rotierenden Zylinder gesetzt und die Dauer auf dem an Geschwindigkeit zunehmenden Zylinder gemessen, bis die Maus hinunter fällt.

\subsubsection{Morris Water Maze}

Angelehnt an den ursprünglichen Versuchsaufbau von Morris im Jahre 1981/84 und den 2006 entstandenen Versuchsprotokollen von Vorhees und Williams, werden die Mäuse im Morris Water Maze (MWM) neben Hippocampus abhängigem Lernen auch auf das räumliche Bezugsgedächtnis getestet (Morris 1984; D’Hooge und De Deyn 2001). Die Mäuse sollten lernen, eine in einem Wasserbecken (Durchmesser $110 \mathrm{~cm}$ ) unter der Wasseroberfläche verborgene Plattform zu lokalisieren und zu besteigen. Während der drei Testphasen (Cued Training, Acquisition Training und Probe Trial) erfolgte dies durch Zuhilfenahme visueller räumlicher Hinweise am Beckenrand. Die Plattform hatte einen Durchmesser von $10 \mathrm{~cm}$. Um Boden und Plattform unkenntlich zu machen, wurde das gewöhnliche Leitungswasser im Becken mit gesundheitlich unbedenklicher weißer Farbe (Lukas Cryl Studio Titanium White 4608, Lukas-Nerchau, Düsseldorf, Deutschland) gemischt und konstant bei einer Temperatur von $20^{\circ} \mathrm{C}$ gehalten.

Es wurden zwei imaginäre Achsen durch das runde Becken gezogen, sodass eine Einteilung gemäß eines „,+“-Symbols entstand, also in vier gleiche Quadranten. Diese wurden nach dem jeweiligen Verhältnis zur Plattform als Zielquadrant, linker, rechter oder gegenüberliegender Quadrant bezeichnet (Abbildung 6, B). Das Ende jeder Achse bezeichnete dann vier Punkte, an denen während des Acquisition Trainings und des Probe Trials Fahnen als visueller Hinweis befestigt wurden. Diese Punkte wurden mit Norden $(\mathrm{N})$, Osten (O), Süden (S) und Westen (W) bezeichnet (Abbildung 6, A).

Dieser Test bediente sich der natürlichen Aversion der Mäuse gegen Wasser, sodass eine höhere Motivation bestand, die Plattform zu erreichen und somit die Möglichkeit dem Wasser zu entkommen (Vorhees und Williams 2006). Die Mäuse wurden gemäß eines vorgegebenen Protokolls an verschiedenen Startpunkten am Rand des Beckens mit dem Gesicht zur Beckenwand vorsichtig ins Wasser gesetzt. Die Bewegungen der Mäuse wurden mithilfe einer Kamera (Computar, Commack, NY, USA) und dem AnyMaze Video 
Tracking System (Stoelting Co, Wood Dale, IL, USA) aufgezeichnet und anschließend ausgewertet.

Laut dem Protokoll, nach dem das MWM in unserem Labor durchgeführt wurde, erfolgte dieser Lerntest in drei verschiedenen Phasen: Cued Training (drei Tage), Acquisition Training (fünf Tage), und einem Testtag (Probe Trial). Pro Trainingstag erfolgten vier Durchgänge, die höchstens 1 min pro Durchgang andauerten, abhängig davon, wie schnell die unter der Wasseroberfläche verdeckte Plattform von der Maus identifiziert und erklommen wurde. In der Zeit zwischen den Durchgängen wurden die Mäuse in einen trockenen, mit Tüchern ausgekleideten Käfig gesetzt, der mit einer Rotlicht-Wärmelampe bestrahlt wurde, um eine mögliche Unterkühlung der Tiere zu vermeiden. Nur, wenn sich die Maus vollständig getrocknet hatte, wurde der nächste Durchgang gestartet, sodass die Zeit zwischen den Durchgängen etwa $10-15$ min betrug.

\section{Cued Training}

Um sicherzustellen, dass die Voraussetzungen zur Teilnahme am Test erfüllt waren, erfolgte die dreitägige Probephase im Cued Training. Hierbei wurde beobachtet, ob die Mäuse die Plattform, die mit einer dreieckigen Fahne markiert wurde, im Zeitraum von 60 s erreichen konnten. Dabei konnten Rückschlüsse auf die Schwimm- und Sehfähigkeit geschlossen werden. Wenn die Plattform in der gegebenen Zeit nicht erreicht und bestiegen werden konnte, wurden die Mäuse mithilfe eines Gitters dorthin geleitet. Um die Tiere an die Plattform und die Umgebung zu gewöhnen, durfte jede Maus etwa $10 \mathrm{~s}$ auf der Plattform sitzen, bevor sie zum Trocknen zurück in den Käfig gebracht wurde. Nach jedem der vier Durchgänge wurde sowohl die Position der Plattform als auch die Startposition geändert (Tabelle 3). Ausgewertet wurden die Zeit bis zum Erreichen der Plattform sowie die Schwimmgeschwindigkeit der Mäuse. Im Anschluss an den dritten Tag des Cued Trainings erhielten die Mäuse einen Tag Pause, bevor mit dem Acquisition Training gestartet wurde.

Tabelle 3: Start- und Zielpositionen im Cued Training

\begin{tabular}{c|c|c|c|c|c|c|c|c}
\hline & \multicolumn{2}{|c|}{ 1. Durchgang } & \multicolumn{2}{c|}{ 2. Durchgang } & 3. Durchgang & \multicolumn{2}{c}{ 4. Durchgang } \\
\hline Tag & Start & Ziel & Start & Ziel & Start & Ziel & Start & Ziel \\
\hline $\mathbf{1}$ & $\mathrm{O}$ & $\mathrm{NO}$ & $\mathrm{W}$ & $\mathrm{SO}$ & $\mathrm{N}$ & $\mathrm{SO}$ & $\mathrm{S}$ & SW \\
\hline $\mathbf{2}$ & $\mathrm{W}$ & $\mathrm{NO}$ & $\mathrm{S}$ & $\mathrm{NO}$ & $\mathrm{O}$ & $\mathrm{SO}$ & $\mathrm{N}$ & $\mathrm{NW}$ \\
\hline $\mathbf{3}$ & $\mathrm{S}$ & $\mathrm{NW}$ & $\mathrm{N}$ & $\mathrm{NO}$ & $\mathrm{W}$ & $\mathrm{SW}$ & $\mathrm{O}$ & $\mathrm{NW}$ \\
\hline
\end{tabular}

$(\mathrm{N}=$ Norden, $\mathrm{O}=$ Osten, $\mathrm{S}=$ Süden, $\mathrm{W}=$ Westen, $\mathrm{NO}=$ Nordosten, $\mathrm{SO}=$ Südosten, $\mathrm{NW}=$ Nordwesten, $\mathrm{SW}=$ Südwesten) 


\section{Acquisition Training}

Zusätzlich zu den bereits im Raum bestehenden visuellen Hinweisen wurden nun vier Fahnen, die sich in Form und Farbe deutlich voneinander unterschieden, für die nächsten fünf Tage des Acquisition Trainings am Beckenrand in Bezug zu den Punkten N, W, O und $\mathrm{S}$ angebracht und deren Position nicht mehr verändert. Außerdem wurde die Fahne auf der Plattform entfernt und die Lokalisation der Plattform, im Gegensatz zu den Startpositionen laut Protokoll (Tabelle 4), nicht variiert, um das räumliche Bezugsgedächtnis zu testen. Es erfolgte die gleiche Durchführung, Versuchszeit und Auswertung wie im Cued Training.

Tabelle 4: Start- und Zielpositionen im Acquisition Training

\begin{tabular}{c|c|c|c|c|c|c|c|c}
\hline & \multicolumn{2}{|c|}{ 1. Durchgang } & \multicolumn{2}{c|}{ 2. Durchgang } & \multicolumn{2}{c}{ 3. Durchgang } & \multicolumn{2}{c}{ D. Durchgang } \\
\hline Tag & Start & Ziel & Start & Ziel & Start & Ziel & Start & Ziel \\
\hline $\mathbf{1}$ & NO & NW & O & NW & S & NW & SW & NW \\
\hline $\mathbf{2}$ & S & NW & NO & NW & SW & NW & O & NW \\
\hline $\mathbf{3}$ & SW & NW & S & NW & O & NW & NO & NW \\
\hline 4 & O & NW & SW & NW & NO & NW & S & NW \\
\hline 5 & SW & NW & NO & NW & S & NW & O & NW \\
\hline
\end{tabular}

$(\mathrm{N}=$ Norden, $\mathrm{O}=$ Osten, $\mathrm{S}=$ Süden, $\mathrm{W}=$ Westen, $\mathrm{NO}=$ Nordosten, $\mathrm{SO}=$ Südosten, $\mathrm{NW}=$ Nordwesten, $\mathrm{SW}=$ Südwesten)

\section{Probe Trial}

An Tag neun, $24 \mathrm{~h}$ nach Abschluss des letzten Tages des Acquisition Trainings, folgte die Durchführung des Probe Trials, der Auskunft über das räumliche Bezugsgedächtnis lieferte. Hierzu wurde die Plattform aus dem Becken entfernt und der Startpunkt gegenüber des Zielquadranten gewählt, der dem Quadranten entsprach, in dem die Plattform während des gesamten Acquisition Trainings lokalisiert war (Tabelle 5). Die räumlichen Hinweise, in Form der Fahnen, blieben unverändert bestehen. Die Mäuse wurden dem gewählten Startpunkt entsprechend, gleich des Prozedere der letzten acht Tage, ins Wasser gesetzt und für $60 \mathrm{~s}$ im Becken schwimmen gelassen. Bei intaktem räumlichem Bezugsgedächtnis sollte sich eine klare Tendenz zum Zielquadranten zeigen, sodass die Maus die meiste Zeit dort verbringen sollte (Vorhees und Williams 2006). Im Gegensatz zum Cued Training und Acqusition Training erfolgte die Auswertung nicht nur hinsichtlich der Dauer, die die Maus zum Erreichen der Plattform benötigte sowie deren Schwimmgeschwindigkeit, sondern außerdem hinsichtlich der Prozentzahl, die die Maus in den verschiedenen Quadranten (Zielquadrant, rechter Quadrant, linker Quadrant, gegenüberliegender Quadrant, Abbildung 6 B) verbrachte. 
Tabelle 5: Start- und Zielposition im Probe Trial

\begin{tabular}{c|c|c}
\hline Tag & Start & Ziel \\
\hline 9 & SO & Plattform entfernt \\
\hline
\end{tabular}

$(\mathrm{SO}=$ Südosten $)$
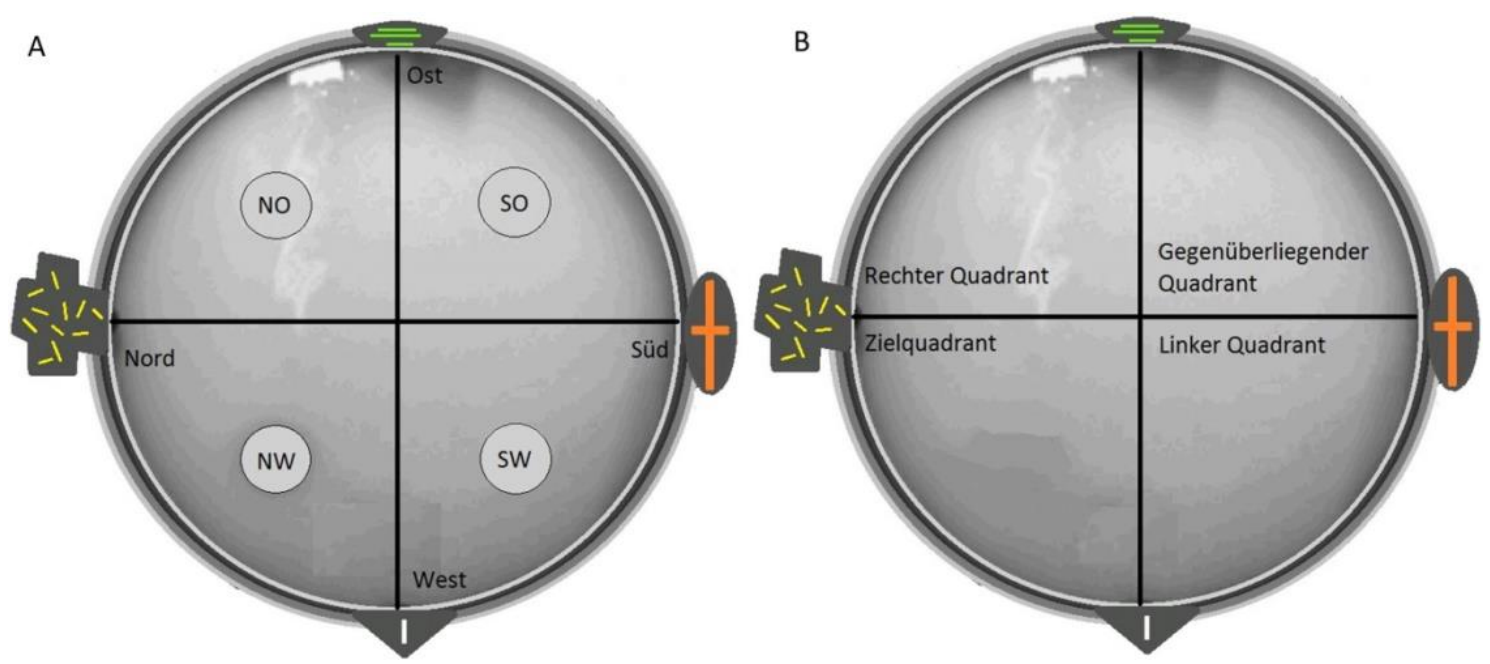

Abbildung 6: Versuchsaufbau Morris Water Maze Nach dem dreitägigen Cued Training und dem anschließenden Acquisition Training (A) folgte der einmalige Probe Trial (B). Hierfür wurde die Plattform entfernt und das Becken in vier virtuelle Quadranten unterteilt. Die visuellen Hilfen am Beckenrand wurden zur Orientierung der Mäuse belassen. Abkürzungen: $\mathrm{NO}=$ Nordosten, $\mathrm{SO}=$ Südosten, NW $=$ Nordwesten, $\mathrm{SW}=$ Südwesten.

\subsubsection{Cross Maze}

Das Arbeitsgedächtnis der Mäuse wurde im Cross Maze evaluiert. Dieses Konstrukt bestand aus vier exakt gleichen Armen (Länge: $30 \mathrm{~cm}$, Breite: $15 \mathrm{~cm}$, Höhe: $8 \mathrm{~cm}$ ) und einem quadratischen Zentrum $(8 \mathrm{~cm} \times 8 \mathrm{~cm})$, das ein kreuzförmiges Labyrinth in „,+“Form bildet (Abbildung 7). Die Auskleidung des Labyrinths bestand aus grauem Plastik. Das Experiment wurde bei Rotlicht durchgeführt, um visuelle Hilfen auszuschließen. Nachdem die Maus mit dem Gesicht zur Wand zufällig in einen Arm des Labyrinths gesetzt wurde, durfte die Maus dieses für eine Dauer von $10 \mathrm{~min}$ frei erkunden. Die Bewegungen der Maus wurden mithilfe einer Kamera (Computar, Commack, NY, USA) aufgezeichnet und mit dem AnyMaze Video Tracking System (Stoelting Co, Wood Dale, IL, USA) ausgewertet.

Dieser Test bezieht sich auf die Tendenz von Mäusen neue, unbekannte Gebiete - in diesem Fall Arme - zu erkunden, anstatt bereits erkundete Arme nach kurzer Zeit erneut zu erkunden (Wietrzych et al. 2005). Es wurde folglich die Anzahl der Armwechsel beobachtet. Ein Armwechsel bestand, wenn die Maus keinen bereits erkundeten Arm erneut erkundete, bevor sie nicht alle drei anderen Arme betreten hatte, zum Beispiel als 
überlappendes Vierfach-Set (z.B. 1, 2, 3, 4 oder 2, 3, 4, 1, nicht 1, 2, 4, 2). Somit wurde die Armwechslungsrate (Alternierungsrate) ermittelt aus dem prozentuellen Anteil der geschehenen Armwechsel an der Gesamtanzahl der Armwechsel (Armwechselgesamt - 3) (Wietrzych et al. 2005). Das Betreten eines Armes wurde nur als solches bewertet, wenn sich die Maus mit allen vier Pfoten im Arm befand. Der direkte Wiedereintritt in einen Arm wurde als einziger Armeintritt gewertet.

Nach Abschluss des Tests wurde das Labyrinth mit Desomed ${ }^{\circledR}$ Rapid AF Tüchern (Desomed, Malsfeld, Deutschland) gereinigt, um mögliche Geruchsspuren zu beseitigen.

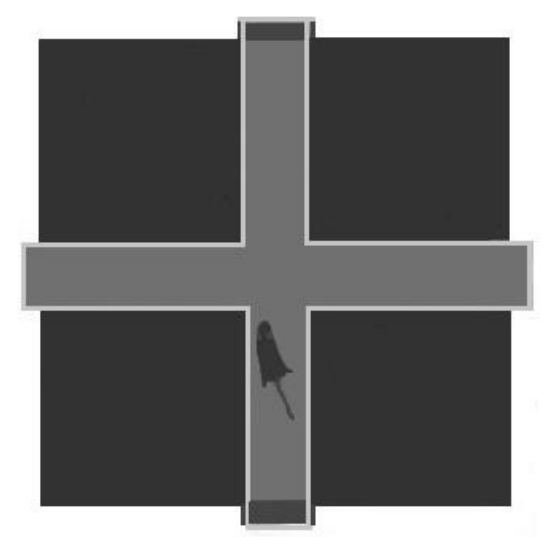

Abbildung 7: Versuchsaufbau Cross Maze Das Arbeitsgedächtnis der Mäuse konnte mit dem Cross Maze getestet werden. Der Test beruht auf dem typischen Bestreben der Mäuse bevorzugt neue Arme zu betreten, anstatt in bereits bekannte Arme zurückzukehren.

\subsubsection{Open Field und Novel Object Recognition Test}

Das Open Field und der Novel Object Recognition Test (NOR) testeten in drei aufeinanderfolgenden Tagen neben Angstverhalten auch die Lernfähigkeit von Nagetieren (Jawhar et al. 2012).

Im Open Field wurde die Maus in das Zentrum einer nach oben geöffneten $50 \times 50 \times 38 \mathrm{~cm}$ quadratischen Box platziert (Abbildung 8 A). Daraufhin durfte die Maus die Umgebung für eine Dauer von 5 min frei erkunden. Dieser Test bedient sich der natürlichen Aversion der Nagetiere vor hellen, ungeschützten Räumen (Denenberg 1969). Dementsprechend versucht eine gesunde Maus in die Peripherie der Box auszuweichen. Diese Einteilung in „Zentrum“ und „Peripherie“ wurde mithilfe des Anymaze Video Tracking Systems (Stoelting Co, Wood Dale, IL, USA) erstellt und die Bewegungen der Maus mit einer Kamera (Computar, Commack, NY, USA) aufgezeichnet. Die prozentual im Zentrum verbrachte Zeit und die zurückgelegte Distanz wurden gemessen und ausgewertet. Außerdem diente das Open Field der Gewöhnung der Maus an die Umgebung in der Box. Nach jedem Durchlauf wurde diese mit Desomed ${ }^{\circledR}$ Rapid AF Tüchern gereinigt, um mögliche Geruchsspuren zu vermeiden. Der Novel Object Recognition Test wurde in der gleichen Box durchgeführt. Es ist ein weit genutzter Test, um Gedächtnis und die Präferenz für Neues in Nagern zu testen (Antunes und Biala 2012). 
Ca. $24 \mathrm{~h}(+/-1 \mathrm{~h})$ nach dem Open Field wurden nun zwei identische Objekte in die Box gesetzt, die die Maus in einem Zeitraum von 5 min frei erkunden durfte (Abbildung 8 B).

Die Bewegungen wurden mit dem oben genannten Programm aufgezeichnet und anschlieBend Geruchsspuren durch das Putzen mit Desomed® Rapid AF Tüchern (Desomed, Malsfeld, Deutschland) der Box beseitigt.

Am darauffolgenden Testtag wurde eines der bereits bekannten Objekte durch ein neues Objekt, das sich nicht nur in der Farbe sondern auch im Material unterschied, ersetzt (Abbildung 8 C). Die exakte Lokalisation der Objekte über die zwei Probetage wurde bedacht und beibehalten. Mit dem Anymaze Video Tracking System wurden die Bewegungen der Maus aufgezeichnet. Ausgewertet wurden die zurückgelegte Distanz und der Prozentanteil der Zeit am neuen Objekt im Vergleich zum bekannten Objekt.

Dieser berechnet sich wie folgt:

$$
\text { Neues Objekt [\%] }=\frac{\text { neues Objekt }}{(\text { neues Objekt }+ \text { bekanntes Objekt })} * 100
$$
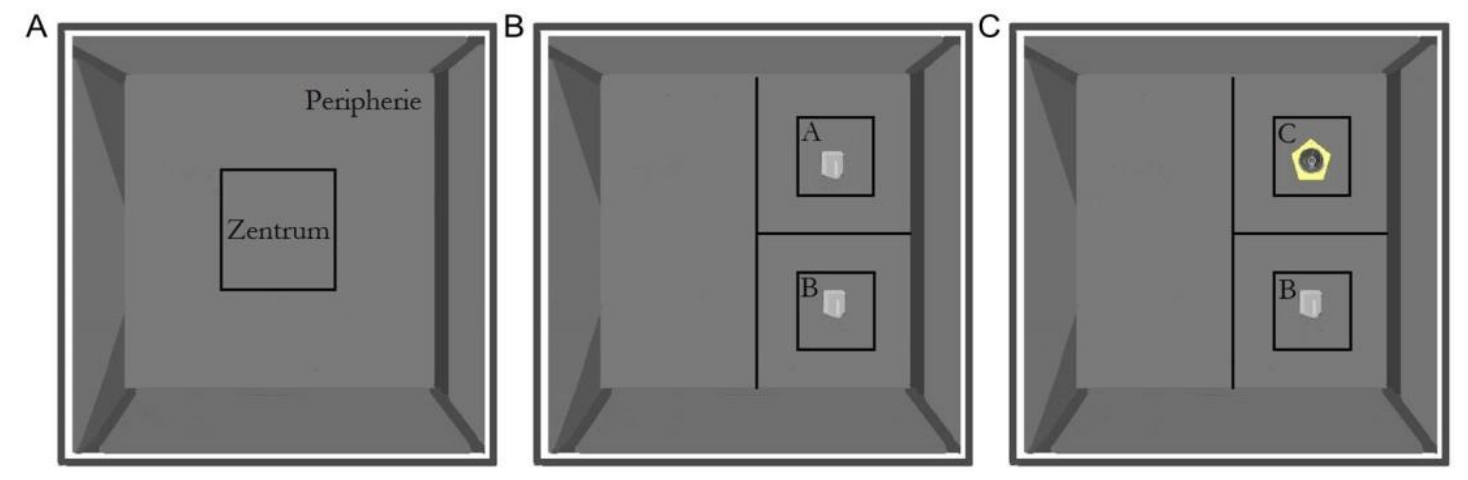

Abbildung 8: Versuchsaufbau Open Field und Novel Object Recognition Test Die Mäuse durchliefen drei Testtage. (A) Zunächst konnte die Maus im Open Field die Umgebung frei erkunden. Gleichzeitig wurde das Angstverhalten der Mäuse getestet, indem sich die Mäuse typischerweise in der geschützten Peripherie aufhielten, anstatt im ungeschützten Zentrum. (B) Zwei identische Objekte $(A$ und $B)$ durften 5 min am ersten Tag des Novel Object Recognition Tests erkundet werden, (C) 24 h später wurde eines der bereits bekannten Objekte durch ein unbekanntes, neues Objekt ( $B$ und $C$ ) ausgetauscht, um das Gedächtnis und die Lernfähigkeit der Mäuse zu testen.

\subsubsection{Elevated Plus Maze}

Das Elevated Plus Maze wird genutzt, um angstgesteuertes Verhalten in Mäusen zu testen und bedient sich der Aversion gegenüber offenen, exponiert erhöhten Plätzen (Pellow et al. 1985; Jawhar et al. 2012). 
Das Labyrinth bestand aus vier exakt gleich langen Armen $(15$ x $5 \mathrm{~cm})$, die ein „,+ " bildeten und befand sich in $75 \mathrm{~cm}$ Höhe über einer gepolsterten Oberfläche. Die jeweils gegenüberliegenden Arme waren entweder offen oder mit einer durchsichtigen $15 \mathrm{~cm}$ hohen Schutzwand von drei Seiten begrenzt, sodass also zwei „offene“ und zwei „geschlossene“ Arme entstanden (Abbildung 9). Die Maus wurde in die Mitte (5 x $5 \mathrm{~cm}$ ) des Labyrinths gesetzt und konnte nun für die Dauer von 5 min ihre Umgebung frei erkunden. Die Bewegungen der Maus wurden mithilfe des AnyMaze Video Tracking Systems (Stoelting Co, Wood Dale, IL, USA) ausgewertet, das an eine Kamera (Computar, Commack, NY, USA) angeschlossen war, die diese detektierte. Der Test fand bei Rotlicht statt und wurde gegebenenfalls pausiert, wenn die Maus von einem der offenen Arme fiel, wobei sie unmittelbar wieder auf diesen gesetzt wurde, um das Experiment fortzuführen. Die Zeit, die in den „offenen“ oder ,geschlossenen“ Armen verbracht wurde, und außerdem die Anzahl der Eintritte in die verschiedenen Arme ließen Rückschlüsse auf das Angstverhalten der Mäuse zu. So bestand auf der einen Seite das Bedürfnis nach Schutz und Sicherheit, auf der anderen Seite war die Maus aber bestrebt ihre Umgebung möglichst gründlich zu explorieren, obwohl dies potentielle Schutzlosigkeit bedeutete (Onaivi et al. 1990). Eine erhöhte Präsenz in den offenen Armen im Verhältnis zur Gesamtdauer des Experiments kann als ein vermindertes Angstverhalten interpretiert werden (Pellow et al. 1985; Pellow und File 1986).

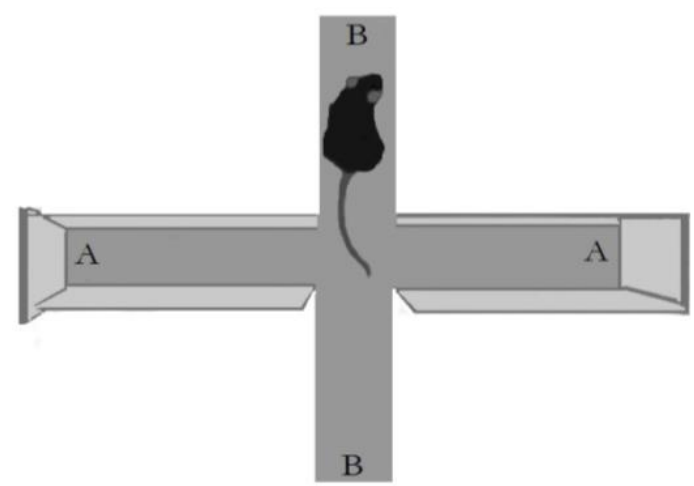

Abbildung 9: Versuchsaufbau Elevated Plus Maze Test zum Evaluieren des Angstverhaltens. Mäuse verbringen typischerweise mehr Zeit in den geschlossenen Armen (A) als in den offenen Armen (B) aufgrund ihrer Präferenz für geschützte Räume.

\subsubsection{Dark/Light Box}

Weitere Auskunft über das Angstverhalten der Mäuse konnte mit der Dark/Light Box gegeben werden, denn auch hier wurde das Tier einem Konflikt zwischen zwei Verhaltensweisen ausgesetzt. Zum einen ist die Maus bestrebt, hell beleuchtete Areale zu vermeiden und sich in der schützenden Dunkelheit zu verstecken. Gleichzeitig besteht jedoch das Bedürfnis, die unbekannte Umgebung $\mathrm{zu}$ erkunden. Eine längere 
Explorationszeit des helleren Areals kann als geringere Ängstlichkeit interpretiert werden (Bourin und Hascoët 2003).

In diesem Test wurde die Maus in eine Box (TSE, Bad Homburg) gesetzt, die in zwei Kompartimente aufgeteilt war. Ein Kompartiment war mit hellgrauen Plastikwänden umrandet. Außerdem konnte Licht des offenen Dachs des Kompartiments eindringen (aversives Kompartiment, $42 \mathrm{~cm}$ x $31 \mathrm{~cm}$ ). Lichtgeschützt, durch ein schwarzes Dach und mit schwarzem Plastik ausgekleidete Wände, entstand ein dunkel gehaltenes, protektives Kompartiment $(31 \mathrm{~cm}$ x $25 \mathrm{~cm})$. Beide Kompartimente trennte eine Mittelwand, die eine kleine Tür $(5 \mathrm{~cm} \times 5 \mathrm{~cm})$ enthielt, sodass ein Hin- und Herlaufen zwischen beiden Bereichen ermöglicht werden konnte (Abbildung 10).

Die Maus wurde mit dem Gesicht zur Wand in den offenen Bereich gesetzt und ihr Verhalten für einen Zeitraum von 5 min beobachtet. Die Bewegungen der Maus wurden mithilfe einer Kamera (Computar, Commack, NY, USA) und des AnyMaze Video Tracking Systems (Stoelting Co, Wood Dale, IL, USA) aufgezeichnet und ausgewertet. Neben der Zeit, die die Maus im hellen Kompartiment verbrachte, wurde außerdem die Zeitspanne bis zum ersten Eintritt in das schützende Kompartiment sowie die Anzahl der Zonenwechsel gemessen.

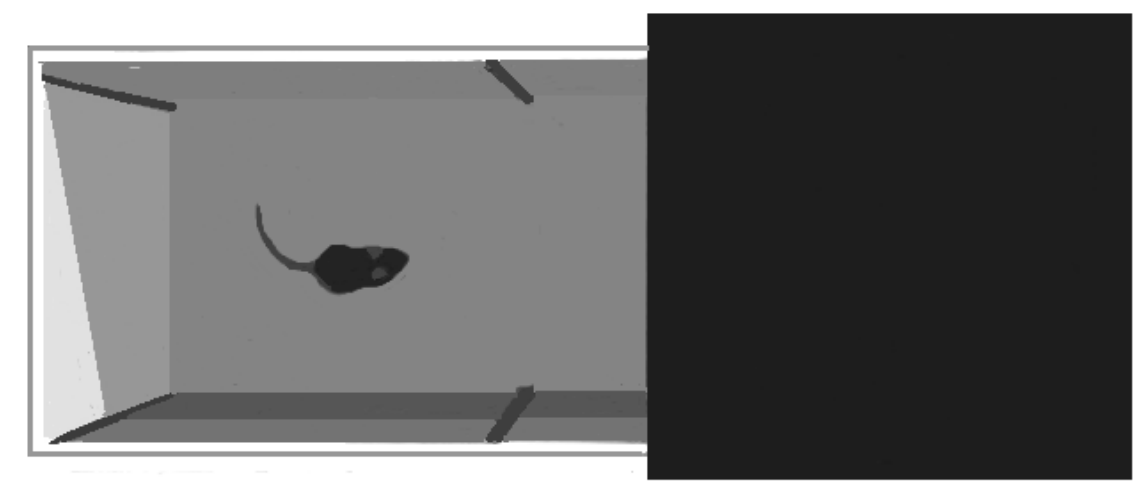

Abbildung 10: Versuchsaufbau Dark/Light Box Das Angstverhalten von Mäusen wurde getestet, indem die Reaktion der Mäuse auf lichtdurchflutete helle Flächen mit dem Ausweg eines geschützten dunklen Bereiches untersucht wurde.

\subsection{Gewinnung und Präparation von ZNS-Gewebe}

\subsubsection{Zervikale Dislokation}

Die Anästhesie der Mäuse erfolgte mithilfe einer intraperitonealen Injektion $(10 \mathrm{ml} / \mathrm{kg} \mathrm{KG})$. Die Mischung aus Xylazin (Xylariem ${ }^{\circledR}$, Pharma-Partner $\mathrm{GmbH}$, Hamburg, Deutschland), Ketamin (10\%, Medistar Arzneimittelvertrieb GmbH, Ascheberg, Deutschland) und destilliertem Wasser $\left(\mathrm{dH}_{2} \mathrm{O}\right)$ im Verhältnis von 2:1:7 wurde von Yvonne Bouter durchgeführt, die eine entsprechende Genehmigung für das 
Verabreichen der Substanzen besaß. Nach einigen Minuten Einwirkdauer, in der die Maus in einem Einzelkäfig in Isolation von anderen Mäusen untergebracht wurde, wurden die Reflexe der Maus getestet, damit eine ausreichende Narkosewirkung vorausgesetzt werden konnte. Dies wurde mit dem Zwischenzehenreflex getestet (Underwood und Anthony 2013).

Die zervikale Dislokation erfolgte unmittelbar nach ausreichend tiefer Narkose. Es folgte die Dekapitation und die Entfernung von Haut, subkutanem Fettgewebe und die Schädeleröffnung. Dazu wurde die Schädelkalotte mit einer chirurgischen Schere geöffnet und mit einer Pinzette vorsichtig entfernt. Das Gehirn konnte nun mit einem Spatel aus der Schädelbasis herausgelöst werden. Mit einem Skalpell wurden die beiden Hemisphären voneinander getrennt, wobei die linke Hemisphäre in eine Einbettkassette Polyoxymethylen (Carl Roth, Karlsruhe, Deutschland) platziert wurde, die unmittelbar in eine $4 \%$ igen phosphatgepufferten Formaldehydlösung, PFA (Roti-Histofix, Carl Roth, Karlsruhe, Deutschland), gegeben wurde.

\subsection{Quantifizierung der Expression von Beta-Amyloid, Neuroinflammationsmarkern und dem Cannabinoidrezeptor}

\subsubsection{Paraffineinbettung}

Nachdem die linken Gehirnhälften mindestens $72 \mathrm{~h}$ in PFA (Roti-Histofix, Carl Roth, Karlsruhe, Deutschland) gelagert wurden, folgte das Einbetten der Kassetten in Paraffin. Dies erfolgte mithilfe des TP 1020 Automatic Tissue Processors (Leica, Wetzlar, Deutschland). Hierbei wurde folgendes Protokoll verwendet: 5 min in $4 \%$ Histofix (Carl Roth, Karlsruhe, Deutschland); 30 min in Leitungswasser; $1 \mathrm{~h}$ in $50 \%, 60 \%, 70 \%, 80 \%$ und $90 \%$ EtOH-Lösung (CVH, Hannover, Deutschland); zweimal $1 \mathrm{~h}$ in $100 \% \mathrm{EtOH}$; $1 \mathrm{~h}$ in Xylol (Carl Roth, Karlsruhe, Deutschland) und zweimal $1 \mathrm{~h}$ in geschmolzenem Paraffin (Carl Roth, Karlsruhe, Deutschland). Nach der Prozedur wurden die Proben mithilfe der EG1140 H Einbettstation (Leica, Wetzlar, Deutschland) eingebettet.

\subsubsection{Schnittgewinnung durch Arbeit am Mikrotom}

Die Schnittgewinnung aus den in Paraffin eingebetteten Gehirnen erfolgte durch die Arbeit am Mikrotom. Benutzt wurde hierbei das Modell HM335 E (Thermo Fisher Scientific, Waltham, USA). Die $4 \mu \mathrm{m}$ dünnen Sagittalschnitte wurden in ein Kaltwasserbad gegeben und jeweils zwei Schnitte auf einen Objektträger (Thermo Fisher Scientific, Braunschweig, Deutschland) aufgezogen. Anschließend wurde dieser in ein $45-50{ }^{\circ} \mathrm{C}$ Warmwasserbad (Medax, Olching, Deutschland) gegeben, sodass sich das Gewebe entfalten konnte. Bevor die Schnitte Verwendung in der immunhistochemischen Färbung finden konnten, wurden 
diese zunächst 10 min auf einer $52^{\circ} \mathrm{C}$ heißen Platte (Medax, Olching, Deutschland) und dann über Nacht im Inkubator bei $37^{\circ} \mathrm{C}$ getrocknet und gelagert.

\subsubsection{Diaminobenzidin (DAB)-Färbung}

Die Technik der immunhistochemischen DAB-Färbung wurde auf $4 \mu \mathrm{m}$ Sagittalhirnschnitten angewandt, um Antigene auf den Geweben nachzuweisen und zu quantifizieren. Zunächst wurde der Prozess der Entparaffinierung durchgeführt, um Paraffin von den Schnitten zu entfernen und die Schnitte zu rehydrieren: 2 x 5 min in Xylol, (Roth, Karlsruhe, Deutschland); 10 min in 100\% EtOH (Carl Roth, Karlsruhe, Deutschland); $5 \mathrm{~min}$ in $95 \% \mathrm{EtOH} ; 5 \mathrm{~min}$ in $70 \% \mathrm{EtOH}$ und $1 \mathrm{~min}$ in $\mathrm{dH}_{2} \mathrm{O}$. Anschließend wurden die Schnitte in eine Lösung aus $0.3 \% \mathrm{H}_{2} \mathrm{O}_{2}$ (Carl Roth, Karlsruhe, Deutschland) in 0,01 M PBS gegeben, um endogene Peroxidasen zu blockieren. Nach $1 \mathrm{~min}$ in $\mathrm{dH}_{2} \mathrm{O}_{2}$ folgte die Mikrowellenbehandlung der Schnitte zur Demaskierung von Antigenen. Zur Demaskierung des intrazellulären Beta-Amyloids wurden die Schnitte mit 0,01 M Citratpuffer ( $\mathrm{pH}$ 6,0; Carl Roth, Karlsruhe, Deutschland) zunächst bei $800 \mathrm{~W}$ für ca. 2 min zum Kochen gebracht und für die restliche Zeit auf eine geringere Leistung von 200 W gestellt. Nachdem die Schnitte für 15 min bei Raumtemperatur abgekühlt waren, wurden sie $1 \mathrm{~min}$ in $\mathrm{dH}_{2} \mathrm{O}$ gestellt und anschließend zur Permeabilisierung der Membranen für 15 min in 0,1 \% Triton X-100 (Carl Roth, Karlsruhe, Deutschland) gebadet. Es folgte die einminütige Waschung in 0,01 M PBS. Um intrazellulares Abeta besser darzustellen, wurden die Schnitte für 3 min in $88 \%$ Ameisensäure (Carl Roth, Karlsruhe, Deutschland) gebadet. Es folgte eine fünfminütige Waschung in 0,01 M PBS, um mögliche Überreste der Ameisensäure zu entfernen. Die Schnitte wurden mit einem Lipidstift (Pap Pen; Kisker Biotech, Steinfurt, Deutschland) umkreist und mit der folgenden Lösung für eine Stunde bei Raumtemperatur inkubiert: 10 \% Fetales Kuhserum (fetal cow serum, FCS, Thermo Fisher Scientific, Waltham, MA, USA) und $4 \%$ Milchpuder (Carl Roth, Karlsruhe, Deutschland) in $0.01 \mathrm{M}$ PBS.

Nach Entfernung der Lösung wurde der Primäre Antikörper (Tabelle 6), der in 0,01 M PBS und $10 \%$ FCS in errechneter Konzentration gelöst wurde, auf die Schnitte pipettiert. Es folgte die Inkubation über Nacht bei $37^{\circ} \mathrm{C}$. Am nächsten Tag wurden die Schnitte $3 \mathrm{x}$ 5 min in 0,01 M PBS mit 0,1\% Triton und anschließend mit 0.01 M PBS gewaschen. Diese wurden nun mit dem sekundären Antikörper, in der gleichen Lösung wie bereits beim primären Antikörper beschrieben, für 60 min inkubiert (Tabelle 6). Mit der Waschung der Schnitte für $15 \mathrm{~min}$ in 0,01 M PBS konnte die Antikörperlösung von diesen entfernt werden. Es folgte die Inkubation für $1,5 \mathrm{~h}$ bei $37^{\circ} \mathrm{C}$ mit dem Avidin-Biotin-Komplex (ABC). Die ABC-Lösung wurde nach der Herstelleranleitung hergestellt (Vectastain Elite ABC Kit, Vector Labaratories, Burlingame, CA, USA). Hierzu wurde jede Komponente der Ausrüstung im Verhältnis von 1:100 ml PBS zu einer 0.01 M PBS Lösung mit 10 \% FCS hinzugegeben. Die ABC-Lösung wurde etwa $30 \mathrm{~min}$ im Voraus angesetzt und bei $4{ }^{\circ} \mathrm{C}$ 
gelagert. Es erfolgte erneut eine 15-minütige Waschung der Schnitte in 0,01 M PBS. Anschließend wurde die eigentliche DAB-Färbung durchgeführt.

In diesem Schritt wurde ein DAB Peroxidase(HRP)-substrat Kit verwendet (Carl Roth, Karlsruhe, Deutschland). Die DAB-Stock-Lösung wurde nach Anweisung des Herstellers angesetzt. Die Schnitte wurden mit DAB inkubiert und die Enzymreaktion sorgfältig unter dem Lichtmikroskop beobachtet. Hierbei wurde die Zeit gestoppt bis ein ideales Verhältnis von Hintergrund und spezifischer Färbung erreicht wurde (DAB-Zeit siehe Tabelle 6: Primäre und sekundäre Antikörper). Um die DAB-Lösung zu entfernen, erfolgte abermals eine 3 x 5 min Waschung mit 0,01 M PBS, bevor die Schnitte in die Alkoholreihe gegeben wurden. Diese entsprach folgendem Protokoll: 1 min $70 \% \mathrm{EtOH} ; 5$ min 95\% EtOH; 10 min $100 \%$ EtOH; 2 x 5 min Xylol. Die so präparierten Schnitte wurden mit einigen Tropfen des synthetischen Einschlussmittels Roti-Histokitt (Carl Roth, Karlsruhe, Deutschland) benetzt und vorsichtig mit einem Deckglässchen (Menzel-Gläser $24 \times 60 \mathrm{~mm}$, Thermo Fisher Scientific, Waltham, MA, USA) eingedeckt, sodass Lufteinschlüsse vermieden werden konnten.

Tabelle 6: Primäre und sekundäre Antikörper

\begin{tabular}{c|c|c|c|c}
\hline Färbung & $\begin{array}{c}\text { Prim. } \\
\text { Antikörper }\end{array}$ & Verdünnung & $\begin{array}{c}\text { DAB- } \\
\text { Zeit }\end{array}$ & Hersteller \\
\hline Abeta (24311) & anti-rabbit & $1: 500$ & $55 \mathrm{~s}$ & AG Bayer \\
\hline GFAP & anti-guinea pig & $1: 1000$ & $50 \mathrm{~s}$ & $\begin{array}{c}\text { Synaptic Systems, } \\
\text { Göttingen, } \\
\text { Deutschland }\end{array}$ \\
\hline IBA1 & anti-guinea pig & $1: 500$ & $55 \mathrm{~s}$ & $\begin{array}{c}\text { Synaptic Systems, } \\
\text { Göttingen, } \\
\text { Deutschland }\end{array}$ \\
\hline CB1 & anti-rabbit (goat) & $1: 2000$ & $55 \mathrm{~s}$ & $\begin{array}{c}\text { Abcam, Cambridge, } \\
\text { Vereinigtes } \\
\text { Königreich }\end{array}$ \\
\hline
\end{tabular}

\begin{tabular}{c|c|c}
\hline Sek. Antikörper & Verdünnung & Hersteller \\
\hline Goat anti-rabbit biotinyliert & $1: 200$ & $\begin{array}{c}\text { Jackson ImmunoResearch } \\
\text { Laboratories, West Grove, USA }\end{array}$ \\
\hline $\begin{array}{c}\text { Goat anti-guinea pig } \\
\text { biotinyliert }\end{array}$ & $1: 200$ & $\begin{array}{c}\text { Jackson ImmunoResearch } \\
\text { Laboratories, West Grove, USA }\end{array}$ \\
\hline
\end{tabular}




\subsubsection{Mikroskopie und Auswertung}

Mithilfe des Lichtmikroskops (Olympus BX51, Tokio, Japan) wurden Bilder der Hirnschnitte (Absatz 2.5.3) angefertigt. Im Abstand von $20 \mu \mathrm{m}$ wurden je drei Hirnschnitte pro Tier und Färbung ausgewählt, beginnend bei Bregma 0,4 mm. Mithilfe des Motic Picture Image Programm (Motiv Image Plus 2.0, Motic China Group. Co, Hong Kong, China) und der 10 x Objektivvergrößerung wurden Hippocampus und Cortex detektiert und fotografiert. Pro Maus und Färbung wurden drei Bilder des Hippocampus und neun Bilder des Cortex angefertigt. Bei letzterem wurde darauf geachtet, dass drei unterschiedliche Hirnregionen rostral (Abbildung 11, 1), dorsal (Abbildung 11, 2) und kaudal (Abbildung 11, 3) des Hippocampus erfasst wurden. Die Belichtungszeit sowie die Lichtintensität wurden innerhalb der Gruppen nicht verändert.

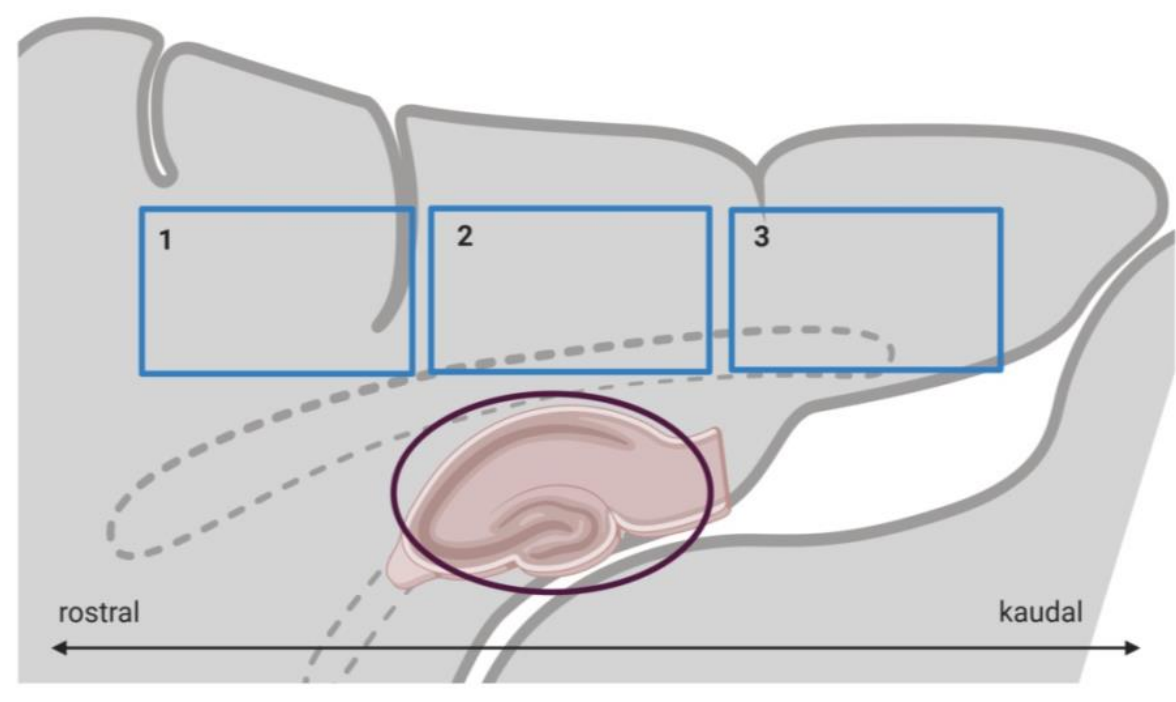

Abbildung 11: Schematische Darstellung eines Ausschnitts von Cortex und Hippocampus eines Mausehirns im Sagittalschnitt Es wurden drei Bilder an unterschiedlichen Hirnregionen des Cortex angefertigt (blauer Kasten, 1 - 3). Die Region des Hippocampus diente als Leitstruktur (lila Oval) und wurde ebenfalls fotografiert. Erstellt nach Paxinos und Franklin (2013).

Die Auswertung der Bilder wurde mithilfe der ImageJ Software (ImageJ.51.f, National Institute of Health, USA) durchgeführt. Die Bildanalyse erfolgte dann automatisch über ein Makro. Dieses beinhaltete eine Folge von Anweisungen, um so die spezifisch angefärbten Bereiche als Flächenanteile des Gesamtbildes darstellen zu können. Hierbei wurde zunächst der Hintergrund gefiltert, um mögliche Artefakte wie Faltenbildung auszuschließen. Anschließend wurde das Bild in ein Einkanal-8Bit Graustufenbild verwandelt. Es folgte die Bestimmung des Schwellenwerts für die Analyse der Hirnschnittbilder. Dieser sollte so gesetzt werden, dass auch kleine gewünschte Bereiche mit abgedeckt wurden, der Hintergrund des Bildes jedoch nicht mit in die Auswertung gezählt wurde. 


\subsection{Statistik}

Vergleiche zwischen den verschiedenen Gruppen wurden mit einfacher und zweifacher Varianzanalyse (ANOVA) mit Bonferroni Korrektur oder Zweistichproben-t-Tests für unabhängige Strichproben (ungepaarter t-Test) durchgeführt. Alle Daten sind dargestellt als Mittelwert \pm Standardfehler (SEM, Strandard Error of the Mean). Die Signifikanzniveaus

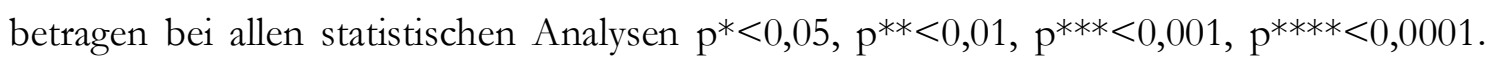
Alle Daten wurden mit GraphPad Prism 8 für Windows (GraphPad Software, San Diego, CA, USA) ausgewertet. Die Identifizierung statistisch signifikanter Outlier durch den Grubbs-Test wurde mit GraphPad QuickCalcs (GraphPad Software, San Diego, CA, USA) durchgeführt. Die Anzahl der verwendeten Tiere pro Gruppe (n) ist unter den jeweiligen Graphen angegeben.

\subsection{Software}

Die im Rahmen dieser Arbeit vorliegenden Bilder und Abbildungen wurden mit Paint 6.3 (Microsoft Corparation, Redmont, WA, USA) und BioRender.com erstellt und mit Microsoft PowerPoint 2010 (Microsoft Corparation, Redmont, WA, USA) bearbeitet. Die Verschriftlichung der Arbeit erfolgte mit Mircosoft Office Word 2010 (Microsoft Corparation, Redmont, WA, USA) und mithilfe des Literaturverwaltungsprogramms Citavi 6 für Windows (Campuslizenz, Swiss Academic Software, Wädenswil, Schweiz). 


\section{Ergebnisse}

\subsection{Nachweis des Transgens von 5XFAD-Mäusen}

Die Zugehörigkeit der in dieser Arbeit verwendeten Mäuse zur transgenen 5XFADMauslinie wurde per Genotypisierung, wie in Absatz 2.1.3 beschrieben, nachgewiesen. Als Positiv-Kontrolle diente ein bereits in vorherigen Studien verifiziertes 5XFAD-Tier, während die nicht transgenen Geschwistertiere als Negativ-Kontrolle verwendet wurden. Humanes APP wurde im Bereich von 290 Basenpaaren erwartet und bei den hemizygoten 5XFAD-Mäusen nachgewiesen.

In Abbildung 12 sind exemplarisch die gelelektrophoretisch nachgewiesenen charakteristischen Banden dargestellt.

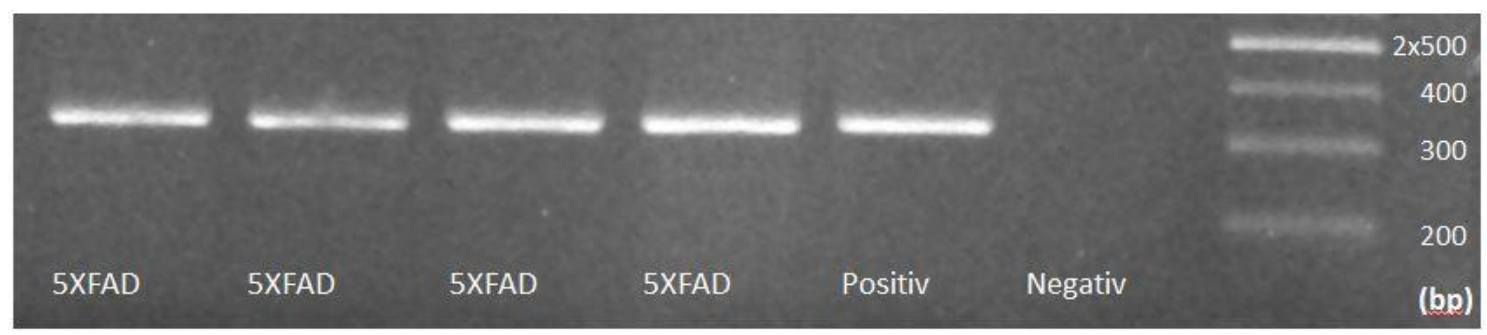

Abbildung 12: Exemplarische Gelelektrophorese 5XFAD-Mäuse zeigten im Bereich von 290 Basenpaaren eine typische Bande. Bp = Basenpaare.

\subsection{Auswirkungen von THC und CBD auf das Verhalten von 5XFAD-Mäusen}

Auf einen Vergleich der Pathologien von 5XFAD-Mäusen zwischen den Geschlechtern wurde aufgrund einer geschlechterabhängigen Progression verzichtet. Daher wurden weibliche 5XFAD-Mäuse mit THC behandelt und männliche 5XFAD-Mäuse einer Behandlung mit CBD unterzogen. Beide Behandlungsgruppen wurden jeweils mit einer vehikelbehandelten Kontrollgruppe verglichen. Um den Effekt der Behandlungen in einzelnen Verhaltenstest $\mathrm{zu}$ verdeutlichen, wurden die o.g. Gruppen mit WTKontrollgruppen verglichen. 


\subsubsection{Auswirkungen von THC und CBD auf das Gewicht von 5XFAD-Mäusen}

Die Behandlung von 5XFAD-Mäusen mit THC oder CBD hatte keinen Einfluss auf das Körpergewicht der Tiere. Diese wurden ab Beginn der Behandlung wöchentlich gewogen und das Gewicht dokumentiert (siehe Absatz 2.2.1). Es zeigte sich kein Unterschied zwischen weiblichen THC-behandelten oder männlichen CBD-behandelten 5XFADMäusen und deren jeweiliger vehikelbehandelter Kontrollgruppe im Verlauf der Behandlung (zweifache Varianzanalyse mit Messwiederholungen mit BonferroniKorrektur, Abbildung 13 A und B). Das Endgewicht der Mäuse bei beiden Behandlungen zeigte keinen signifikanten Unterschied zu vehikelbehandelten Artgenossen (ungepaarter tTest).
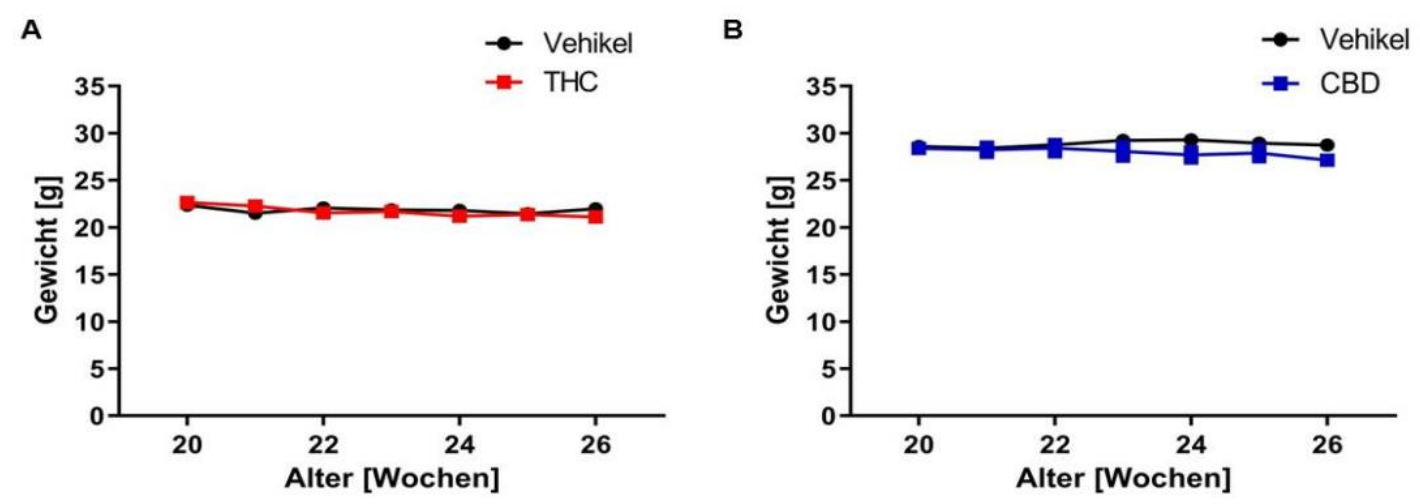

Abbildung 13: Unbeeinträchtigtes Gewicht von 5XFAD-Mäusen während des Behandlungszeitraums Weibliche THC- (A) und männliche CBD-behandelte (B) 5XFAD-Mäuse zeigten ein konstantes Gewicht verglichen mit der jeweiligen vehikelbehandelten Kontrollgruppe. Zweifache Varianzanalyse mit Messwiederholungen mit Bonferroni-Korrektur, n= 8-12 Mäuse pro Gruppe. Daten dargestellt als Mittelwert \pm SEM.

\subsubsection{Auswirkungen von THC und CBD auf das Clasping-Verhalten von 5XFAD- Mäusen}

Wie in Absatz 2.3.1 beschrieben, wurde das Clasping-Verhalten von 5XFAD-Mäusen untersucht. Weibliche THC-behandelte 5XFAD-Mäuse zeigten keinen signifikanten Unterschied im Clasping-Verhalten im Vergleich zur vehikelbehandelten Kontrollgruppe (ungepaarter t-Test, Abbildung $14 \mathrm{~A}$ ).

Männliche CBD-behandelte 5XFAD-Mäuse unterschieden sich im Vergleich zur vehikelbehandelten Kontrollgruppe signifikant hinsichtlich einer Reduktion des ClaspingVerhaltens (ungepaarter t-Test, $\mathrm{p}=0,0254$, Abbildung $14 \mathrm{~B}$ ). 

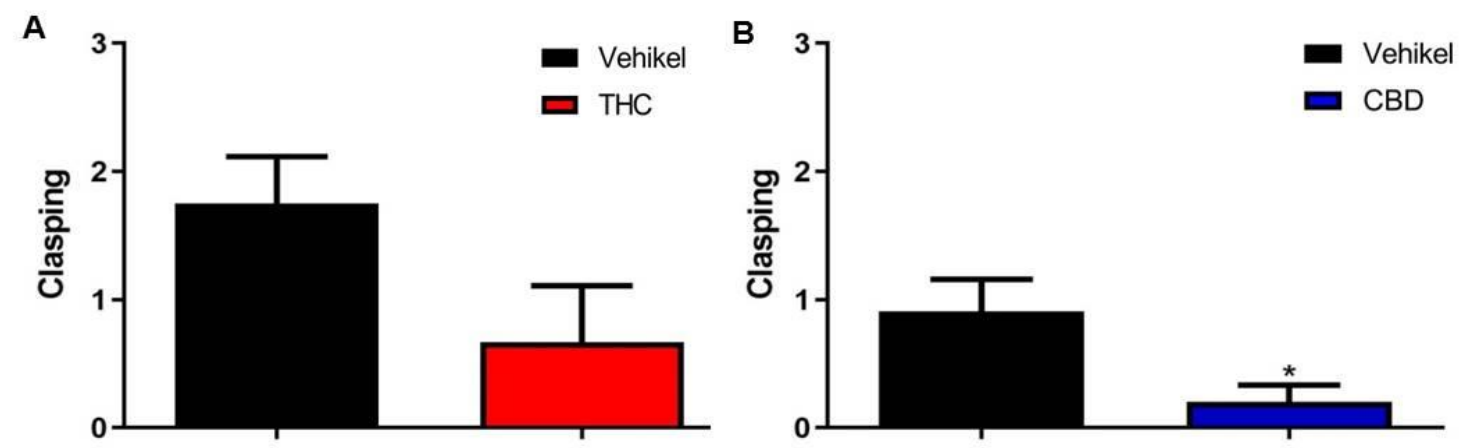

Abbildung 14: Aufschluss über motorische Defizite als Zeichen von Neurodegeneration in 5XFADMäusen mithilfe des Clasping-Verhaltens Weibliche THC-behandelte 5XFAD-Mäuse zeigten keine signifikante Veränderung des Clasping-Verhaltens, wohingegen eine Reduktion nach CBD-Behandlung in männlichen Tieren erkennbar wurde. Ungepaarter t-Test, $n=8-12$ Mäuse pro Gruppe, $\mathrm{p}^{*}<0,05$, Daten dargestellt als Mittelwert \pm SEM.

\subsubsection{Auswirkungen von THC und CBD auf die Motorik von 5XFAD-Mäusen im Rotarod}

Um den Einfluss von THC und CBD auf motorische Lernfähigkeiten, Ausdauer und Koordination zu evaluieren, wurden die 5XFAD-Mäuse im Rotarod getestet (Absatz 2.3.2.).

Es zeigte sich kein signifikanter Unterschied zwischen weiblichen 5XFAD-Mäusen, die mit THC behandelt und denen, die mit der Vehikellösung behandelt wurden hinsichtlich der Dauer des Verbleibs auf dem Zylinder (zweifache Varianzanalyse mit Messwiederholungen mit Bonferroni-Korrektur). Beide Gruppen verbrachten jedoch nach acht Durchgängen signifikant mehr Zeit auf dem Zylinder als zu Beginn des Tests (zweifache Varianzanalyse mit Messwiederholungen mit Bonferroni-Korrektur; Durchgang: THC $\mathrm{p}<0,0041$; Vehikel $\mathrm{p}<0,0355$, Abbildung 15 A).

Mit zunehmender Zahl der Durchgänge steigerte sich bei männlichen CBD-behandelten 5XFAD-Mäusen und der vehikelbehandelten Kontrollgruppe die Zeit, die auf dem Zylinder verbracht wurde, signifikant (zweifache Varianzanalyse mit Messwiederholungen mit Bonferroni-Korrektur, Durchgang: CBD p <0,0001; Vehikel p $>0,0048$, Abbildung 15 B). Es zeigte sich kein signifikanter Unterschied zwischen den Behandlungsgruppen. 
A

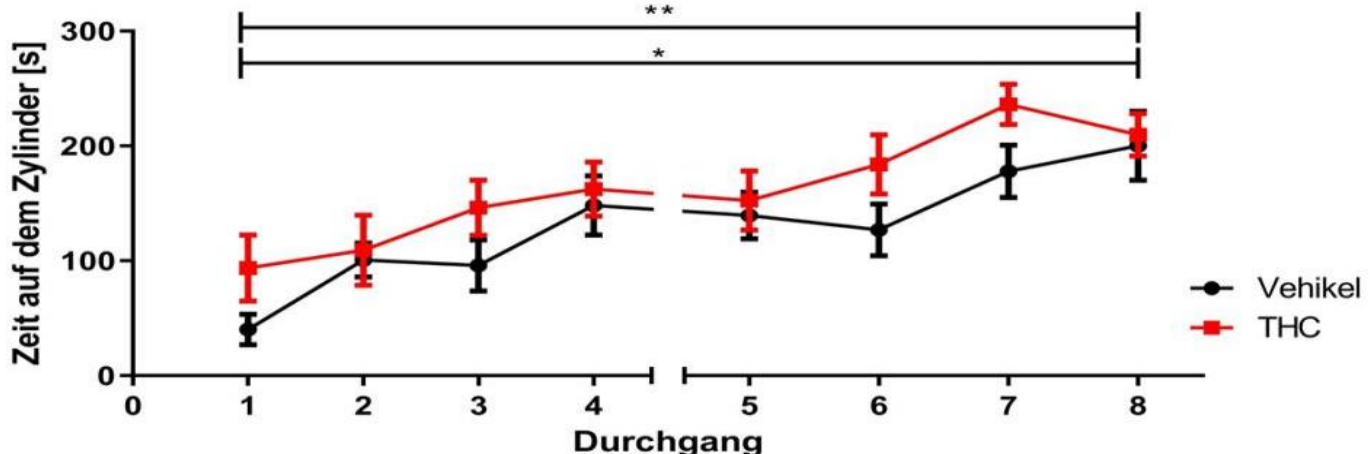

B

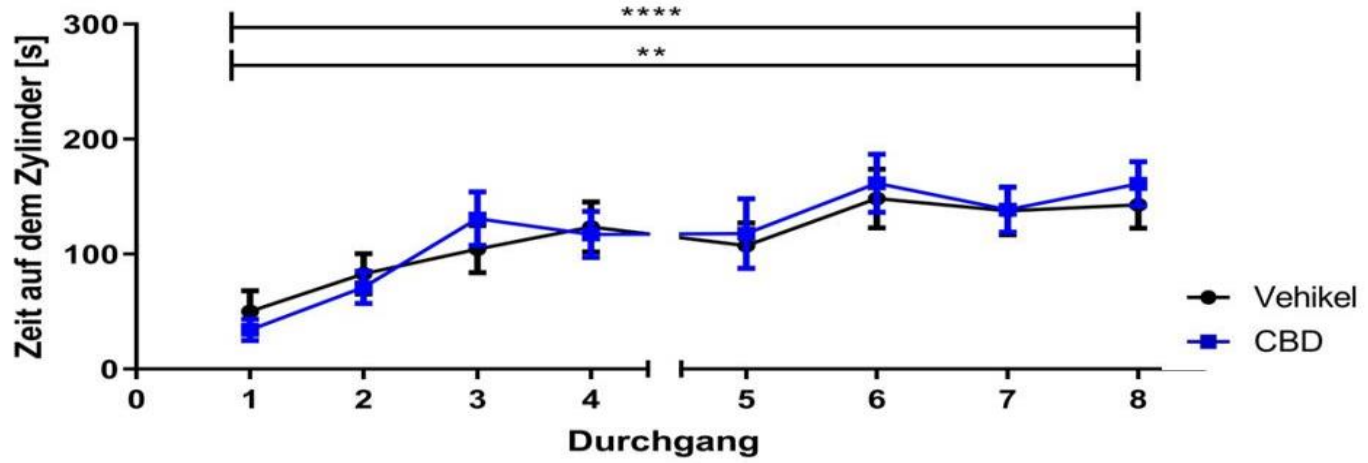

Abbildung 15: Unauffällige motorische Fähigkeiten im Rotarod Weder THC- (A) noch CBDbehandelte (B) 5XFAD-Mäuse zeigten im Vergleich zur jeweiligen Vehikelkontrollgruppe motorische Defizite im Rotarod. Zweifache Varianzanalyse mit Messwiederholungen mit Bonferroni-Korrektur, $\mathrm{p}^{*}<0,05$,

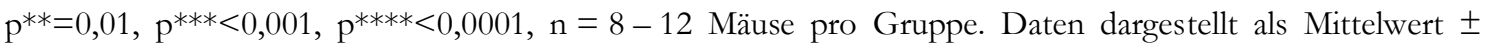
SEM.

\subsubsection{Auswirkungen von THC und CBD auf das Lernverhalten von 5XFAD- Mäusen im Morris Water Maze}

Im Cued Training zeigten alle Gruppen signifikant verbesserte Zeiten bis zum Erreichen der Plattform, die mit einer Fahne markiert war. Hierbei verbesserten sich sowohl die weiblichen THC-behandelten 5XFAD-Mäuse als auch deren vehikelbehandelte Kontrollgruppe über die drei Tage des Cued Trainings (zweifache Varianzanalyse mit Messwiederholungen mit Bonferroni-Korrektur; Tage: THC $p=0,0005$; Vehikel $p=0,0184$, Abbildung 16 A). Ein signifikanter Unterschied bezüglich der Schwimmgeschwindigkeit bestand nicht (Abbildung 16 B). 
A

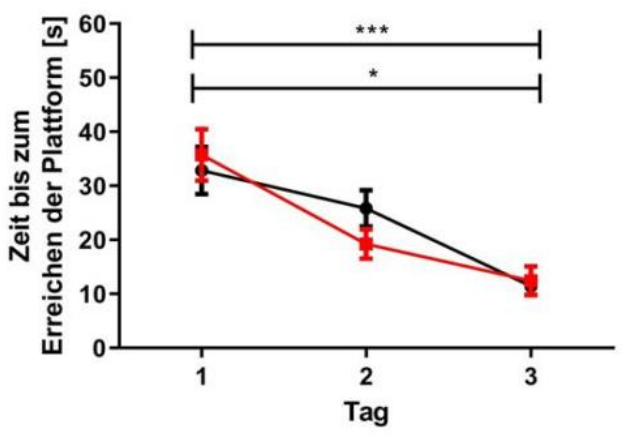

B

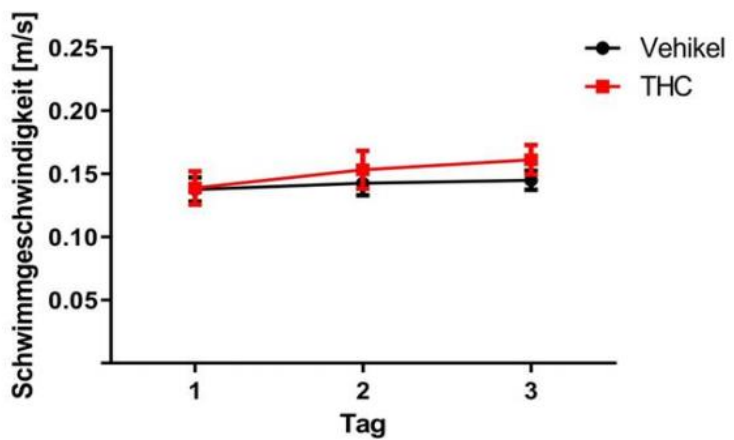

Abbildung 16: Ausschluss motorischer und visueller Defizite weiblicher THC- und vehikelbehandelter 5XFAD-Mäuse mittels des Cued Trainings Alle Mäuse zeigten eine verkürzte Zeit bis zum Erreichen der Plattform als Reaktion auf das Training (A) und erreichten die Kriterien zum Fortführen des Tests. Die Schwimmgeschwindigkeit unterschied sich nicht (B). Zweifache Varianzanalyse mit Messwiederholungen mit Bonferroni-Korrektur, $\mathrm{p}^{*}<0,05, \mathrm{p}^{* * *}<0,001, \mathrm{n}=8-9$ Mäuse pro Gruppe. Daten dargestellt als Mittelwert \pm SEM.

Männliche CBD-behandelte 5XFAD-Mäuse sowie die vehikelbehandelte Kontrollgruppe zeigten im Cued Training eine signifikante Reduktion der Zeit bis zum Erreichen der Plattform (zweifache Varianzanalyse mit Messwiederholungen mit Bonferroni-Korrektur; Tage: CBD p=0,0107; Vehikel p<0,0001, Abbildung 17 A). Ein signifikanter Unterschied zwischen der CBD-behandelten Gruppe und der Kontrollgruppe bestand nicht. Selbiges gilt hinsichtlich der Schwimmgeschwindigkeit (Abbildung 17 B). Mögliche visuelle und motorische Defizite konnten folglich ausgeschlossen werden.

A

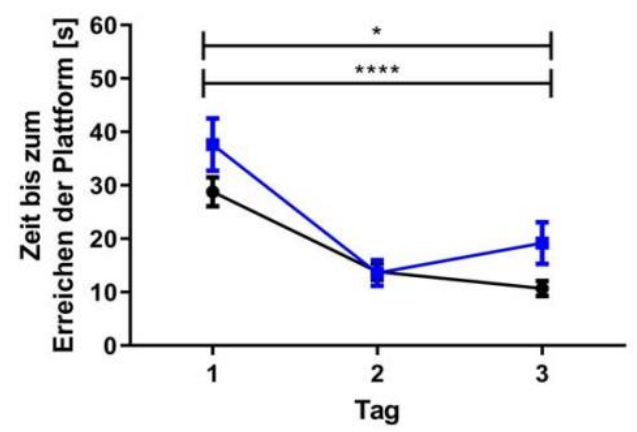

B

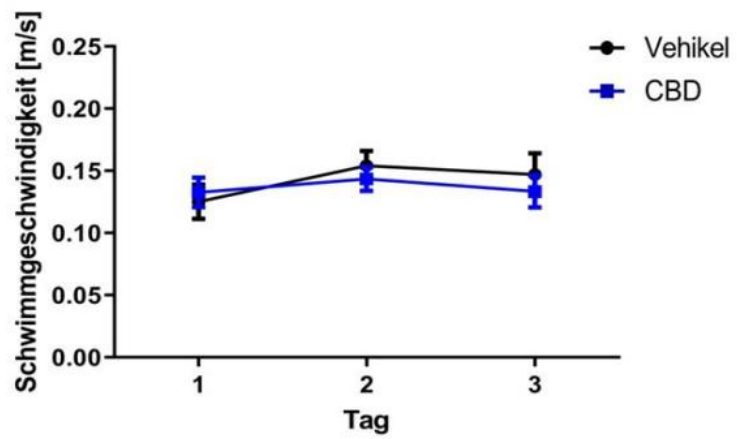

Abbildung 17: Ausschluss motorischer und visueller Defizite männlicher CBD- und vehikelbehandelter 5XFAD-Mäuse mittels des Cued Trainings Als Reaktion auf das dreitägige Cued Training zeigte sich in beiden Behandlungsgruppen eine signifikante Verkürzung der Zeit bis zum Erreichen der Plattform (A). Ein Unterschied in der Schwimmgeschwindigkeit ließ sich nicht detektieren (B). Zweifache Varianzanalyse mit Messwiederholungen mit Bonferroni-Korrektur, $\mathrm{p}^{*}<0,05, \mathrm{p} * * * * 0,0001, \mathrm{n}=10-12$ Mäuse pro Gruppe. Daten dargestellt als Mittelwert \pm SEM. 
Im darauffolgenden fünftägigen Acquisition Training verbesserte die weibliche THCbehandelte Gruppe ihre Zeit bis zum Erreichen der Plattform (zweifache Varianzanalyse mit Messwiederholungen mit Bonferroni-Korrektur; Tage: THC $\mathrm{p}=0,0058$; Vehikel $\mathrm{p}=0,0717$, Abbildung 18 A). Es zeigte sich hierbei kein signifikanter Behandlungseffekt. Die Schwimmgeschwindigkeit unterschied sich nicht zwischen den beiden Gruppen (Abbildung 18 B).

A

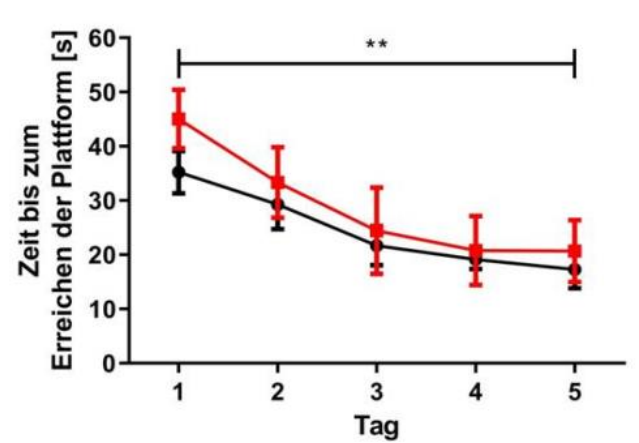

B

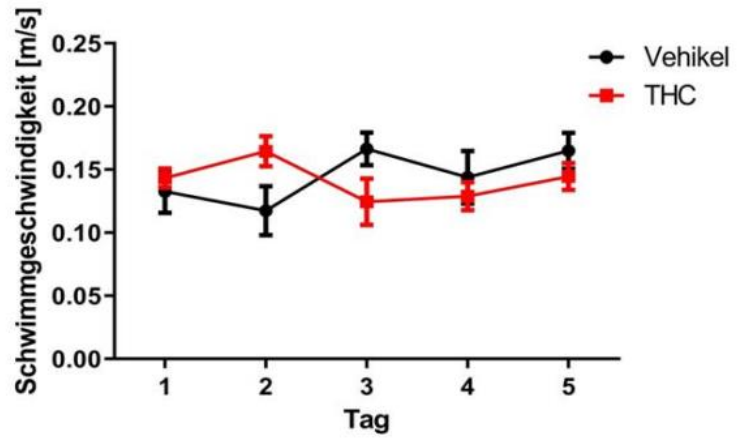

Abbildung 18: THC hat keinen Einfluss auf das räumlichen Gedächtnis von weiblichen THC- und vehikelbehandelten 5XFAD-Mäusen im Acquisition Training Während des fünftägigen Acquisition Training zeigten beide Gruppen eine Abnahme der Zeit bis zum Erreichen der Plattform (A). Die Schwimmgeschwindigkeit zeigte keine Unterschiede und blieb konstant (B). Zweifache Varianzanalyse mit Messwiederholungen mit Bonferroni-Korrektur, $\mathrm{p}^{* *}<0,01, \mathrm{n}=8-9$ Mäuse pro Gruppe. Daten dargestellt als Mittelwert \pm SEM.

Es zeigte sich kein Effekt hinsichtlich der Behandlung von männlichen 5XFAD-Mäusen mit CBD, jedoch konnte die mit vehikelbehandelte Kontrollgruppe die Zeit bis zum Erreichen der Plattform innerhalb der fünf Tage signifikant reduzieren (zweifache Varianzanalyse mit Messwiederholungen mit Bonferroni-Korrektur; Tage: CBD p=0,2133; Vehikel p=0,0004, Abbildung 19 A). Da die Schwimmgeschwindigkeit auch im Acquisition Training bei männlichen CBD-behandelten 5XFAD-Mäusen und deren vehikelbehandelter Kontrollgruppe im Vergleich keinen signifikanten Unterschied hervorbrachte, konnte ein Vorteil hinsichtlich der Zeit bis zum Erreichen der Plattform ausgeschlossen werden (zweifache Varianzanalyse mit Messwiederholungen mit Bonferroni-Korrektur, Abbildung $19 \mathrm{~B})$. 
A

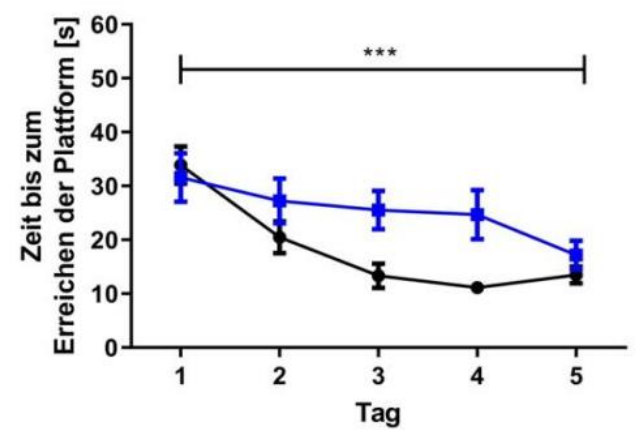

B

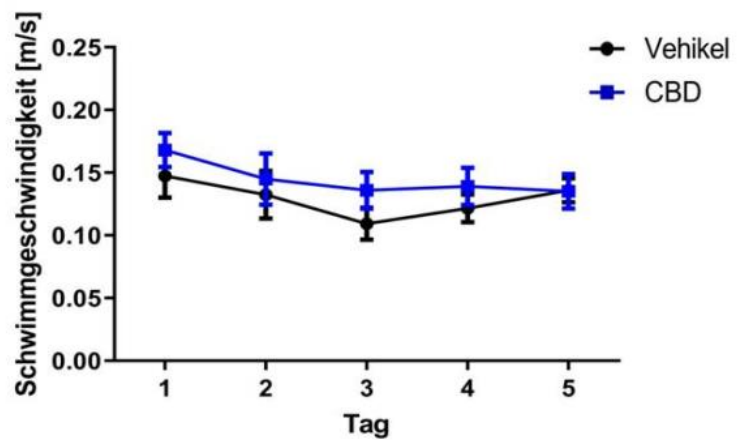

Abbildung 19: CBD hat keinen Einfluss auf das räumliche Gedächtnis von männlichen CBD- und vehikelbehandelten 5XFAD-Mäusen im Acquisition Training Es zeigte sich kein Behandlungseffekt von CBD im Vergleich zur vehikelbehandelten Kontrollgruppe hinsichtlich der Zeit bis zum Erreichen der Plattform (A). Bezüglich der Schwimmgeschwindigkeiten konnte kein Unterschied detektiert werden (B).

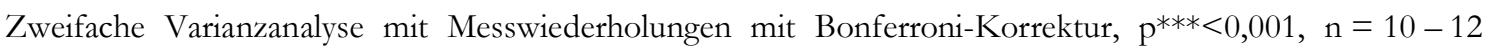
Mäuse pro Gruppe. Daten dargestellt als Mittelwert \pm SEM. 
Weibliche THC-behandelte 5XFAD-Mäuse zeigten eine klare Präferenz für den Zielquadranten gegenüber den anderen Quadranten und offenbarten somit ein intaktes Lernverhalten während des Probe Trials (einfache Varianzanalyse, THC: $p=0,0013$ Zielquadrant gegen linken Quadranten, $\mathrm{p}=0,0111$ Zielquadrant gegen rechten Quadranten, $\mathrm{p}=0,0043$ Zielquadrant gegen gegenüberliegenden Quadranten, Abbildung 20 A). Die vehikelbehandelten 5XFAD-Mäuse verbrachten nicht signifikant mehr Zeit im Zielquadrant als in den anderen Quadranten, sodass eine Beeinträchtigung im räumlichen Bezugsgedächtnis festgestellt werden konnte. Ein signifikanter Unterschied bezüglich der Schwimmgeschwindigkeit konnte nicht detektiert werden und schloss damit einen Einfluss auf die o.g. Ergebnisse aus (ungepaarter t-Test, Abbildung 20 B).

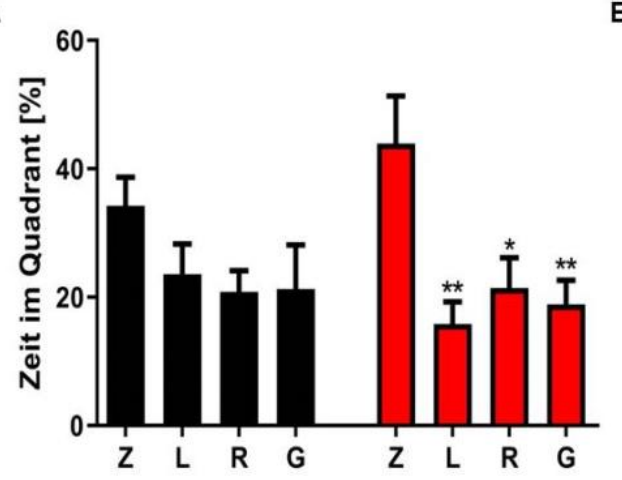

B

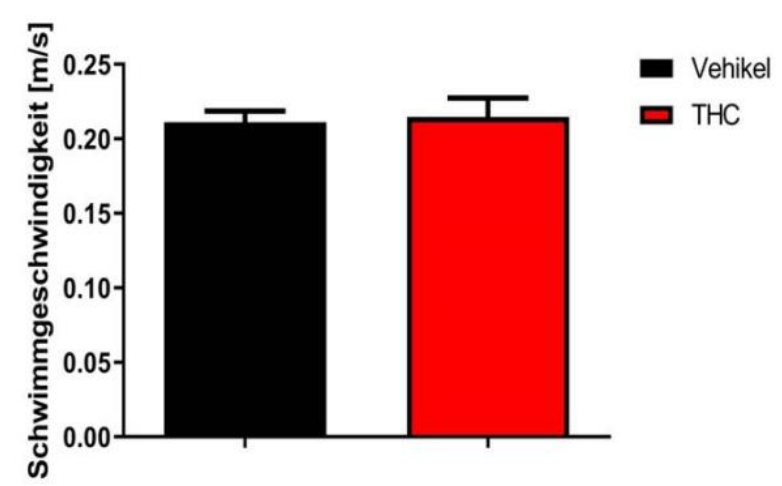

Abbildung 20: Intaktes räumliches Gedächtnis bei weiblichen THC-behandelten 5XFAD-Mäusen im Probe Trial THC-behandelte 5XFAD-Mäuse verbrachten signifikant mehr Zeit im Zielquadranten und zeigten somit im Vergleich zu gleichaltrigen vehikelbehandelten 5XFAD-Mäusen ein intaktes räumliches Gedächtnis (A). Es konnte kein Unterschied hinsichtlich der Schwimmgeschwindigkeit erfasst werden (B). Abkürzungen: $\mathrm{Z}=$ Zielquadrant, $\mathrm{L}=$ linker Quadrant, $\mathrm{R}=$ rechter Quadrant, $\mathrm{G}=$ gegenüberliegender Quadrant. Einfache Varianzanalyse mit Messwiederholungen mit Bonferroni-Korrektur (A), ungepaarter t-

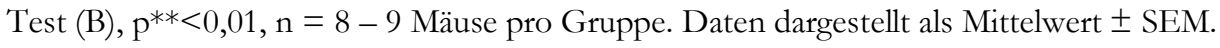


Im Probe Trial zeigten männliche CBD-behandelte sowie vehikelbehandelte 5XFADMäuse im Vergleich eine klare Tendenz zum Zielquadranten (einfache Varianzanalyse, CBD: $p=0,0424$ Zielquadrant gegen linken Quadranten, $p=0,0018$ Zielquadrant gegen rechten Quadranten; Vehikel: $\mathrm{p}=0,0023$ Zielquadrant gegen linken Quadranten, $\mathrm{p}<0,0001$ Zielquadrant gegen rechten Quadranten, $\mathrm{p}=0,0002$ Zielquadrant gegen gegenüberliegenden Quadranten, Abbildung 21 A). Folglich hatte CBD keinen Effekt auf das Lernverhalten der 5XFAD-Mäuse im Morris Water Maze. Bezüglich der Schwimmgeschwindigkeit konnte mittels ungepaartem t-Test kein Unterschied festgestellt werden (Abbildung $21 \mathrm{~B}$ ).

A

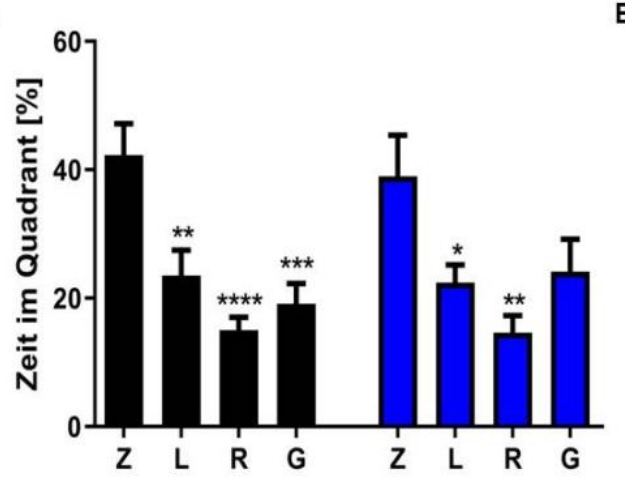

B

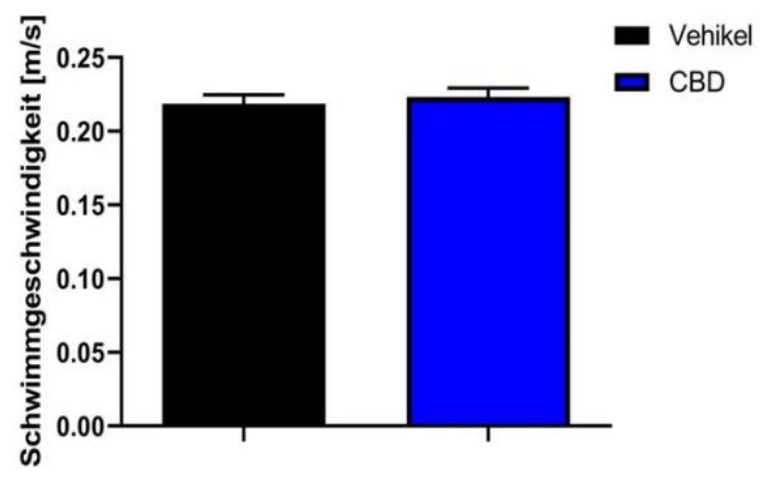

Abbildung 21: Unbeeinträchtigtes räumliches Gedächtnis von männlichen CBD- und vehikelbehandelten 5XFAD-Mäusen im Probe Trial CBD-behandelte 5XFAD-Mäuse und deren vehikelbehandelte Kontrollgruppe zeigten beide ein intaktes räumliches Gedächtnis durch eine signifikant erhöhte Zeit im Zielquadranten (A). Kein Unterschied in der Schwimmgeschwindigkeit zwischen beiden Gruppen (B). Abkürzungen: $Z=$ Zielquadrant, $L=$ linker Quadrant, $\mathrm{R}=$ rechter Quadrant, $\mathrm{G}=$ gegenüberliegender Quadrant. Zweifache Varianzanalyse mit Messwiederholungen mit BonferroniKorrektur (A), ungepaarter t-Test (B), $\mathrm{p}^{*<0,05}, \mathrm{p}^{* *}<0,01, \mathrm{p}^{* * *}<0,001, \mathrm{p}^{* * * *}<0,0001, \mathrm{n}=10-12$ Mäuse pro Gruppe. Daten dargestellt als Mittelwert \pm SEM.

Im Gegensatz zu CBD verbesserte THC das Lernverhalten von weiblichen 5XFADMäusen im Morris Water Maze. 


\subsubsection{Auswirkungen von THC und CBD auf das Lernverhalten von 5XFAD- Mäusen im Novel Object Recognition Test}

Um den Einfluss von THC und CBD auf das Lernverhalten von 5XFAD-Mäusen zu testen, wurde der Novel Object Recognition Test (NOR) durchgeführt. Ausgewertet wurden die zurückgelegte Distanz und der Prozentanteil der Zeit am neuen Objekt im Vergleich zum bekannten Objekt. Dieser gibt das Lernverhalten der Mäuse wieder (siehe Absatz 2.3.5).

Weibliche 5XFAD-Mäuse, die mit THC behandelt wurden, zeigten keine klare Präferenz und somit mehr Interesse für das neue Objekt als für das bereits bekannte Objekt. Als Kontrolle dienten die vehikelbehandelten 5XFAD-Mäuse, die ebenfalls nicht signifikant mehr Zeit am neuen Objekt verbrachten (Abbildung 22 A). Hinsichtlich der zurückgelegten Distanz zeigten sich keine Unterschiede zwischen THC-behandelten 5XFAD-Mäusen und der vehikelbehandelten Kontrollgruppe (Abbildung 22 B).

A

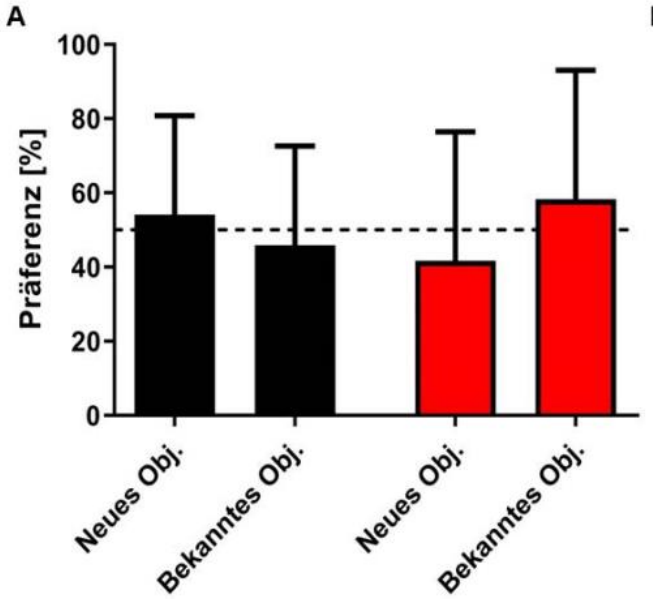

B

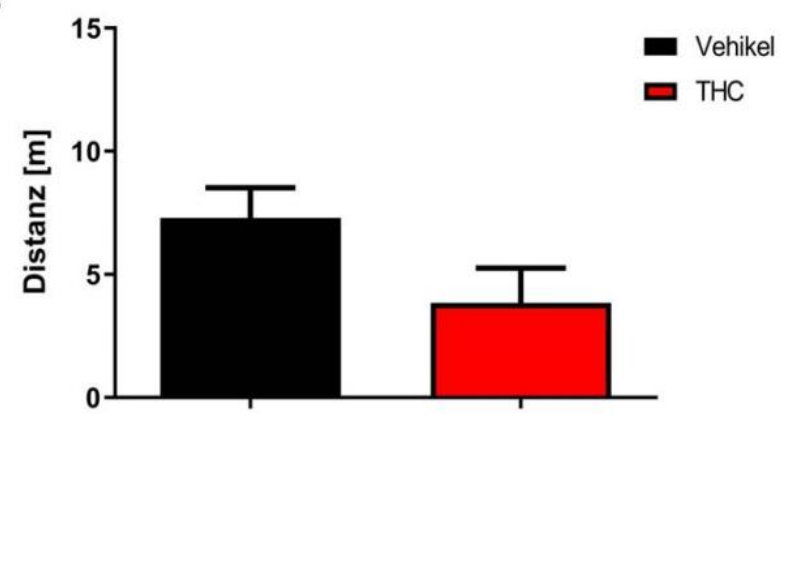

Abbildung 22: Unbeeinträchtigtes Lernverhalten von weiblichen 5XFAD-Mäusen im NOR-Test nach THC-Behandlung Weder die mit THC behandelten Mäuse noch die vehikelbehandelte Kontrollgruppe zeigte eine eindeutige Präferenz für das neue Objekt (A). Ein Unterschied in der zurückgelegten Distanz wurde nicht gemessen (B). Abkürzungen: Obj. = Objekt. Ungepaarter t-Test, $\mathrm{n}=8-$ 9 Mäuse pro Gruppe. Daten dargestellt als Mittelwert \pm SEM.

Männliche 5XFAD-Mäuse, die mit CBD behandelt wurden, zeigten keinen signifikanten Unterschied hinsichtlich der Präferenz für das neue Objekt im Vergleich zu dem bereits bekannten Objekt (Abbildung 23 A). Bei der vehikelbehandelten Kontrollgruppe wurde ebenfalls kein Effekt nachgewiesen. Zusammengefasst hatte CBD keinen Einfluss auf das Lernverhalten im NOR-Test (Abbildung 23 B). 

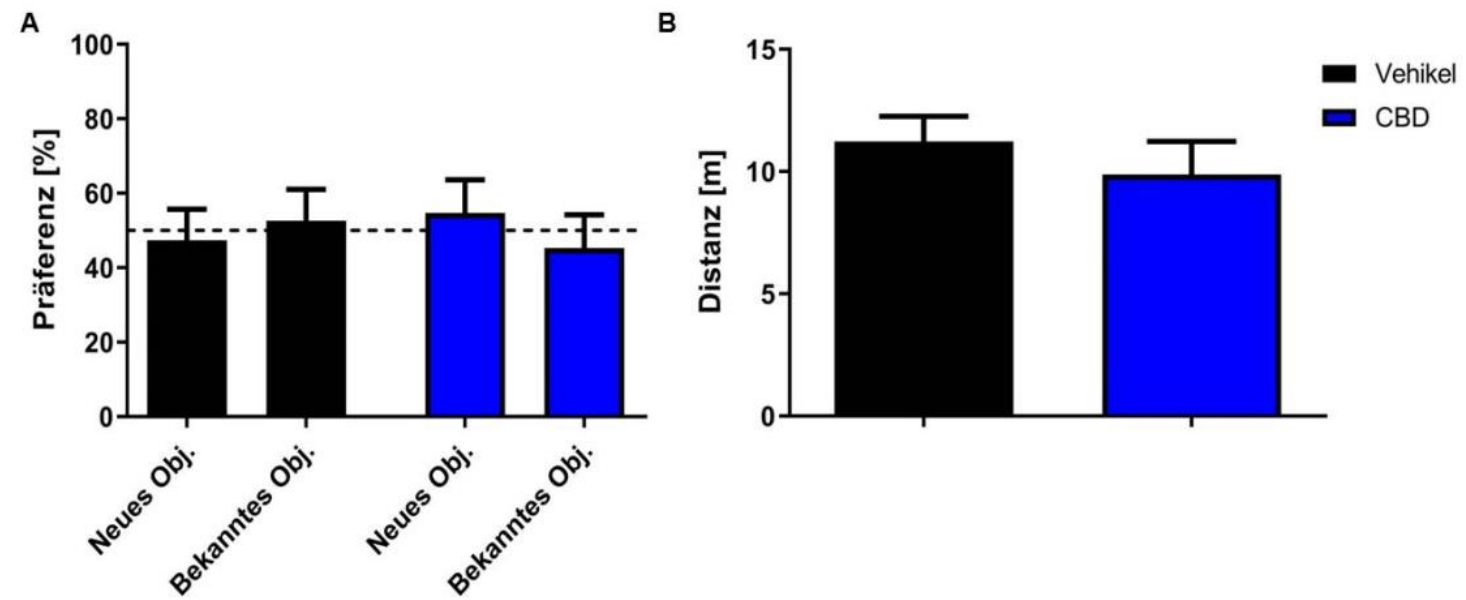

Abbildung 23: Unbeeinträchtigtes Lernverhalten von 5XFAD-Mäusen im NOR-Test nach CBDBehandlung Beide männlichen Behandlungsgruppen zeigten keine signifikante Präferenz für das neue Objekt (A). Unterschiede in der zurückgelegten Distanz ergaben sich nicht (B). Abkürzung: Obj. = Objekt. Ungepaarter t-Test, $\mathrm{n}=10-12$ Mäuse pro Gruppe. Daten dargestellt als Mittelwert \pm SEM.

\subsubsection{Auswirkungen von THC und CBD auf das Lernverhalten von 5XFAD- Mäusen im Cross Maze}

Um den Einfluss von THC oder CBD auf das Arbeitsgedächtnis in 5XFAD-Mäusen zu testen, wurde das Cross Maze angewandt. Wie bereits in Absatz 2.3.4 beschrieben, wurden die Armwechselrate und außerdem die zurückgelegte Distanz gemessen, um einen Einfluss von verminderter Mobilität der Mäuse auf die Armwechselrate auszuschließen. Diese gibt Auskunft über das Erkundungsverhalten der Mäuse. Normalerweise neigen Mäuse dazu, neue Arme zu erkunden, anstatt kürzlich erkundete Arme erneut zu betreten (Wietrzych et al. 2005).

Weibliche THC-behandelte 5XFAD-Mäuse zeigten im Vergleich zu vehikelbehandelten Mäusen keine signifikanten Unterschiede bezüglich der Armwechselrate (ungepaarter tTest, Abbildung 24 A). 5XFAD-Mäuse, die mit THC behandelt wurden, zeigten allerdings einen signifikanten Unterschied in der zurückgelegten Distanz, sodass sich vehikelbehandelte Mäuse wesentlich mehr im Versuchsaufbau bewegten als die mit THC behandelten Artgenossen (ungepaarter t-Test, p=0,0005, Abbildung 24 B). 


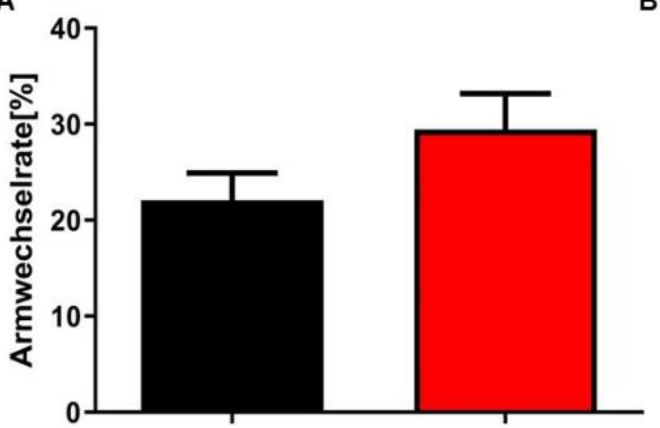

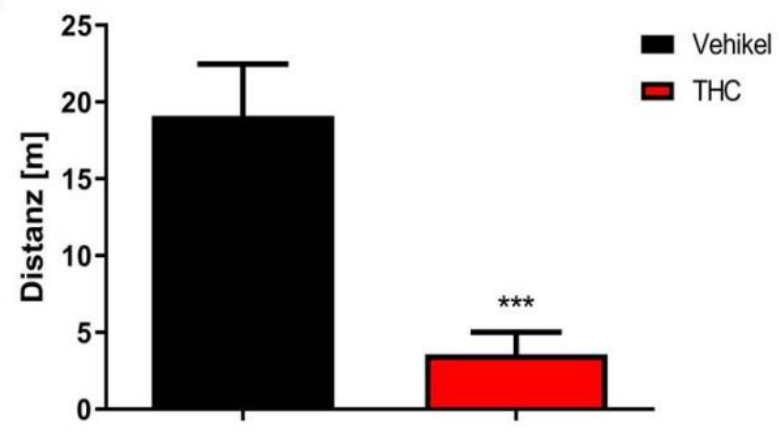

Abbildung 24: Kein Behandlungseffekt von THC auf das Arbeitsgedächtnis von weiblichen 5XFADMäusen im Cross Maze Die Armwechselrate (A) blieb im Vergleich zur Vehikelkontrollgruppe gleich, jedoch zeigte sich ein Effekt auf die zurückgelegte Distanz der mit THC behandelten Mäuse im Cross Maze

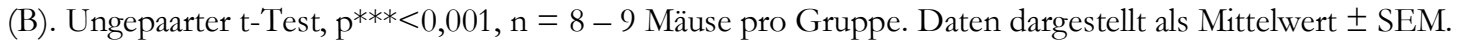

Es zeigte sich weder ein signifikanter Unterschied in der Armwechselrate noch in der zurückgelegten Distanz zwischen männlichen CBD- und vehikelbehandelten 5XFADMäusen (ungepaarter t-Test, Abbildung $25 \mathrm{~A}$ und B).

Ein von der Behandlung unbeeinträchtigtes Arbeitsgedächtnis konnte folglich angenommen werden.

A

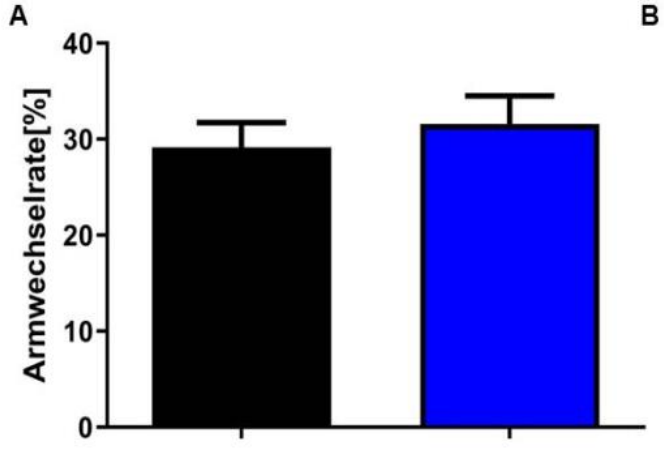

B

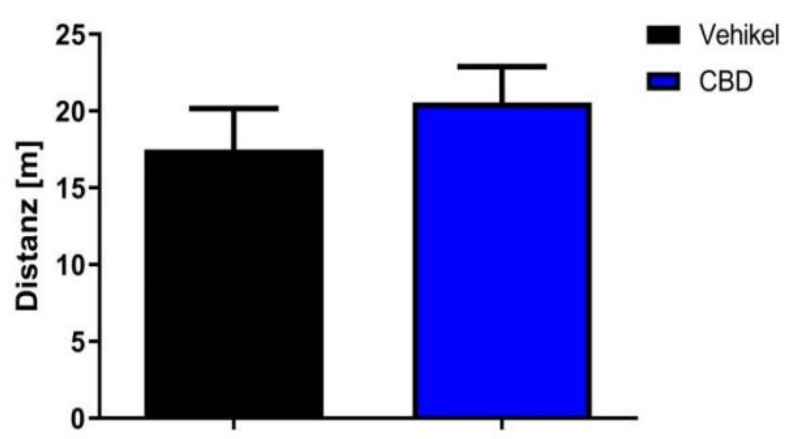

Abbildung 25: Unverändertes Arbeitsgedächnis von männlichen CBD- und vehikelbehandelten 5XFAD-Mäusen im Cross Maze Unterschiede zwischen den Behandlungsgruppen hinsichtlich der Armwechselrate (A) und der zurückgelegten Distanz im Cross Maze (B) konnten nicht beobachtet werden. Ungepaarter t-Test, $\mathrm{n}=10-12$ Mäuse pro Gruppe. Daten dargestellt als Mittelwert \pm SEM. 


\subsubsection{Auswirkungen von THC oder CBD auf das Angstverhalten von 5XFAD- Mäusen im Open Field}

Um den Einfluss von THC oder CBD in 5XFAD-Mäusen auf deren spontanes Erkundungsverhalten zu untersuchen, wurde das Open Field durchgeführt. Dieser Test gab außerdem Aufschluss über ein mögliches Angstverhalten der Mäuse, indem Mäuse, die ein ängstlicheres Verhalten zeigten, mehr Zeit in der Peripherie als im Zentrum der Box verbrachten (Denenberg 1969). Die zurückgelegte Distanz der Mäuse wurde ebenfalls ausgewertet, um einen Einfluss von verminderter Mobilität auf die Testauswertung auszuschließen (Absatz 2.3.5).

Es zeigten sich nach THC-Behandlung weder signifikante Unterschiede hinsichtlich der zurückgelegten Distanz noch in der Zeit, die die Mäuse im Zentrum verbrachten (ungepaarter t-Test, Abbildung 26 A und B). Folglich hatte die Behandlung mit THC keinen Einfluss auf das spontane Erkundungs- und Angstverhalten von weiblichen 5XFAD-Mäusen.

A

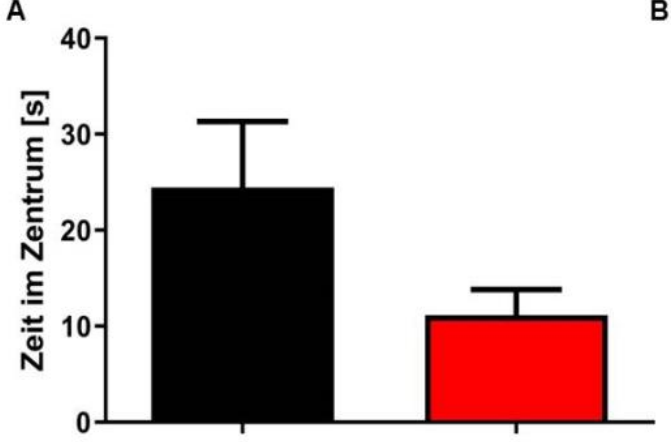

B

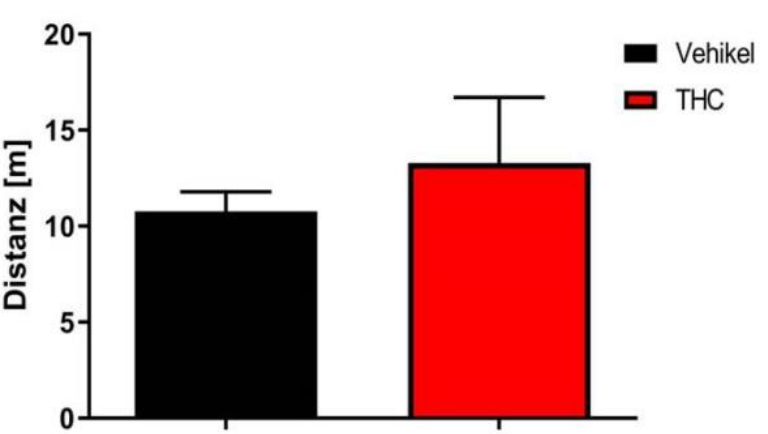

Abbildung 26: Unbeeinträchtigtes Erkundungs- und Angstverhalten von weiblichen 5XFADMäusen im Open Field nach THC-Behandlung Weder konnte ein Unterschied zwischen den Behandlungsgruppen hinsichtlich der verbrachten Zeit im Zentrum der Versuchsbox (A) noch auf die zurückgelegte Distanz (B) gemessen werden. Ungepaarter t-Test, $\mathrm{n}=8-9$ Mäuse pro Gruppe. Daten dargestellt als Mittelwert \pm SEM.

Männliche Mäuse, die mit $\mathrm{CBD}$ behandelt wurden, zeigten keine signifikanten Unterschiede bei der Bewältigung des Tests im Vergleich zur vehikelbehandelten Kontrollgruppe (ungepaarter t-Test, Abbildung 27 A und B). Eine CBD-Behandlung hatte also weder einen Einfluss auf die Mobilität der Mäuse noch auf deren Angstverhalten im Open Field. 

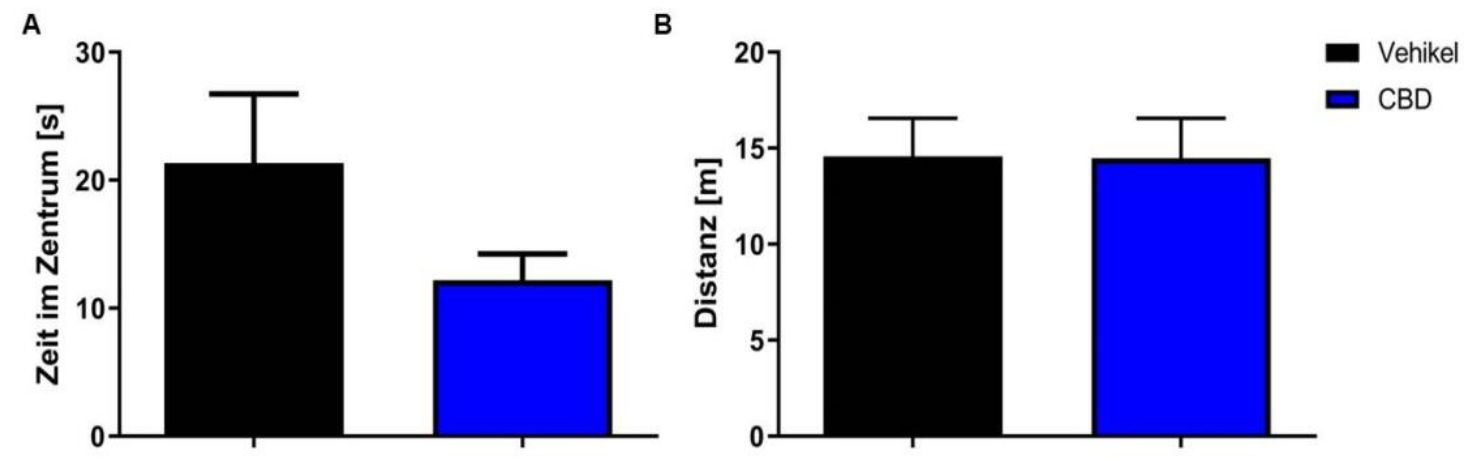

Abbildung 27: Unbeeinträchtigtes Erkundungs- und Angstverhalten von männlichen 5XFADMäusen im Open Field nach CBD-Behandlung CBD-behandelte Mäuse verbrachten nicht signifikant weniger Zeit im Zentrum (A) als ihre Vehikelkontrollgruppe. Hinsichtlich der zurückgelegten Distanz zeigten sich keine Unterschiede (B). Ungepaarter t-Test, $\mathrm{n}=10-12$ Mäuse pro Gruppe. Daten dargestellt als Mittelwert \pm SEM.

\subsubsection{Auswirkungen von THC und CBD auf das Angstverhalten von 5XFAD- Mäusen im Elevated Plus Maze}

Das Elevated Plus Maze wurde verwendet, um einen möglichen Einfluss von THC oder CBD auf das Angstverhalten der Mäuse näher zu untersuchen (Campos et al. 2013). Dargestellt wurde die Zeit, die die Mäuse in den offenen Armen verbrachten, im Verhältnis zur Gesamtdauer des Experiments, wie bereits in Absatz 2.3.6 erläutert.

Als Kontrollexperiment diente der Vergleich zwischen vehikelbehandelten 5XFADMäusen und vehikelbehandelten gesunden WT'-Mäusen.

Beim Vergleich der weiblichen Gruppen konnte ein deutlicher Unterschied im Angstverhalten der Artgenossen gezeigt werden, denn die weiblichen 5XFAD-Mäuse verbrachten signifikant mehr Zeit in den offenen Armen als vehikelbehandelte WT-Mäuse (ungepaarter t-Test, $\mathrm{p}=0,0076$, Abbildung 28 A). Verglich man die weiblichen THCbehandelten 5XFAD-Mäuse mit deren vehikelbehandelter Kontrollgruppe, zeigte sich ebenfalls ein signifikanter Unterschied in der Zeit, die in den offenen Armen verbracht wurde (ungepaarter t-Test, $\mathrm{p}=0,0381$, Abbildung $28 \mathrm{~B}$ ). Daraus lässt sich folgern, dass THC das Angstverhalten von weiblichen 5XFAD-Mäusen, die im Alter von sechs Monaten schon einen deutlich weniger ängstlicheren Phänotyp aufwiesen als ihre gesunden Artgenossen, nahezu auf das Niveau letztgenannter normalisierte.

Ein signifikanter Unterschied hinsichtlich der zurückgelegten Distanz im Elevated Plus Maze konnte zwischen gesunden WT-Mäusen und vehikelbehandelten 5XFAD-Mäusen nicht gezeigt werden (ungepaarter t-Test, Abbildung $28 \mathrm{C}$ ). Zwischen weiblichen THCbehandelten 5XFAD-Mäusen und der vehikelbehandelten Kontrollgruppe konnte eine signifikant geringer zurückgelegte Distanz von weiblichen THC-behandelten 5XFAD- 
Mäusen nachgewiesen werden, sodass THC einen Einfluss auf die Mobilität der Mäuse offenbarte (ungepaarter t-Test, $\mathrm{p}=0,0112$, Abbildung $28 \mathrm{D}$ ).

A
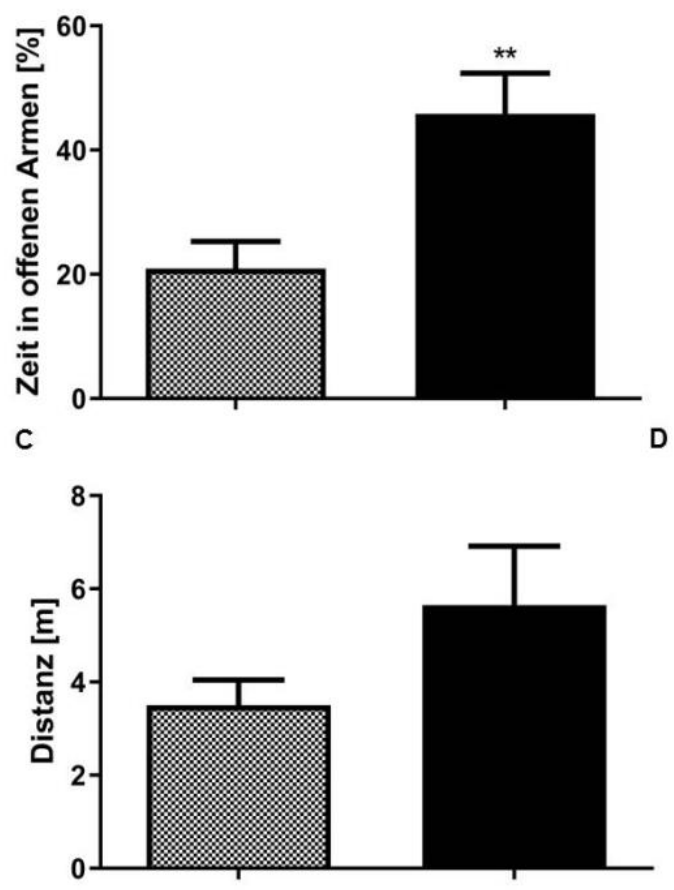

B
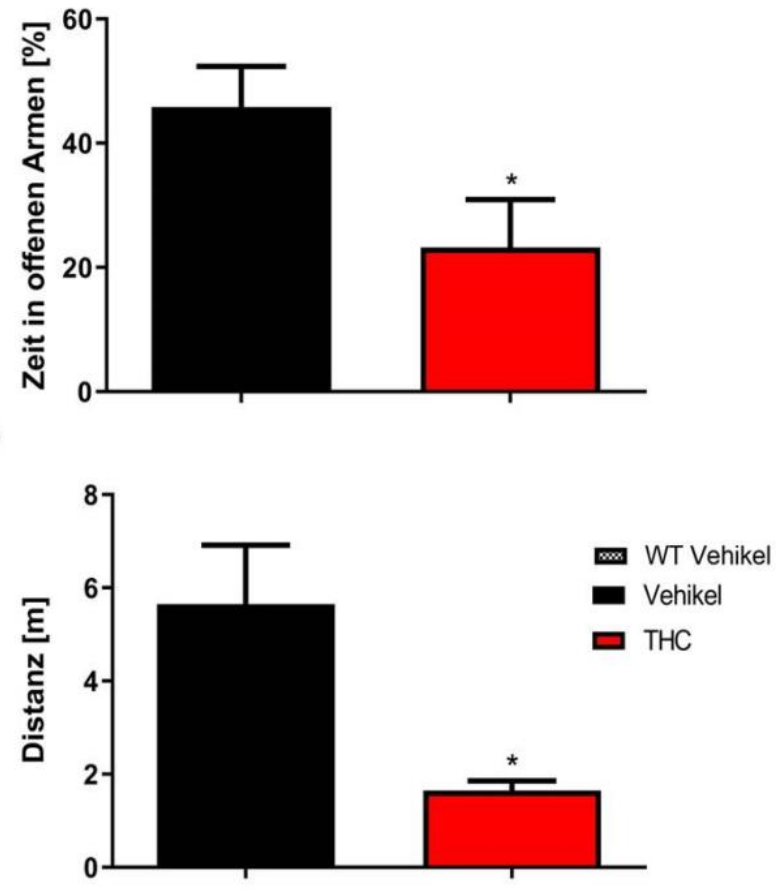

Abbildung 28: Normalisierung des Angstverhaltens von weiblichen 5XFAD-Mäusen nach THC-

Behandlung Weibliche 5XFAD-Mäuse zeigten im Vergleich ein weniger ängstliches Verhalten als gesunde WT-Mäuse (A). THC-behandelte 5XFAD-Mäuse verbrachten signifikant weniger Zeit in den offenen Armen als vehikelbehandelte 5XFAD-Mäuse (B). Gesunde WT-Mäuse zeigten im Vergleich zu vehikelbehandelten 5XFAD-Mäusen keinen Unterschied hinsichtlich der zurückgelegten Distanz (C). Weibliche THC-behandelte 5XFAD-Mäuse legten signifikant weniger Distanz zurück als die vehikelbehandelte Kontrollgruppe (D). Ungepaarter t-Test, $\mathrm{p}^{*}=0,05, \mathrm{p}^{* *}<0,01, \mathrm{n}=7-13$ Mäuse pro Gruppe. Daten dargestellt als Mittelwert \pm SEM.

Bei der männlichen Gruppe wurde kein signifikanter Unterschied zwischen 5XFADMäusen und W'T-Mäusen deutlich (ungepaarter t-Test, Abbildung 29 A). Männliche 5XFAD-Mäuse zeigten also im Alter von sechs Monaten ein ähnliches Angstverhalten wie gesunde vehikelbehandelte WT-Mäuse. Männliche CBD-behandelte 5XFAD-Mäuse demonstrierten kein verändertes Angstverhalten im Vergleich zur vehikelbehandelten Kontrollgruppe (ungepaarter t-Test, Abbildung 29 B). Die zurückgelegte Distanz ergab keinen Hinweis auf verminderte Mobilität nach CBD-Behandlung (ungepaarter t-Test, Abbildung 29 D). Ein Effekt von CBD auf das Angstverhalten im Elevated Plus Maze blieb aus. 
A

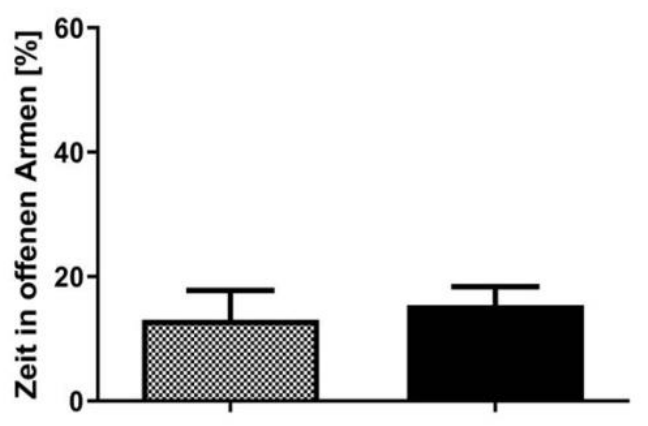

C

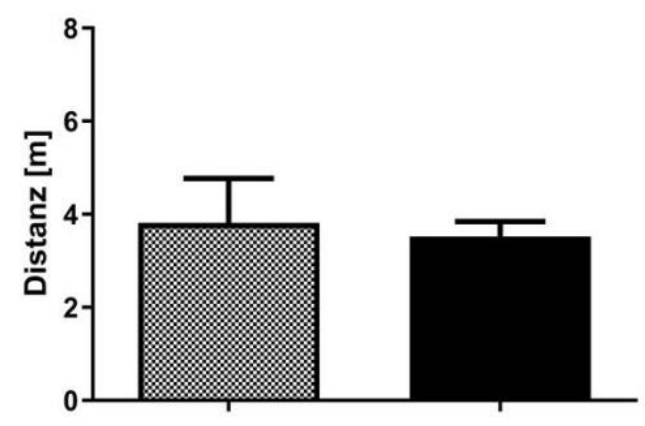

B

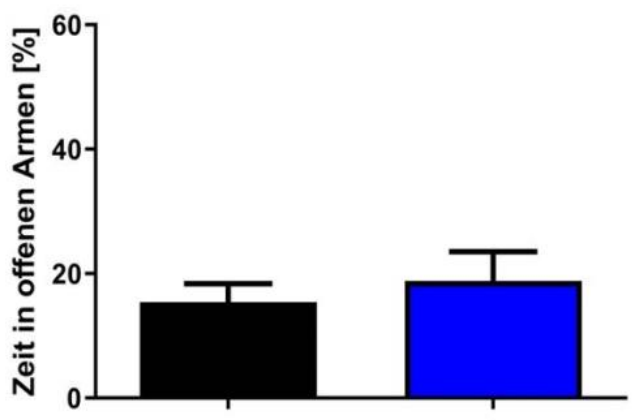

D

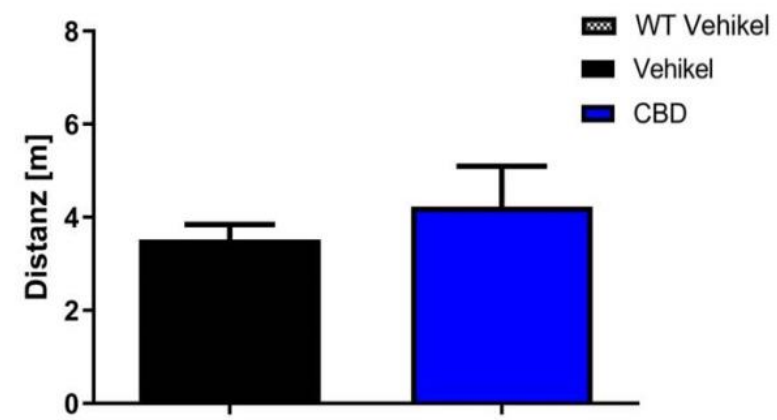

Abbildung 29: Unbeeinträchtigtes Angstverhalten von männlichen 5XFAD-Mäusen und WTMäusen im Elevated Plus Maze nach CBD-Behandlung Männliche 5XFAD-Mäuse zeigen keinen Unterschied zu gesunden WT-Mäusen hinsichtlich der verbrachten Zeit in den offenen Armen des Elevated Plus Maze (A). Verglich man CBD-behandelte 5XFAD-Mäuse mit deren vehikelbehandelten Kontrollgruppe, erkannte man eine Differenz hinsichtlich der Zeit in den offenen Armen (B). Die zurückgelegte Distanz unterschied sich weder zwischen WT-Mäusen und vehikelbehandelten 5XFAD-Mäusen (C) noch zwischen männlichen CBD-behandelten 5XFAD-Mäusen und der vehikelbehandelten Kontrollgruppe (D). Ungepaarter t-Test, $\mathrm{n}=7-11$ Mäuse pro Gruppe. Daten dargestellt als Mittelwert \pm SEM.

\subsubsection{Auswirkungen von THC und CBD auf das Angstverhalten von 5XFAD- Mäusen in der Dark/Light Box}

Ein möglicher Einfluss von THC oder CBD auf das Angstverhalten in Mäusen wurde auch mithilfe der Dark/Light Box überprüft (Bourin und Hascoët 2003). Neben der Zeit, die die Maus in der hellen Zone verbrachte, wurde außerdem die Zeitspanne bis zum ersten Eintritt in das schützende Kompartiment, also der Eintritt in die dunkle Zone, gemessen (siehe Absatz 2.3.7).

Es zeigte sich kein signifikanter Unterschied hinsichtlich der Zeit, die weibliche THCbehandelte 5XFAD-Mäuse im Vergleich zu vehikelbehandelten Kontrollmäusen im hellen Kompartiment verbrachten (ungepaarter t-Test, Abbildung 30 A). Betrachtete man die Zeit, die benötigt wurde, um die dunkle Zone das erste Mal zu betreten, ließ sich kein signifikanter Unterschied zwischen THC-behandelten und vehikelbehandelten Kontrollmäusen evaluieren (ungepaarter t-Test, Abbildung 30 B). 
Da die zurückgelegte Distanz im dunklen Kompartiment nicht aufgezeichnet werden konnte, wurde die Anzahl der Zonenwechsel benutzt, um eine Aussage über die Mobilität der Mäuse zu treffen. Weibliche THC-behandelte Mäuse zeigten einen Trend hinsichtlich einer niedrigeren Anzahl von Zonenwechsel im Vergleich zur Kontrollgruppe (ungepaarter t-Test, $\mathrm{p}=0$,0540, Abbildung $30 \mathrm{C}$ ).

A

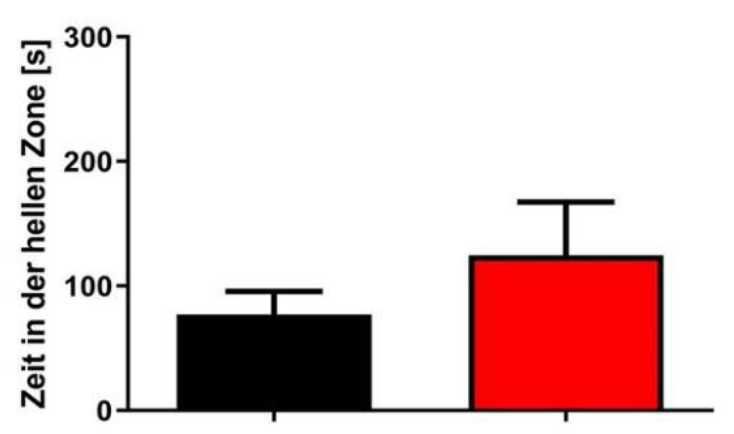

C

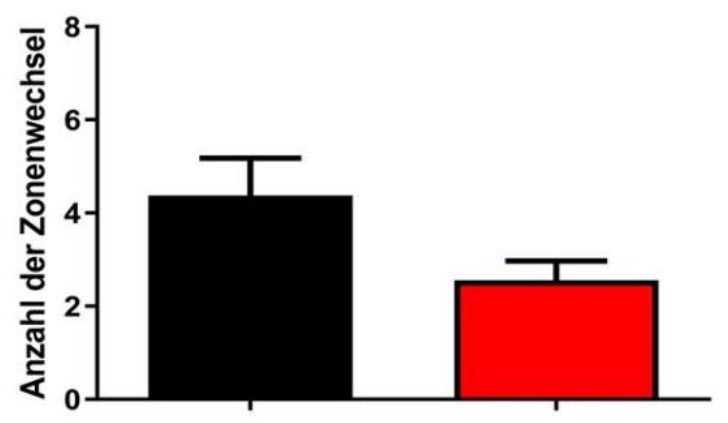

$B$

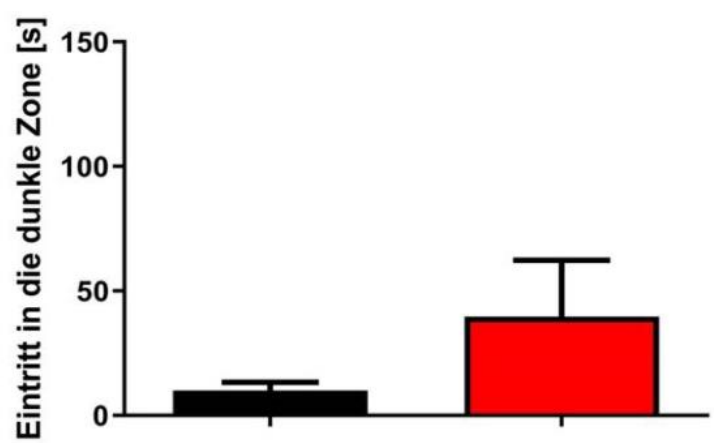

- Vehikel

Abbildung 30: Unbeeinträchtigtes Angstverhalten von weiblichen 5XFAD-Mäusen in der Dark/Light Box nach THC-Behandlung THC-behandelte 5XFAD-Mäuse verbrachten nicht signifikant mehr Zeit in der hellen Zone (A) im Vergleich zur vehikelbehandelten Kontrollgruppe. Keine Unterschiede zeigten sich hinsichtlich der Zeit bis zum Eintritt in die dunkle Zone (B) oder der Anzahl der Zonenwechsel als Parameter für die Mobilität der Mäuse (C). Ungepaarter t-Test, $n=7-9$ Mäuse pro Gruppe. Daten dargestellt als Mittelwert \pm SEM.

Männliche CBD-behandelte 5XFAD-Mäuse zeigten im Vergleich zur vehikelbehandelten Kontrollgruppe keinen signifikanten Unterschied hinsichtlich der Zeit, die im hellen Kompartiment verbracht wurde (ungepaarter t-Test, Abbildung 31 A). Betrachtete man die Anzahl der Zonenwechsel, wurde deutlich, dass CBD-behandelte 5XFAD-Mäuse signifikant häufiger die Kompartimente wechselten als die vehikelbehandelten Kontrollmäuse (ungepaarter t-Test, p=0,0286, Abbildung 31 C). Ein Einfluss von CBD auf die Zeit bis zum erstmaligen Eintritt in die dunkle Zone konnte nicht evaluiert werden (ungepaarter t-Test, Abbildung $31 \mathrm{~B}$ ). 
A

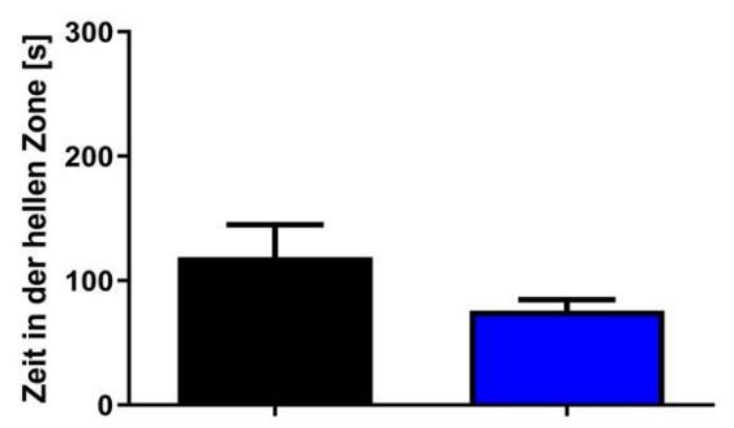

C

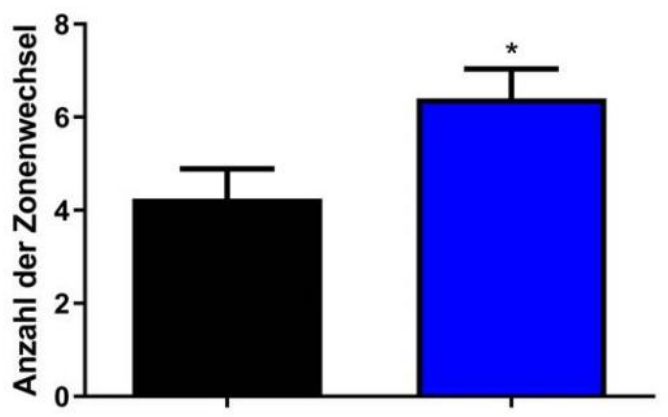

B

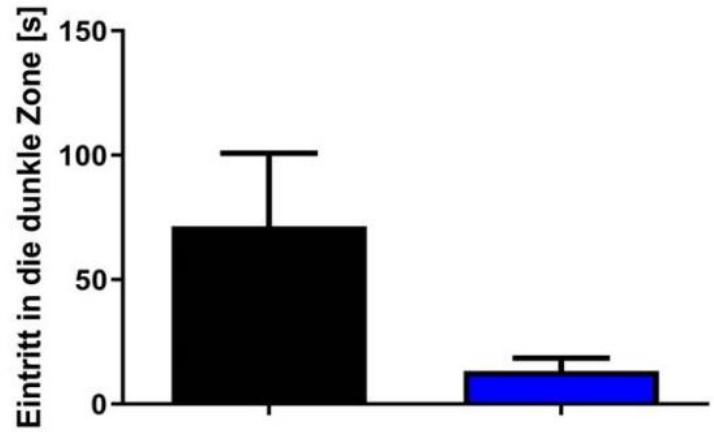

Abbildung 31: Unbeeinträchtigtes Angstverhalten von 5XFAD-Mäusen in der Dark/Light Box nach CBD-Behandlung Verglichen mit der Vehikelkontrollgruppe zeigten die männlichen CBD-behandelten 5XFAD-Mäuse keinen Unterschied hinsichtlich der Zeit, die sie in der hellen Zone (A) verbrachten. Auch die Zeit bis zum Eintritt in die dunkle Zone war nicht signifikant verändert (B). Ein Einfluss von CBD auf die Mobilität der Tiere konnte mithilfe der Anzahl der Zonenwechsel erfasst werden. Diese war signifikant erhöht (C). Ungepaarter t-Test, $\mathrm{n}=10-12$ Mäuse pro Gruppe. Daten dargestellt als Mittelwert \pm SEM.

THC und CBD zeigten keinen Einfluss auf das Angstverhalten von Mäusen in der Dark/Light Box.

\subsection{Auswirkungen von THC und CBD auf die Expression von Beta- Amyloid, Neuroinflammationsmarkern und dem Cannabinoidrezeptor in 5XFAD-Mäusen}

Um einen möglichen Einfluss von THC oder CBD auf den Beta-Amyloid Plaqueload, Neuroinflammation und CB1-Rezeptorexpression im 5XFAD-Mausmodell zu untersuchen, wurde Hirngewebe mit speziellen Markern für oben genannte Prozesse angefärbt und graphisch ausgewertet. Hierbei wurden die jeweiligen Behandlungsgruppen von THC oder CBD mit deren vehikelbehandelten Kontrollgruppen verglichen. 


\subsubsection{Auswirkungen von THC und CBD auf den Beta-Amyloid Plaqueload in 5XFAD-Mäusen}

Der pan-Antikörper 2431-1 wurde benutzt, um die Beta-Amyloid Belastung in 5XFADMäusen zu evaluieren. THC-behandelte Mäuse zeigten verglichen mit der vehikelbehandelten Kontrollgruppe eine signifikant geringere Beta-Amyloid (Abeta) Konzentration im Cortex (ungepaarter t-Test, $\mathrm{p}=0,0005$, Abbildung $32 \mathrm{~B}-\mathrm{D}$ ), jedoch nicht im Hippocampus (ungepaarter t-Test, Abbildung $32 \mathrm{~A}$ ).

A

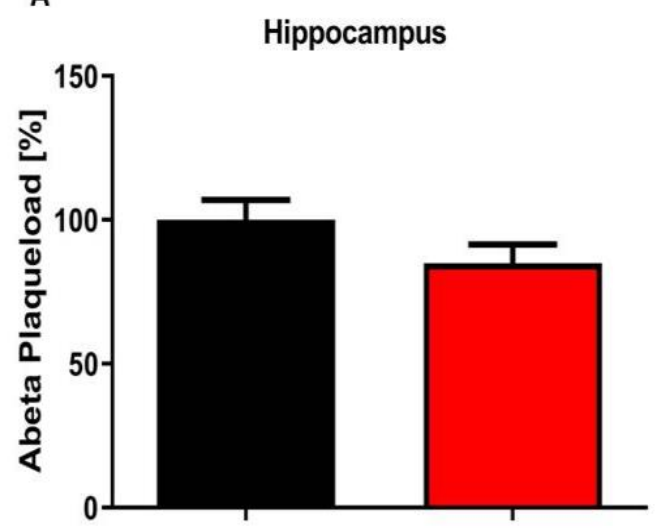

C

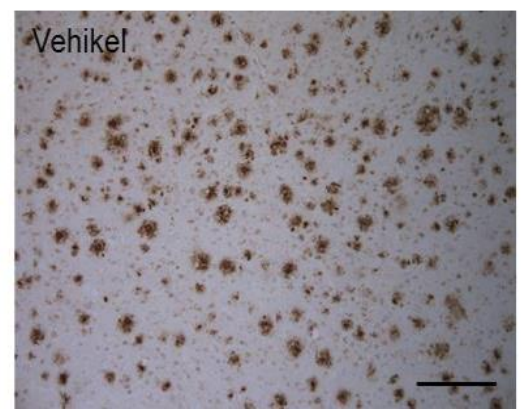

B

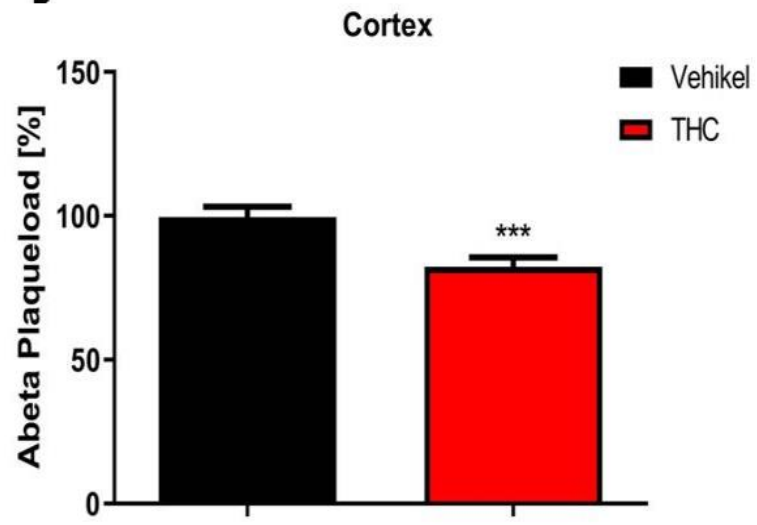

D

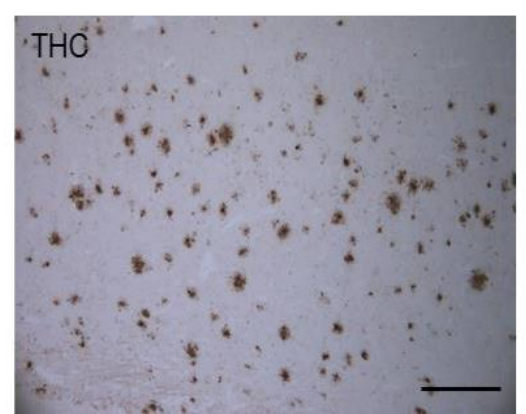

Abbildung 32: Signifikante Reduktion des Beta-Amyloid Plaqueloads im Cortex von weiblichen 5XFAD-Mäusen nach THC-Behandlung Die Beta-Amyloid (Abeta) Belastung im Hippocampus zeigte sich im Vergleich zwischen den Behandlungsgruppen unverändert (A). Ein signifikant geringerer Abeta Plaqueload im Cortex von THC-behandelten 5XFAD-Mäusen konnte im Vergleich zur vehikelbehandelten Kontrollgruppe detektiert werden (B). Beispielbild des Cortex einer weiblichen 5XFAD-Maus aus der vehikelbehandelten Kontrollgruppe (C) im Vergleich zum Cortex einer THC-behandelten 5XFAD-Maus (D). Maßstab $100 \mu \mathrm{m}$. Ungepaarter t-Test, $\mathrm{p}^{* * *}<0,001, \mathrm{n}=7-9$ Mäuse pro Gruppe. Daten dargestellt als Mittelwert \pm SEM. 
Männliche 5XFAD-Mäuse, die mit CBD behandelt wurden, zeigten ebenfalls eine signifikante Reduktion der Amyloid-Plaques im Hippocampus (ungepaarter t-Test, $\mathrm{p}=0,0011$, Abbildung $33 \mathrm{~A}, \mathrm{C}$ und $\mathrm{D}$ ), allerdings nicht im Cortex (ungepaarter t-Test, Abbildung 33 B).

A

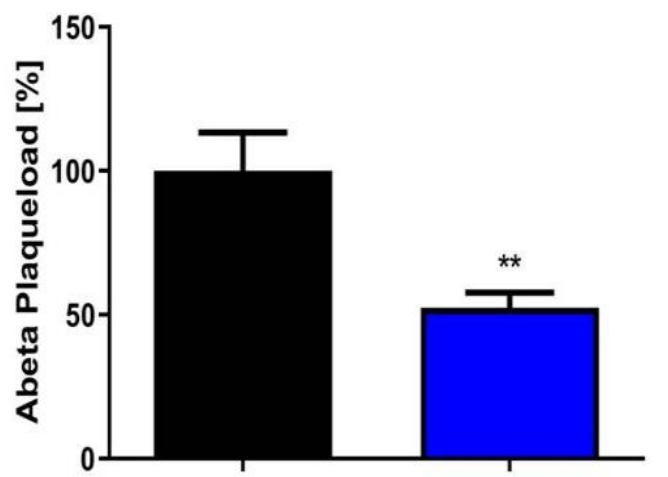

C

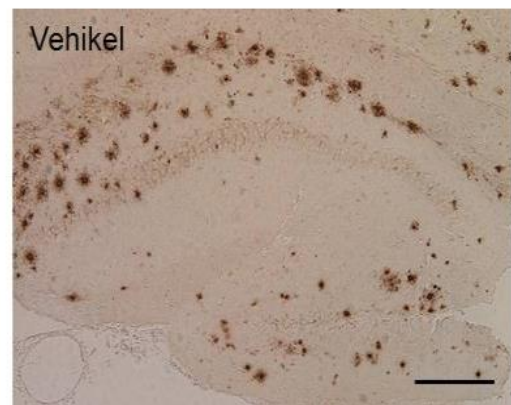

B

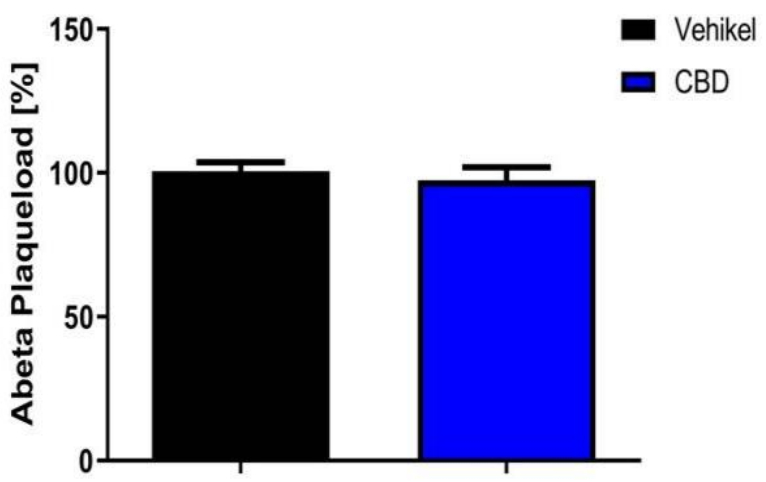

D

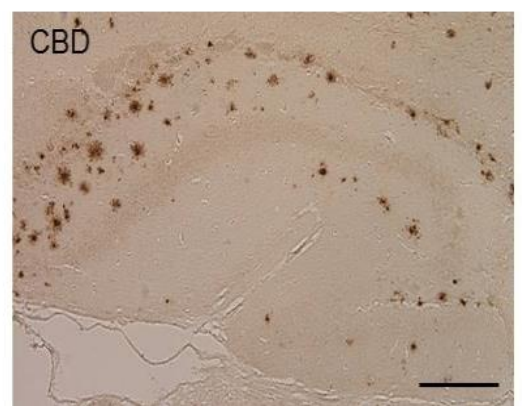

Abbildung 33: Signifikante Reduktion der Beta-Amyloid Expression in männlichen 5XFAD-Mäusen nach CBD-Behandlung im Hippocampus Im Hippocampus (A) zeigt sich eine signifikante Reduktion des Beta-Amyloid (Abeta) Plaqueloads von CBD-behandelten Tieren im Vergleich mit der Vehikelkontrollgruppe. Im Cortex (B) zeigte sich diese Veränderung nicht. Beispielbilder der Färbung von Abeta männlicher 5XFAD-Mäuse, die mit Vehikel (C) oder CBD (D) behandelt wurden. Maßstab $200 \mu \mathrm{m}$.

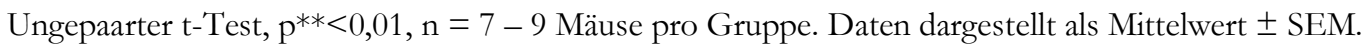




\subsubsection{Auswirkungen von THC und CBD auf die Expression des Astrozytenmarkers GFAP in 5XFAD-Mäusen}

Die immunhistochemische Färbung mit dem Inflammationsmarker GFAP ergab eine signifikant erhöhte Expression im Cortex von weiblichen THC-behandelten 5XFADMäusen im Vergleich zur vehikelbehandelten Kontrollgruppe (ungepaarter t-Test, $\mathrm{p}=0,0042$, Abbildung $34 \mathrm{~B}-\mathrm{D})$. Diese gesteigerte Astrozytose zeigte sich nicht im Hippocampus der Mäuse (ungepaarter t-Test, Abbildung 34 A).

A

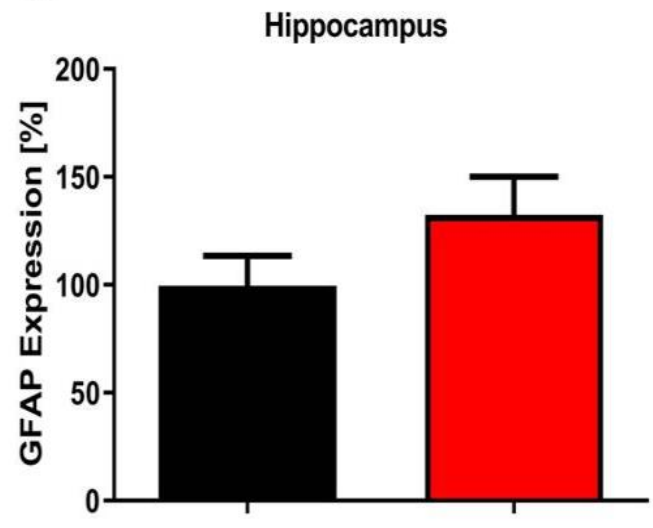

C

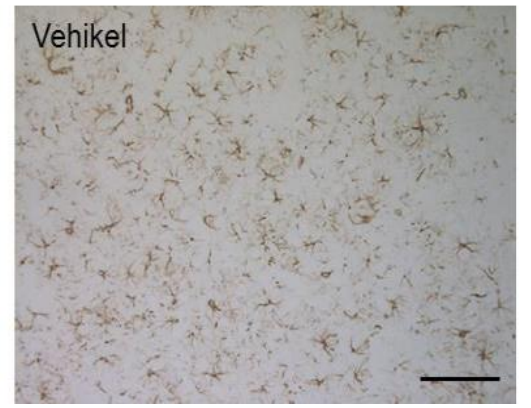

B

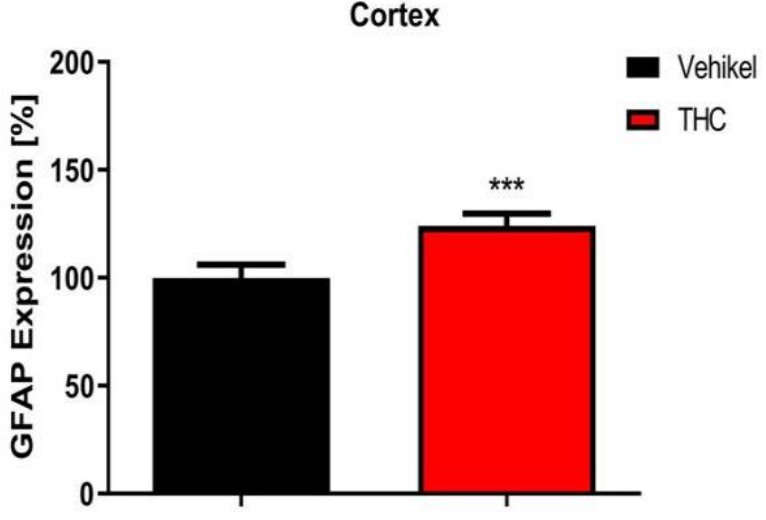

D

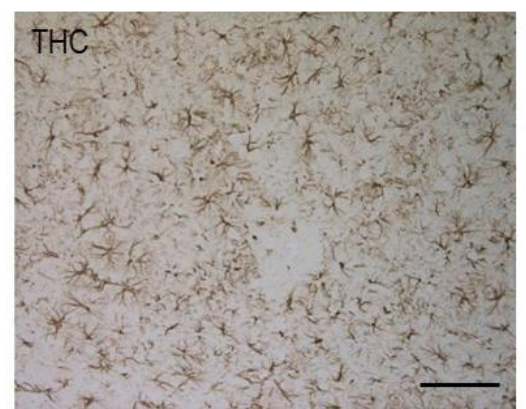

Abbildung 34: Gesteigerte Expression des Astrozytenmarkers GFAP im Cortex von weiblichen 5XFAD-Mäusen nach THC-Behandlung GFAP im Hippocampus von THC-behandelten 5XFADMäusen zeigte sich nicht signifikant verändert (A), jedoch im Cortex signifikant erhöht (B). Beispielbilder der Färbung von GFAP im Cortex von weiblichen vehikelbehandelten (C) und THC-behandelten (D) 5XFAD-

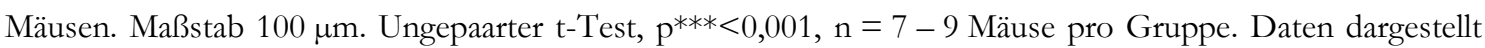
als Mittelwert \pm SEM. 
Ein signifikanter Behandlungseffekt zeigte sich in männlichen CBD-behandelten 5XFADMäusen durch die erhöhte Konzentration von GFAP im Hippocampus (ungepaarter tTest, $\mathrm{p}=0,0134$, Abbildung 35 A). Im Cortex ähnelte sich die Expression von GFAP in beiden Gruppen (ungepaarter t-Test, Abbildung 35 B).

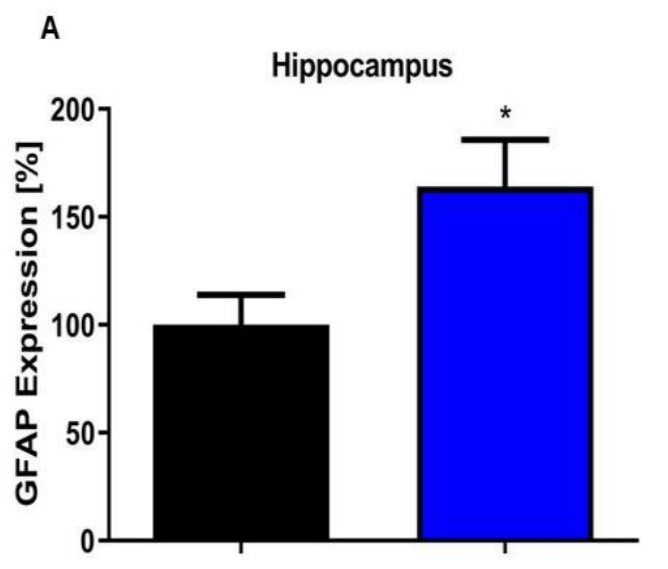

C

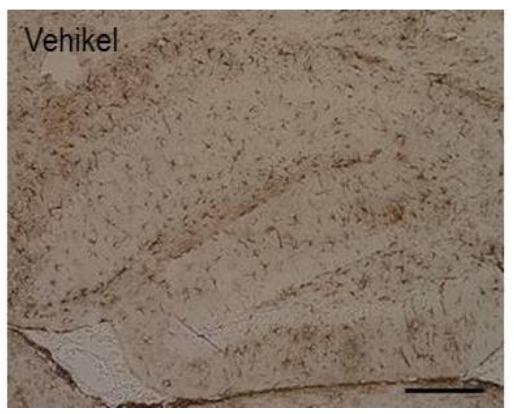

B
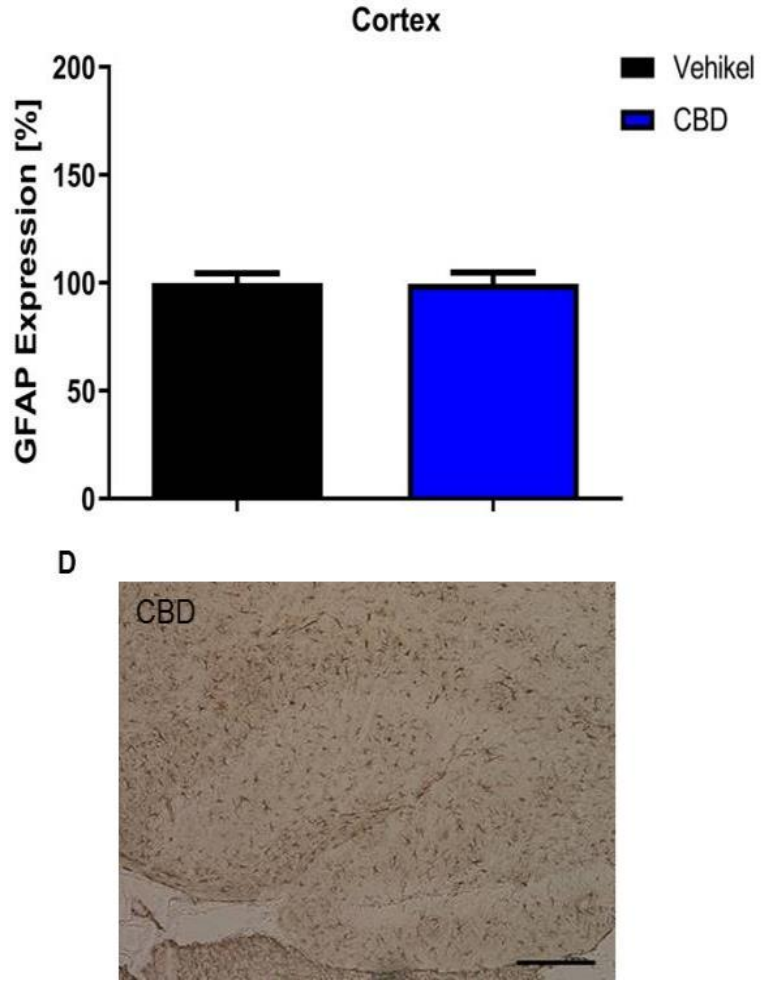

Abbildung 35: Gesteigerte Expression des Astrozytenmarkers GFAP im Hippocampus von männlichen 5XFAD-Mäusen nach CBD-Behandlung GFAP wurde im Hippocampus von CBDbehandelten 5XFAD Mäusen signifikant höher exprimiert (A), im Cortex blieb die Expression unverändert (B). Beispielbilder der Färbung von GFAP im Hippocampus von männlichen vehikelbehandelten (C) und CBD-behandelten (D) 5XFAD-Mäusen. Maßstab $200 \mu \mathrm{m}$. Ungepaarter t-Test, $\mathrm{p}^{*}<0,05, \mathrm{n}=7-9$ Mäuse pro Gruppe. Daten dargestellt als Mittelwert \pm SEM. 


\subsubsection{Auswirkungen von THC und CBD auf die Expression des Mikrogliamarkers} IBA1 in 5XFAD-Mäusen

Im Cortex von weiblichen THC-behandelten 5XFAD-Mäusen zeigte sich eine signifikante Reduktion des Mikrogliamarkers IBA1 im Sinne einer Abnahme der reaktiven Mikrogliose im Vergleich zur Kontrollgruppe (ungepaarter t-Test, $p=0,0069$, Abbildung 36 B - D), die jedoch nicht im Hippocampus detektiert wurde (ungepaarter t-Test, Abbildung 36 A).

A

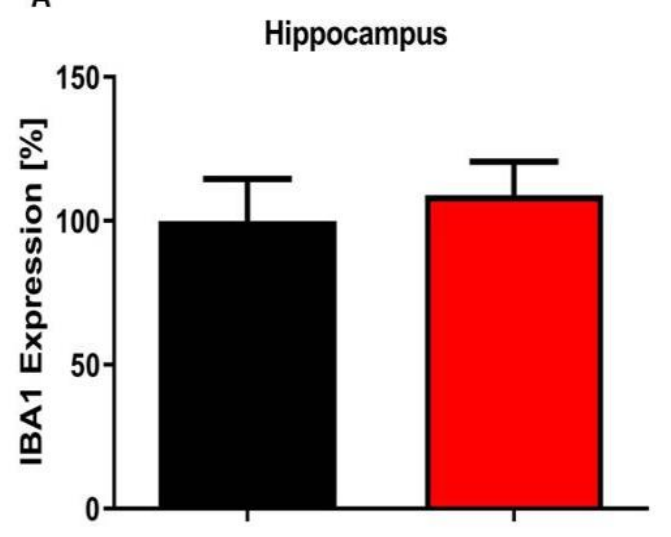

C

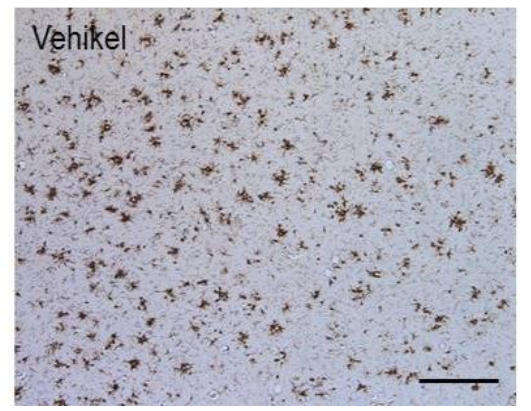

B

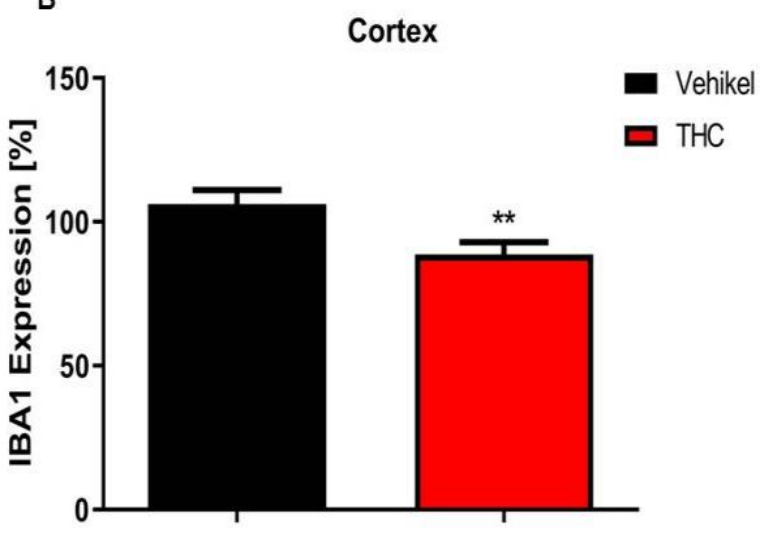

D

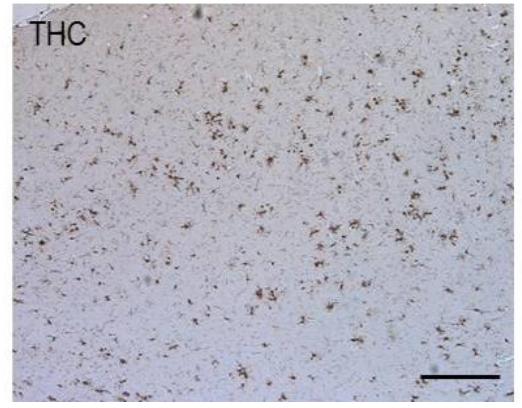

Abbildung 36: Verringerte Expression von IBA1 im Cortex von weiblichen 5XFAD-Mäusen nach THC-Behandlung Unveränderte Expression von IBA1 im Hippocampus (A), jedoch zeigte sich eine verringerte Expression im Cortex von THC-behandelten 5XFAD-Mäusen im Vergleich zur vehikelbehandelten Kontrollgruppe (B). Beispielbilder der Färbung von IBA1 im Cortex von vehikelbehandelten (C) und THC-behandelten (D) 5XFAD-Mäusen. Maßstab $100 \mu \mathrm{m}$. Ungepaarter t-Test, $\mathrm{p}^{* *}<0,01, \mathrm{n}=7-9$ Mäuse pro Gruppe. Daten dargestellt als Mittelwert \pm SEM. 
Gegenteilig verhielt sich die CBD-behandelte männliche Gruppe im Vergleich zu ihren vehikelbehandelten Artgenossen. Hier zeigte sich eine reduzierte reaktive Mikrogliose durch eine signifikante Reduktion der IBA1 Expression im Hippocampus (ungepaarter tTest, $\mathrm{p}=0,0012$, Abbildung 37 A, C und D), aber nicht im Cortex (ungepaarter t-Test, Abbildung $37 \mathrm{~B})$.

A

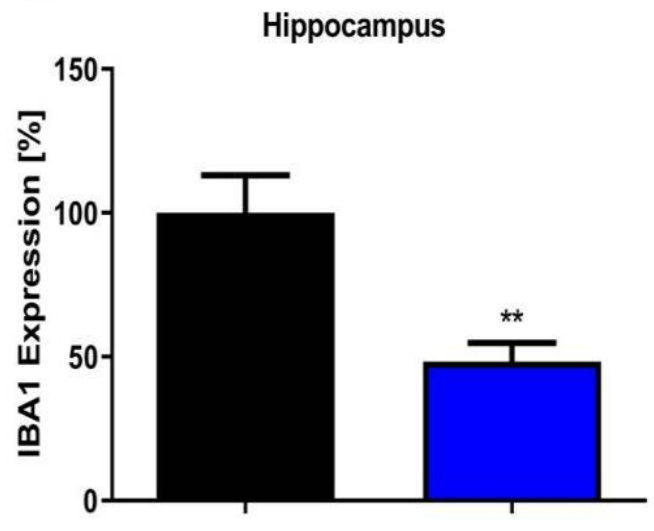

C

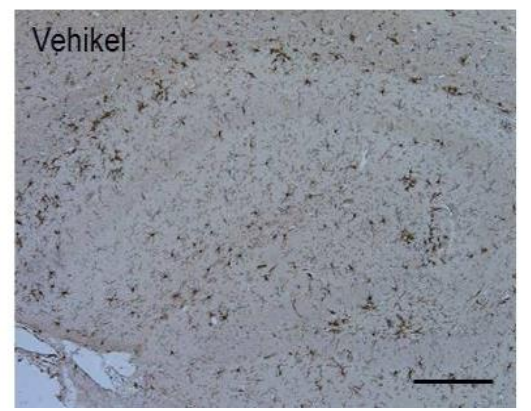

B

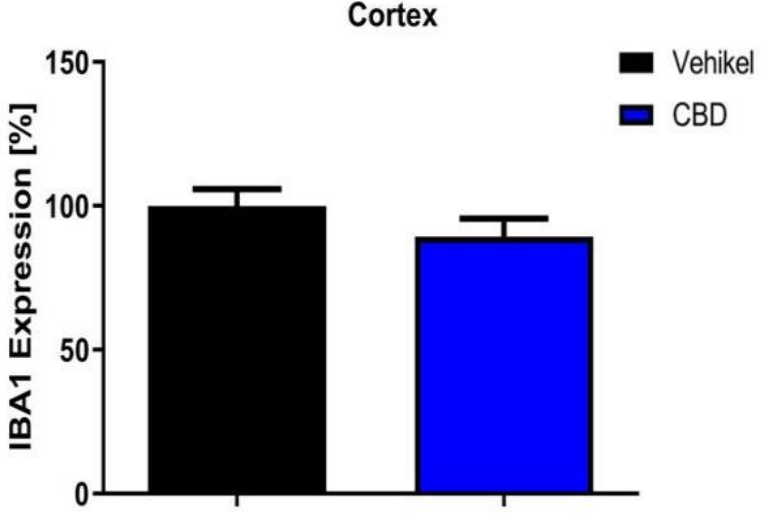

D

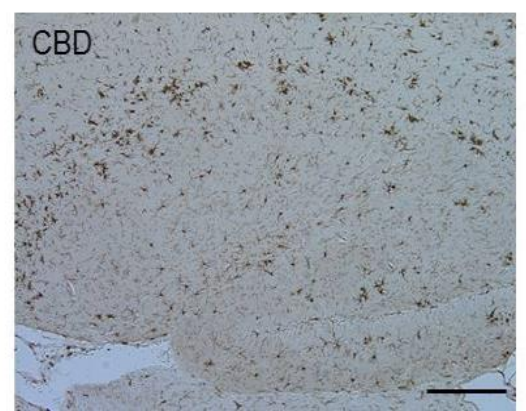

Abbildung 37: Verringerte Expression des Mikrogliamarkers IBA1 im Hippocampus von männlichen 5XFAD-Mäusen nach CBD-Behandlung Signifikanter Effekt von CBD auf die IBA1 Expression im Hippocampus (A), jedoch nicht im Cortex (B). Beispielbilder der Färbung von IBA1 im Hippocampus von männlichen vehikelbehandelten (C) und CBD-behandelten (D) 5XFAD-Mäusen. Maßstab

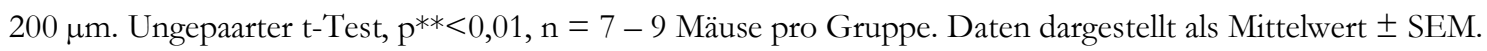




\subsubsection{Auswirkung von THC und CBD auf die Expression des CB1-Rezeptors in 5XFAD-Mäusen}

Mittels der CB1-Rezeptorexpression konnten Rückschlüsse gezogen werden, ob THC oder $\mathrm{CBD}$ an den Rezeptor gebunden werden. Es zeigte sich eine signifikante Reduktion der CB1-Rezeptorexpression bei weiblichen THC-behandelten 5XFAD-Mäusen sowohl im Hippocampus (ungepaarter t-Test, $\mathrm{p}<0,0001$, Abbildung 38 A, C und D) als auch im Cortex (ungepaarter t-Test, $\mathrm{p}<0,0001$, Abbildung 38 B).

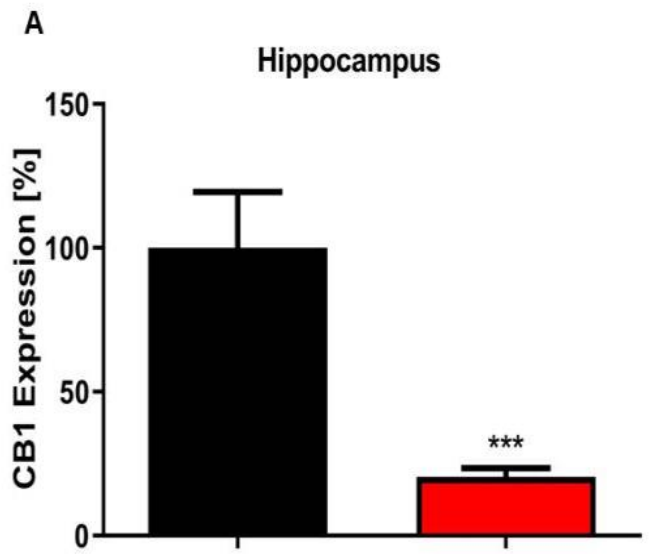

C

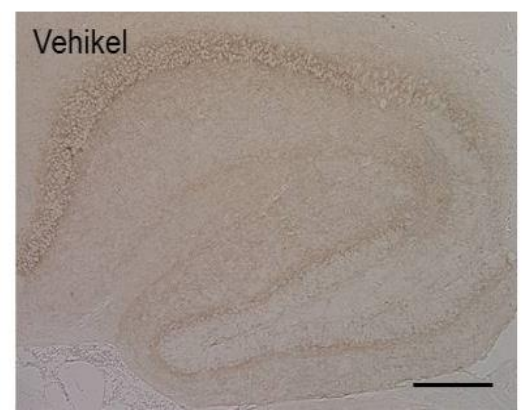

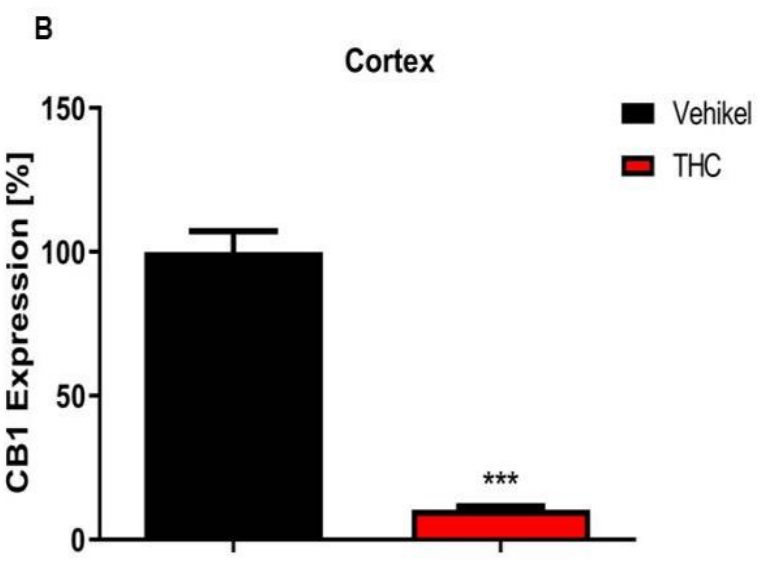

D

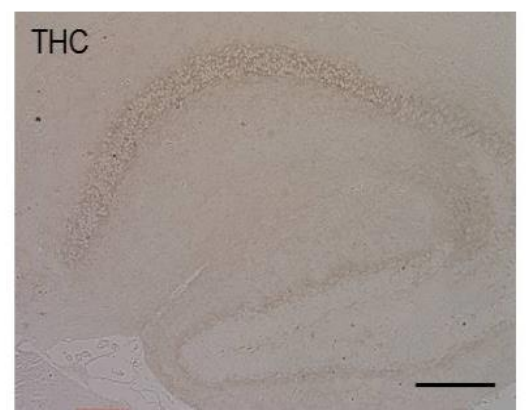

Abbildung 38: Signifikant geringere CB1-Rezeptorexpression nach THC-Behandlung von weiblichen 5XFAD-Mäusen Sowohl im Hippocampus (A) als auch im Cortex (B) von weiblichen THCbehandelten 5XFAD-Mäusen zeigte sich eine signifikant niedrigere Expression des CB1-Rezeptors. Beispielbilder der Färbung des CB1-Rezeptors im Hippocampus von weiblichen vehikelbehandelten (C) und

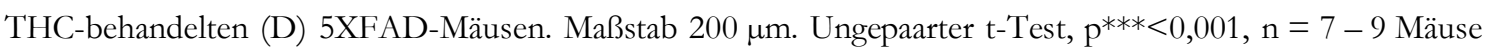
pro Gruppe. Daten dargestellt als Mittelwert \pm SEM. 
Hinsichtlich der Expression von CB1 in männlichen CBD-behandelten Mäusen zeigte sich kein signifikanter Unterschied im Hippocampus (ungepaarter t-Test, Abbildung 39 A) und Cortex (ungepaarter t-Test, Abbildung 39 B).

A

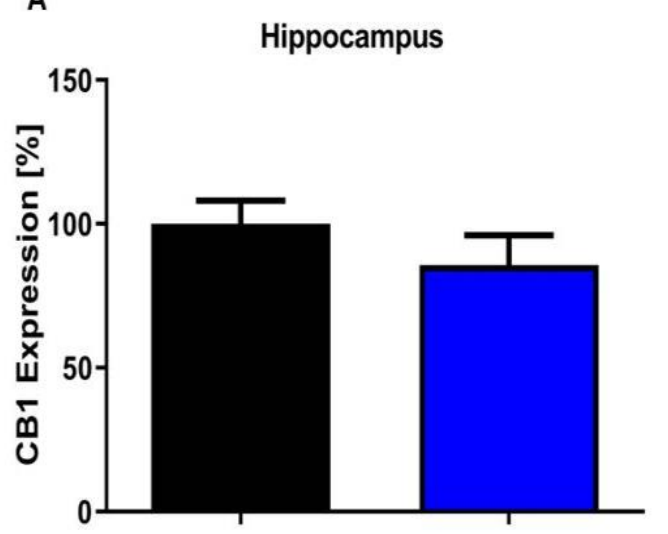

C

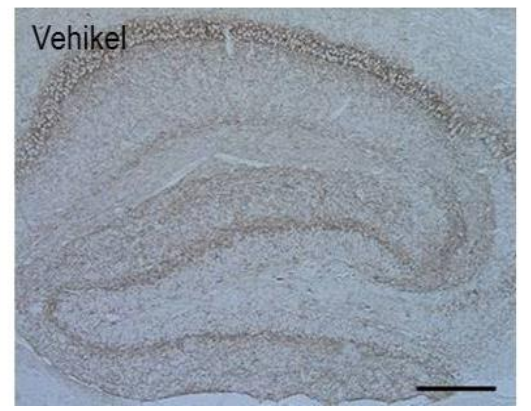

B

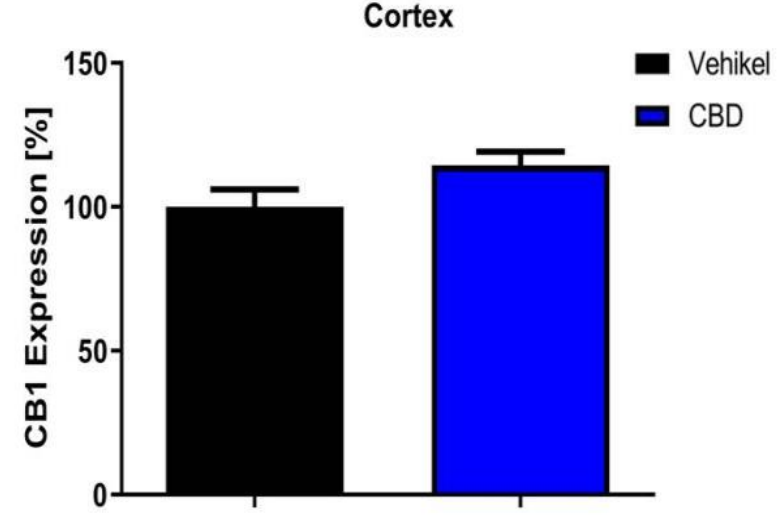

D

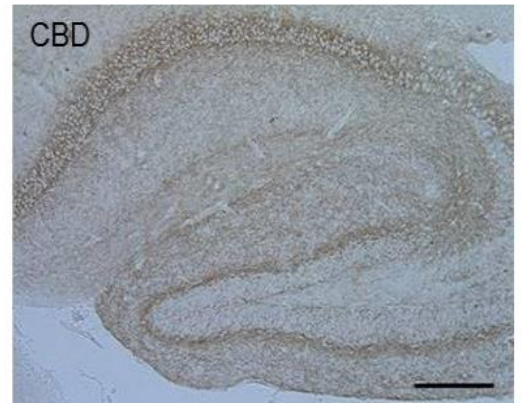

Abbildung 39: Unbeeinträchtigte CB1-Rezeptorexpression von männlichen 5XFAD-Mäusen nach CBD-Behandlung Weder im Hippocampus (A) noch im Cortex (B) zeigten CBD-behandelte 5XFAD Mäuse eine unterschiedliche Expression des CB1-Rezeptors im Vergleich zur vehikelbehandelten Kontrollgruppe. Beispielbilder der Färbung des CB1-Rezeptors im Cortex von männlichen vehikelbehandelten (C) und CBD-behandelten (D) 5XFAD-Mäusen. Maßstab $200 \mu \mathrm{m}$. Ungepaarter t-Test, $\mathrm{n}=7-9$ Mäuse pro Gruppe. Daten dargestellt als Mittelwert \pm SEM. 


\section{Diskussion}

Die Cannabisforschung ist eine junge Disziplin, deren Forschung bislang ein verbessertes Verständnis über das ECS brachte, welches jedoch in seiner Komplexität noch nicht vollständig erforscht ist. Medizinisches Cannabis wird aufgrund seiner Fähigkeit, das ECS $\mathrm{zu}$ modulieren, als aussichtsreiche Behandlungsmethode angesehen (Koppel und Davies 2008).

\subsubsection{Dosierung von Cannabinoiden}

Es sollte angemerkt werden, dass es derzeit eine inkonsistente Datenlage zur Behandlungsdosis von Cannabinoiden im Menschen gibt. Aufgrund von Ergebnissen weniger kontrollierter klinischen Studien erfolgte in zahlreichen Ländern wie Kanada, den USA und auch in einigen europäischen Ländern die Zulassung von medizinischem Cannabis ohne genaue Dosierungshinweise (Aguilar et al. 2018).

In Deutschland beträgt die aktuell zugelassene Verschreibungshöchstmenge $100 \mathrm{~g}$ Cannabis in Form von Blüten (unabhängig vom THC Gehalt) für 30 Tage. Tagesdosen schwanken abhängig von Nutzern in unterschiedlichen Ländern jedoch zwischen 0,2 - $3 \mathrm{~g}$ (Grotenhermen und Häußermann 2017). Für einen ca. $70 \mathrm{~kg}$ schweren Mann beträgt die maximale tägliche Dosis ca. $10 \mathrm{mg} / \mathrm{kg} \mathrm{KG}$. Verglichen mit der Dosierung in dieser Studie ist dies um ein Vielfaches weniger. Bezüglich der Dosis orientierten wir uns an in der Literatur beschriebenen Effekten der Dosis von $20 \mathrm{mg} / \mathrm{kg} \mathrm{KG}$ (Mechoulam und Parker 2013). Durch die intraperitoneale Gabe der Wirkstoffe wurde darauf geachtet, dass die Dosierung von $20 \mathrm{mg} / \mathrm{kg}$ KG genau eingehalten werden konnte. Die orale oder inhalative Aufnahme der Stoffe wäre zum einen geringer und zum anderen schlechter steuerbar (Grotenhermen und Müller-Vahl 2012).

Die letale Dosis 50 (LD50) für THC in der Maus, die in $50 \%$ der Fälle zum Tod führt, beträgt bei intravenöser Gabe $42 \mathrm{mg} / \mathrm{kg}$, bei oralem Konsum $482 \mathrm{mg} / \mathrm{kg}$ (Teuscher und Lindequist 1988). Der LD50-Wert beim Menschen lässt sich nicht verlässlich hochrechnen. Man geht jedoch davon aus, dass eine Überdosis von Cannabis oder THC, aufgrund der geringen CB1-Rezeptordichte im atmungs- und kreislaufregulierendem Hirnstamm, in gesunden Menschen nicht tödlich wirkt (Lu und Mackie 2016). Die LD50 nach intravenöser Applikation von CBD beträgt im Rhesus-Affen $212 \mathrm{mg} / \mathrm{kg}$. Der LD50-Wert nach oraler Aufnahme von CBD konnte aufgrund der geringen oralen Bioverfügbarkeit nicht bestimmt werden (Mechoulam et al. 2002). 


\subsubsection{Geschlechterunterschiede hinsichtlich des Endocannabinoidsystems und der Krankheitsentstehung von Morbus Alzheimer}

Möglichweise spielt die höhere Vulnerabilität weiblicher Gehirne, vor allem die des Hippocampus, eine entscheidende Rolle bei der Krankheitsentstehung des Morbus Alzheimer. Da das in dieser Arbeit verwendete 5XFAD-Mausmodell zu unterschiedlichen Zeitpunkten die alzheimertypische Pathologie ausbildete, wurde auf einen Vergleich zwischen männlichen und weiblichen Mäusen verzichtet und jeweils ein Geschlecht mit einer der beiden Substanz therapiert (Oakley et al. 2006; Maarouf et al. 2013). In einem fünftägigen Stresstest konnte ausschließlich in weiblichen 5XFAD-Mäusen eine gesteigerte Expression der Beta-Sekretase BACE1 ( $\beta$-site of APP cleaving ensyme) beobachtet werden. Ähnlich dazu verhielt sich auch der Anstieg von APP im Hippocampus weiblicher 5XFAD-Mäuse, der hingegen in männlichen 5XFAD-Mäusen ausblieb (Devi et al. 2010). Allerdings zeigten diverse Mausmodelle eine höhere Belastung mit Beta-Amyloid bei weiblichen als bei männlichen Mäusen. Es wurde ein schlechteres und dabei gleichzeitig früheres Auftreten von kognitiven Defiziten in weiblichen transgenen ( $\mathrm{Tg}$ ) Mäusen beobachtet im Vergleich zu männlichen transgen veränderten Mäusen. Dies wurde unter anderem für Mausmodelle, die das APP überexprimieren und unter der Kontrolle des Prion Protein Promotors $(\operatorname{PrP})$ stehen, erforscht. Es zeigte sich eine deutlich höhere Expression von APP in weiblichen Tg-Mäusen als in gleichalten männlichen Tg-Mäusen. Diese Geschlechterunterschiede verkomplizieren eine mögliche Interpretation und einen Vergleich von Therapien in solchen Mausmodellen (Melnikova et al. 2016).

Wichtig ist außerdem, dass man sich neben bereits diskutierten, allgemeinen Geschlechterunterschieden in der Krankheitsentstehung der Alzheimer-Krankheit auch mit dem Reifungsprozess des ECS im Alter auseinandersetzt. Dessen entscheidende Rolle konnte insbesondere pränatal und in der Pubertät gezeigt werden (Schneider et al. 2015). Allerdings ist bislang noch wenig über die Veränderungen des ECS im fortgeschrittenen Erwachsenenalter bekannt. Da bereits gezeigt werden konnte, dass Geschlechtshormone einen modulierenden Effekt auf Cannabinoide im Mausmodell hatten, vermuten verschiedene Forschungsgruppen eine unterschiedliche Sensitivität der Geschlechter gegenüber Cannabinoiden (Marusich et al. 2015). Insbesondere weibliche Tiere sind sensitiver für die Effekte von THC als männliche (Craft et al. 2012; Marusich et al. 2014).

\subsubsection{Auswirkungen von THC und CBD auf die CB1-Rezeptorexpression von 5XFAD-Mäusen}

Die Analyse von Obduktionsproben der an Morbus Alzheimer erkrankten Menschen ergab einige Änderungen der ECS-Zusammensetzungen und der Signalübertragung in Alzheimergehimen. Die ursächliche Pathophysiologie bleibt abschließend noch zu erforschen. Vor allem die Veränderung am CB1-Rezeptor wird vielfältig diskutiert. Während einige Forschungsgruppen eine signifikante Reduktion des CB1-Levels in 
kortikalen Strukturen unabhängig von senilen Plaques beschrieben (Ramírez et al. 2005; Solas et al. 2013), zweifelten andere Forschende Expression, Verteilung und Verfügbarkeit des CB1-Rezeptors gänzlich an (Benito et al. 2003; Lee et al. 2010; Mulder et al. 2011; Ahmad et al. 2014). Wieder andere konnten die Veränderungen in Alzheimergehirnen nicht von denen des normalen Alters trennen (Westlake et al. 1994). Eine Korrelation zwischen CB1-Rezeptor und molekularen Markern der Alzheimer-Krankheit wurde bislang nicht gefunden (Solas et al. 2013). Im Gegensatz dazu gibt es keine Kontroverse in Bezug auf die signifikante Erhöhung der CB2-Expression in Alzheimergehirnen, die hauptsächlich mit Rezeptoren auf Mikrogliazellen korrespondiert, die von senilen Plaques umgeben sind (Ramírez et al. 2005; Solas et al. 2013).

Die beschriebenen Unklarheiten bezüglich der Änderungen des ECS in Alzheimergehirnen ergeben sich einerseits durch eine geringere Rezeptorexpressionsdichte des CB2-Rezeptors und andererseits durch die Verwendung unspezifischer Antikörper (Atwood und Mackie 2010; Zhang et al. 2014; Stempel et al. 2016). Aufgrund dieser Problematik wurde die durchgeführte Färbung des CB2-Rezeptors in dieser Arbeit nicht gezeigt und sich auf den weitläufig zentralnervös vorkommenden CB1-Rezeptor konzentriert.

Studien der letzten Jahre zeigen, dass die Expression des CB1-Rezeptors nach längerem THC-Konsum heruntergeregelt wird. Vermutlich dient diese Adaptation einer Toleranzentwicklung gegenüber der Substanz und den daraus resultierenden Verhaltenseffekten (Sim-Selley 2003). Beobachten kann man außerdem einen Geschlechtereffekt hinsichtlich der Herabregulation der CB1-Rezeptorexpression. Bereits nach einer einwöchigen, täglich durchgeführten intraperitonealen Injektion von $30 \mathrm{mg} / \mathrm{kg} \mathrm{KG}$ THC zeigten weibliche Ratten eine stärkere Herabregulation der Rezeptorexpression als die männliche Vergleichsgruppe (Farquhar et al. 2019). Andere Studien zweifelten diesen Geschlechtereffekt der CB1-Expression an (Silva et al. 2016), diskutierten jedoch ein stärkeres Abhängigkeitsverhalten nach THC-Konsum bei weiblichen als bei männlichen Ratten (Marusich et al. 2014). Erwähnenswert ist, dass auch in menschlichen Gehirnen die Expression des CB1-Rezeptors nach chronischem Cannabiskonsum herunterreguliert wird. Dies wird insbesondere auf den Effekt von THC und dessen höhere Affinität zum CB1-Rezeptor zurückgeführt (Weinstein et al. 2017).

Im Einklang mit diesen Beobachtungen konnte in dieser Arbeit gezeigt werden, dass weibliche THC-behandelte 5XFAD-Mäuse eine signifikante Reduktion der CB1Rezeptorexpression im Hippocampus und im Cortex aufweisen. Aufgrund der bereits beschriebenen geringen Affinität von CBD zum CB1-Rezeptor zeigten sich keine Veränderungen hinsichtlich der CB1-Rezeptorexpression in den männlichen CBDbehandelten 5XFAD-Mäusen. 


\subsection{Auswirkungen von THC und CBD auf das Verhalten von 5XFAD-Mäusen}

\subsubsection{Auswirkungen von THC und CBD auf das Gewicht von 5XFAD-Mäusen}

Beim Einsatz von Cannabinoiden wurden schon in der früheren Medizin Heißhunger und Essattacken beobachtet und dokumentiert (Mechoulam und Hanuš 2001). Insbesondere bei auszehrenden Krankheiten, wie zum Beispiel bei HIV/AIDS oder Krebserkrankungen, hat man sich diesen Effekt zunutze gemacht (Mücke et al. 2016). Bei an Alzheimer erkrankten Personen kommt es neben kognitiven Funktionseinschränkungen und Verhaltensauffälligkeiten in bis zu $40 \%$ der Fälle auch zu einer Gewichtsreduktion durch ein gestörtes Essverhalten.

THC ist der Wirkstoff von Cannabis, dem ein größerer Einfluss auf den Appetit zugesprochen wird (Fride et al. 2004). In Knockout-Mäusen, deren Expression des CB1Rezeptors gezielt ausgeschaltet wurde, konnte gezeigt werden, dass diese im Gegensatz zu deren gesunden Geschwistern weniger aßen, sodass von einer CB1-Rezeptorvermittelten gesteigerten Nahrungsaufnahme, der so genannten Hyperphagie, ausgegangen wird (Di Marzo et al. 2001). Patientinnen und Patienten, die an Morbus Alzheimer erkrankten und Essen verweigerten, wurden sechs Wochen mit THC auf Ölbasis (Dronabinol) behandelt, sodass eine signifikante Steigerung des Gewichts registriert werden konnte (Volicer et al. 1997). Gegensätzlich dazu konnte in der Pilotstudie von Shelef et al. (2016) nach einer vierwöchigen THC-Gabe von maximal 7,5 mg zweimal täglich kein Effekt auf das Gewicht von Alzheimer-Erkrankten beobachtet werden. Dies könnte zum Beispiel auf der Tatsache beruhen, dass sich bei normalgewichtigen Personen in einigen Fällen kein stimulierender Effekt der Cannabinoide zeigte (Haney et al. 2005).

Ein appetithemmender Effekt von CBD wurde nach einer Dosis von 4,4 mg/kg KG bei Ratten beobachtet (Farrimond et al. 2012). Auch unabhängig von der Dosierung (3$100 \mathrm{mg} / \mathrm{kg} \mathrm{KG}$ ) konnte in CBD-behandelten gesunden Mäusen keine Gewichtszunahme beobachtet werden (Bergamaschi et al. 2011). Obwohl sich kein Effekt von CBD auf den Appetit von Ratten zeigte, verhinderte eine Dosis von $20 \mathrm{mg} / \mathrm{kg} \mathrm{KG} \mathrm{CBD} \mathrm{eine}$ Hyperphagie der Ratten, die zuvor mit CB1-Agonisten behandelt wurden (Scopinho et al. 2011).

Weibliche THC- und männliche CBD-behandelte 5XFAD-Mäuse zeigten in der vorgelegten Arbeit während der gesamten Behandlungsdauer ein konstantes Gewicht, was dem Gewicht von gesunden WT-Mäusen entsprach. 


\subsubsection{Auswirkungen von THC und CBD auf motorische Fähigkeiten von 5XFAD- Mäusen}

Neben kognitiven Defiziten und Gedächtnisstörungen werden motorische Einschränkungen ebenfalls mit der Alzheimer-Krankheit assoziiert. Diese äußern sich unter anderem in Gleichgewichtsstörungen sowie Gang- und Haltungsstörungen (O'Keefe et al. 1996; Pettersson et al. 2002; Gras et al. 2015). Diskutiert wird außerdem ein Zusammenhang zwischen motorischen Einschränkungen und der rascheren Entwicklung von Symptomen (Larson et al. 2006; Buchman und Bennett 2014). Im Einklang damit konnte beobachtet werden, dass regelmäßige körperliche Aktivität eine Progression der Krankheit im präklinischen Stadium sogar verzögern kann (Larson et al. 2006). Dies demonstriert die Wichtigkeit, Mausmodelle hinsichtlich motorischer Störungen zu untersuchen.

Das Gewicht kann einen bedeutenden Einfluss auf die Ergebnisse von motorischen Tests haben und sollte deshalb als wichtiger Faktor in die Analyse der motorischen Tests der Mäuse integriert werden. Da sich bei den in dieser Arbeit untersuchten 5XFAD-Mäusen jedoch ein konstantes Gewicht zeigte, wird dessen Einfluss in dieser Arbeit dementsprechend ausgeschlossen.

Ähnlich zu Alzheimer-Patientinnen und -Patienten, zeigen Mausmodelle erst im weiteren Krankheitsprogress motorische Störungen. Kürzlich konnten wir zeigen, dass 5XFADMäuse altersabhängig ein Clasping-Verhalten aufweisen (Wagner et al. 2019). Interessanterweise konnten funktionelle und strukturelle Störungen im Sinne einer Axonopathie in 5XFAD-Mäusen beobachtet werden (Wirths und Bayer 2008; Jawhar et al. 2012).

Männliche CBD-behandelte 5XFAD-Mäuse zeigten in der hier vorliegenden Arbeit im Vergleich mit der vehikelbehandelten Kontrollgruppe ein signifikant reduziertes ClaspingVerhalten. Dies könnte am antiinflammatorischen Effekt von CBD auf eine axonale Neurodegeneration liegen. Weitere Forschung ist für die Überprüfung dieses Zusammenhangs jedoch noch erforderlich. Das motorische Lernen von CBD-behandelten 5XFAD-Mäusen im Rotarod blieb unbeeinträchtigt. Dies stand im Einklang mit den Beobachtungen, dass CBD in unterschiedlichen Konzentrationen (1-, 15-, 30- und $50 \mathrm{mg} / \mathrm{kg} \mathrm{KG}$ ) weder Einfluss auf die motorische Aktivität gesunder Mäuse hatte noch Entzugssymptome hervorrief (Viudez-Martínez et al. 2019). Ein intaktes motorisches Lernen nach einer sechswöchigen Behandlung mit $20 \mathrm{mg} / \mathrm{kg} \mathrm{KG} \mathrm{CBD} \mathrm{konnten} \mathrm{wir} \mathrm{bereits}$ bei gesunden C57BL/6J-Mäusen nachweisen (Schleicher et al. 2019).

Die Behandlung mit THC ließ das Clasping-Verhalten der weiblichen 5XFAD-Mäuse unbeeinträchtigt. Ebenfalls unbeeinträchtigt von einer Behandlung mit THC blieb auch die motorische Ausdauer, Koordination und das Lernverhalten der weiblichen 5XFAD-Mäuse im Rotarod-Test. Untersuchte man die motorische Aktivität von C57BL/6J-Mäusen im eigenen Käfig, zeigte sich nach direkter THC-Einnahme eine signifikante Abnahme der 
motorischen Aktivität (Smoker et al. 2019). Da sich jedoch vor allem in Angsttests eine signifikant geringer zurückgelegte Distanz zeigte, sollte dies unbedingt im Zusammenhang mit einer gesteigerten Ängstlichkeit interpretiert werden (Ennaceur 2014; Lutz et al. 2015). Dieser Effekt wird im Einklang mit anderen Studien ausführlich in Absatz 4.2.4 diskutiert.

\subsubsection{Auswirkungen von THC und CBD auf das Lernverhalten von 5XFAD- Mäusen}

Kognitive Störungen gehören zu den Leitsymptomen der Alzheimer-Krankheit und führen bei Erkrankten zu erheblichen Beeinträchtigungen der Lebensqualität (Millan et al. 2012). Durch die Vermittlung kognitiver Prozesse spielt das ECS eine wichtige Rolle (Katona und Freund 2012). Des Weiteren findet sich eine hohe Dichte an CB1-Rezeptoren in Gehirnregionen, die maßgeblich an der Gedächtnis- und Lernleistung beteiligt sind. Diese sind zum Beispiel der Cortex und der Hippocampus (Kano et al. 2009; Lu und Mackie 2016). Diese Befunde belegen das Potential pflanzlicher Cannabinoide, insbesondere THC, durch eine Modulation des ECS kognitive Verhaltensänderungen hervorrufen zu können (Kano et al. 2009). Mittels etablierter tierexperimenteller Verhaltenstests wie dem MWM, dem NOR-Test und dem Cross Maze konnte der Einfluss von THC oder CBD auf das Lernverhalten von 5XFAD-Mäusen evaluiert werden. Die Datenlage zu Einflüssen von THC oder CBD auf die Alzheimer-Pathologie hinsichtlich einer verbesserten Kognition ist als gering und durchaus heterogen einzustufen.

Im Acquisition Training zeigte sich in weiblichen 5XFAD-Mäusen nach THC-Behandlung kein signifikanter Behandlungseffekt. Interessanterweise erzielten weibliche THCbehandelte 5XFAD-Mäuse insbesondere im Probe Trial bessere Ergebnisse als die vehikelbehandelte Kontrollgruppe und offenbarten damit ein intaktes räumliches Bezugsgedächtnis. Motorische Defizite als Erklärung für diese Ergebnisse ließen sich vor dem Hintergrund der oben beschriebenen unauffälligen Motoriktests sowie einer normalen Performance im Cued Training sowie im Acquisition Training ausschließen. Insgesamt ließ sich ein positiver Einfluss von THC auf die Gedächtnisleistung im MWM evaluieren.

Der Einfluss von THC auf die Gedächtnisleistung scheint von diversen Faktoren abzuhängen. Dazu zählen zum einen eine veränderte strukturelle Hirnpathologie, wie zum Beispiel bei der Alzheimer-Krankheit, und zum anderen das Lebensalter. In humanen Studien sollte zukünftig auch die bisherige Cannabisvorerfahrung beachtet werden.

Forschende der Universität Bonn berichteten über eine verbesserte Gedächtnisleistung zwölf Monate alter C57BL/6J-Mäuse durch eine vierwöchige tägliche Applikation von $3 \mathrm{mg} / \mathrm{kg}$ KG THC im MWM im Vergleich zu unbehandelten Tieren gleichen Alters (Bilkei-Gorzo et al. 2017). Die Leistung der behandelten Tiere entsprach unbehandelten Jungtieren. Zweimonatige Jungtiere, die die gleiche Dosis THC erhielten, verhielten sich jedoch wie zwölf Monate alte unbehandelte Tiere im Sinne eines signifikant schlechteren räumlichen Gedächtnisses im MWM. Dies steht im Einklang mit bekannten schädlichen 
Effekten von THC auf die Kognition junger Menschen, die Cannabis konsumierten (Schneider et al. 2015). In einer Pilotstudie, in der chronische Cannabiskonsumenten mit Nicht-Konsumenten in einem virtuellen MWM verglichen wurden, konnte die Tendenz beobachtet werden, dass die konsumierenden Studienteilnehmern deutlich größere Umwege für den Weg zur Plattform zurücklegten und außerdem eine verlängerte Reaktionszeit bis zum ersten virtuellen Losschwimmen aufwiesen. Dies wurde als geringere Gedächtnisleistung der Cannabiskonsumenten gewertet (Sneider et al. 2013).

Interessanterweise ist der Effekt auf das räumliche Gedächtnis von Mäusen nach intraperitonealer Behandlung mit synthetischen, reinen THC im Vergleich zu THC-haltigen Extrakten im MWM deutlicher ausgeprägt (Fadda et al. 2004; Riedel et al. 2009). Trotz einer unbeeinträchtigten Schwimmgeschwindigkeit zeigten sich bei Ratten mit zunehmender Dosis von 0,5-, 2- oder $5 \mathrm{mg} / \mathrm{kg} \mathrm{KG} \mathrm{THC} \mathrm{kompliziertere} \mathrm{und} \mathrm{längere}$ Schwimmwege bis zum Erreichen der Plattform (Fadda et al. 2004). Eine Vortherapie mit dem CB1-Rezeptor Antagonist SR 141716A konnte die durch THC induzierten kognitiven Defizite im MWM verhindern, weshalb eine CB1-Rezeptorbeteiligung in Hirnstrukturen, die an der Gedächtnisbildung beteiligt sind, diskutiert werden sollte (Da Silva und Takahashi 2002).

Weibliche THC-behandelte 5XFAD-Mäuse zeigten im NOR-Test keine signifikante Präferenz gegenüber dem neuen Objekt und damit keinen Behandlungseffekt von THC auf das Lernverhalten und die Objektdifferenzierung. In elfmonatigen Tg-APP-Alzheimer Mäusen zeigte eine niedrigdosierte Behandlung mit 0,2 mg/kg KG THC über vier Monate keinen Effekt hinsichtlich eines Rückgangs kognitiver Defizite im NOR-Test (MartínMoreno et al. 2012). Auch Dosen von $2-5 \mathrm{mg} / \mathrm{kg} \mathrm{KG}$ konnten per se keinen gedächtnismodifizierenden Effekt im NOR-Test bei Ratten auslösen (Ciccocioppo et al. 2002). In Nrg-1-HET-Mäusen, einem Mausmodell für Schizophrenie, steigerten weder $5 \mathrm{mg} / \mathrm{kg} \mathrm{KG}$ noch $10 \mathrm{mg} / \mathrm{kg} \mathrm{KG} \mathrm{THC} \mathrm{die} \mathrm{Gedächtnisleistung} \mathrm{der} \mathrm{Tiere} \mathrm{(Long} \mathrm{et} \mathrm{al.}$ 2010b). In C57BL/6J-Mäusen konnte kürzlich gezeigt werden, dass eine direkte intraperitoneale Injektion von THC keinen Einfluss auf das Verhalten im NOR-Test hatte (Kasten et al. 2017). Lediglich in CD-1-Mäusen verbesserte sich nach einer siebentägigen Injektion von $10 \mathrm{mg} / \mathrm{kg} \mathrm{KG}$ THC eine Objektdiskriminierung (Barbieri et al. 2016; Busquets-Garcia et al. 2018b).

Hinsichtlich des Arbeitsgedächtnisses der weiblichen THC-behandelten 5XFAD-Mäuse ergab sich im Cross Maze kein Behandlungseffekt. Jedoch konnte eine signifikant verringerte zurückgelegte Distanz bei THC-behandelten 5XFAD-Mäusen beobachtet werden. Dieser Effekt zeigte sich bereits in diversen Studien, in denen THC eine Hypoaktivität in Nagetieren induzierte (Taffe et al. 2015; Todd und Arnold 2016). Veränderte motorische Aktivitäten müssen nicht nur hinsichtlich des Lernverhaltens bewertet, sondern auch in der Interpretation von Angstverhalten (Absatz 4.2.4) betrachtet werden (Brooks et al. 2012; Deacon 2013). 
Das räumliche Gedächtnis von männlichen 5XFAD-Mäusen blieb von einer Behandlung mit CBD unbeeinträchtigt, indem sich weder im fünftägigen Acquisition Training noch im Probe Trial ein signifikanter Behandlungseffekt zwischen den beiden Gruppen zeigte.

Diese Beobachtungen stehen im Einklang mit den Ergebnissen von Fadda et al. (2004), die ein intaktes und somit unbeeinflusstes räumliches Lernen in CBD-behandelten Ratten im MWM fanden. Sogar bei einer Dosis von bis zu $50 \mathrm{mg} / \mathrm{kg} \mathrm{KG}$ konnte kein Effekt beobachtet werden. Interessanterweise konnte bei Mäusen, denen fibrilläres Beta-Amyloid in das Ventrikelsystem des Gehirns injiziert wurde, positive Effekte einer Behandlung mit $20 \mathrm{mg} / \mathrm{kg} \mathrm{KG} \mathrm{CBD}$ auf das räumliche Lernen beschrieben werden (Martín-Moreno et al. 2011).

Männliche CBD-behandelte 5XFAD-Mäuse zeigten ebenso wie die vehikelbehandelte Kontrollgruppe eine klare Präferenz für das neue Objekt im NOR-Test. Dies steht im Einklang mit den Ergebnissen im MWM hinsichtlich eines intakten Lernverhaltens. Interessanterweise deuten Studien darauf hin, dass CBD bei Hirnschäden verlorene Gedächtnisleistung wiederherstellen konnte. Dieser Effekt fand sich unter anderem im NOR-Test bei Mäusen, die mit MK-801 behandelt wurden, um Schizophrenie auszulösen (Gomes et al. 2013), in Ratten, denen während der neonatal Periode ein Überschuss an Eisen verabreicht wurde (Fagherazzi et al. 2012) und in dem transgen veränderten Alzheimer Mausmodell APPswe/PS1E9 (Cheng et al. 2014a). Letztere Studie beobachtete des Weiteren einen Effekt der täglichen Injektion von $20 \mathrm{mg} / \mathrm{kg}$ KG CBD über einen Zeitraum von drei Wochen auf das Sozial- und Lernverhalten der 24 Wochen alten Alzheimer-Mäuse, deren Verlust des Sozial- und Lernverhaltens durch die Behandlung wiederhergestellt werden konnte. Dieser günstige Effekt konnte jedoch nicht in Zusammenhang mit einer Reduktion von Amyloid-Plaques oder einem Schutz vor oxidativen Schäden gebracht werden (Cheng et al. 2014b). Die Behandlung von APPswe/PS1E9-Mäusen mit einer Dosis von $50 \mathrm{mg} / \mathrm{kg} \mathrm{KG} \mathrm{CBD} \mathrm{konnte} \mathrm{die} \mathrm{oben}$ genannten Ergebnisse hinsichtlich eines gebesserten Sozial- und Lernverhaltens reproduzieren und ergab eine moderate Reduktion von unlöslichem A $\beta 40$ im Hippocampus (Watt et al. 2020).

Das mithilfe vom Cross Maze untersuchte Arbeitsgedächtnis von THC- oder CBDbehandelten 5XFAD-Mäusen im Vergleich zu der jeweiligen vehikelbehandelten Kontrollgruppe blieb von der Behandlung unbeeinflusst. Andere Versuchsanordnungen wie zum Beispiel das Y-Maze, bestehend aus drei Armen oder das Radial Maze, einem achtarmigen Versuchsaufbau, prüfen ähnlich wie das Cross Maze das Arbeitsgedächtnis von Nagetieren. Eine dreiwöchigen Behandlung mit 1-, 5-, 10- oder 50 mg/kg KG CBD hatte keinen Effekt auf das Arbeitsgedächtnis von C57BL/6J-Mäusen im Y-Maze (Long et al. 2010a). Außerdem konnte bereits in den 1990er Jahren ein Einfluss von CBD auf das Gedächtnis von Ratten im Radial Maze ausgeschlossen werden (Lichtman et al. 1995). Diese Ergebnisse, kombiniert mit der Beobachtung in der vorgelegten Arbeit, dass CBD 
keinen Effekt auf das Lernverhalten im MWM hatte, lässt folgern, dass eine Behandlung von männlichen 5XFAD-Mäusen mit CBD keine Gedächtnisstörung hervorruft und das Lernverhalten der Tiere unbeeinflusst lässt. Eine CBD-Behandlung von gesunden C57BL/6J-Mäusen führte zum gleichen Ergebnis (Schleicher et al. 2019).

\subsubsection{Auswirkungen von THC und CBD auf das Angstverhalten von 5XFAD- Mäusen}

Eine Vielzahl pharmakologischer und genetischer Studien unterstützt die Rolle des ECS als wichtigen Regulator von Angstverhalten (Graham et al. 2011; Mechoulam und Parker 2013). Es gilt unter anderem auch als regulatorisches Puffersystem für induzierte stressige und emotionale Extremsituationen. Dies soll durch die Plastizität des CB1-Rezeptors möglich sein (Ruehle et al. 2012). In den in der vorliegenden Arbeit durchgeführten Angsttests beobachteten wir eine eindeutigere Wirkung von THC auf das Angstverhalten. Dies könnte sich durch die stärkere Bindungsaffinität von THC für den CB1-Rezeptor erklären.

An Morbus Alzheimer erkrankte Patientinnen und Patienten zeigen im Verlauf der Krankheit oft ein veränderteres Angstverhalten hinsichtlich einer Angstzunahme. Da jedoch die Fähigkeit Risikofaktoren adäquat einzuschätzen abnimmt, wird dies paradoxerweise als Abnahme der Ängstlichkeit interpretiert. Diskutiert wird derzeit, ob eine neu aufgetretene Angsterkrankung im höheren Alter Vorbote einer AlzheimerKrankheit sein könnte. Mit der Zunahme von Angstsymptomen konnte in einer kürzlich veröffentlichten Studie eine Zunahme von Beta-Amyloid mithilfe der PET gezeigt werden (Donovan et al. 2017; Biddle et al. 2020).

Ein Vergleich von gesunden WT-Mäusen mit 5XFAD-Mäusen bestätigte eine geringere Ängstlichkeit von 5XFAD-Mäusen im EPM. Nach Behandlung mit THC normalisierte sich das Angstniveau von 5XFAD-Mäusen nahezu auf das Niveau gesunder WT-Tiere. Dieser Effekt konnte in der vorliegenden Arbeit erstmals empirisch belegt werden. Ein angstverstärkender Effekt von THC ließ sich in behandelten WT-Mäusen im Vergleich mit vehikelbehandelten WT-Mäusen beobachten (Daten nicht gezeigt).

CB1-Rezeptor Agonisten zeigen einen bivalenten Effekt. So haben geringe Dosen einen anxiolytischen Effekt, während höhere Dosen eher angstfördernd wirken (Viveros et al. 2005). Mit steigender Dosis des intraperitoneal verabreichten THC (1-, 5-, und $10 \mathrm{mg} / \mathrm{kg} \mathrm{KG}$ ) verbrachten C57BL/6J-Mäuse signifikant weniger Zeit in den offenen Armen des EPM und demonstrierten damit einen ängstlicheren Phänotyp (Kasten et al. 2019).

Während es naheliegen würde, dass die Ergebnisse des EPM und des Open Fields konsistent wären, wies eine durchgeführte Metaanalyse von Mohammad et al. (2016) darauf hin, dass die beiden Tests nicht zuverlässig hinsichtlich ihrer Aussagekraft übereinstimmen. Dies lässt eine Interpretation der Ergebnisse nur einzeln zu. Insbesondere das Open Field 
weist eine hohe Variabilität hinsichtlich seiner Durchführung auf (Walsh und Cummins 1976). Dies führt zu einer erschwerten Vergleichbarkeit der Ergebnisse verschiedener Studien. Insgesamt wird im Open Field eher das Explorationsverhalten der Tiere geprüft, sodass ein geringerer Fokus auf der Evaluation des Angstverhaltens liegt. Eine gesteigerte Ängstlichkeit resultiert wahrscheinlich in verminderter Mobilität und außerdem der Präferenz, sich in der Peripherie aufzuhalten, als im Zentrum der Box im Open Field (Ennaceur 2014). Es konnte weder in der Dark/Light Box noch im Open Field ein Effekt von THC auf das Angstverhalten der weiblichen 5XFAD-Mäuse in der vorliegenden Arbeit beobachtet werden.

Neben diesen eindeutigen Ergebnissen, müssen auch körperliche Reaktionen der Angst beachtet werden: gesteigerte Herzfrequenz, Vermeidungsverhalten und verminderte Bewegungen (Lutz et al. 2015). Insbesondere Letzteres konnte in den durchgeführten Tests durch Messung der zurückgelegten Distanz im Versuchsaufbau evaluiert werden. So zeigten weibliche THC-behandelte 5XFAD-Mäuse eine signifikant geringere zurückgelegte Distanz im EPM als die vehikelbehandelte Kontrollgruppe. Dies steht im Einklang mit den Ergebnissen von Kasten et al. (2019), deren THC-behandelte C57BL/6J-Mäuse eine deutlich verminderte Mobilität im EPM präsentierten. Des Weiteren konnte in diversen Studien beobachtet werden, dass THC eine Hypoaktivität der Mäuse auslöste. Diese zeigte sich nach CBD Therapie progredient (Todd und Arnold 2016; Kasten et al. 2019).

Angststörungen gehören zu den häufigsten durch chronischen Cannabiskonsum hervorgerufenen Komplikationen, was die Validität der in der vorliegenden Arbeit produzierten Ergebnisse weiter unterstreicht (Kedzior und Laeber 2014). Die Datenlage hinsichtlich des Einflusses von THC auf das Angstverhalten von an Alzheimer erkrankten Personen ist gering. Bislang konnte ausschließlich ein sedierender Effekt von THC ohne Einfluss auf das Angstverhalten in Patientinnen und Patienten mit Morbus Alzheimer beschrieben werden (Ruthirakuhan et al. 2019). In Metaanalysen zeigte sich ein Zusammenhang von Cannabiskonsum mit der Ausbildung von Depressionen, erhöhter Suizidalität und Angststörungen (Lev-Ran et al. 2014; Feingold et al. 2016).

Ein angstlösender Effekt von CBD auf 5XFAD-Mäuse konnte weder im EPM noch in der Dark/Light Box oder im Open Field beobachtet werden. Diese Beobachtungen stehen im Einklang mit den Ergebnissen von C57BL/6J-Mäusen in oben genannten Verhaltenstests, die mit 5-, 10- oder $20 \mathrm{mg} / \mathrm{kg} \mathrm{KG} \mathrm{CBD} \mathrm{behandelt} \mathrm{wurden} \mathrm{(Kasten} \mathrm{et} \mathrm{al.} \mathrm{2019;} \mathrm{Schleicher}$ et al. 2019). Gegensätzlich dazu beobachteten Long et al. (2010b) einen angstlösenden Effekt nach einer dreiwöchigen Behandlung mit $50 \mathrm{mg} / \mathrm{kg} \mathrm{KG}$ in der Dark/Light Box. Nach einer Behandlung mit $1 \mathrm{mg} / \mathrm{kg} \mathrm{KG}$ konnte stattdessen eine längere Zeit, die die Mäuse im hellen Kompartiment der Dark/Light Box verbrachten, registriert werden, die als geringere Ängstlichkeit interpretiert werden konnte (Long et al. 2010b). Interessanterweise spielt neben der Dosisvarianz auch der Zeitpunkt einer Behandlung mit $\mathrm{CBD}$ eine Rolle. Eine Behandlung mit CBD bereits vor Beginn der Pubertät verhinderte 
die Entwicklung eines Schizophrenie-ähnlichen Phänotyps in Ratten (Stark et al. 2019). Bislang fehlen klinische Studien zur Evaluation des Angstverhaltens von AlzheimerErkrankten nach CBD-Behandlung.

\subsection{Auswirkungen von THC und CBD auf histopathologische Aspekte der Alzheimer-Krankheit in 5XFAD-Mäusen}

\subsubsection{Auswirkungen von THC und CBD auf die Plaque-Pathologie von 5XFAD- Mäusen}

In vitro Analysen von Alzheimer N2a/A_PPswe-Zellen zeigten eine signifikante Abnahme von Beta-Amyloid nach THC-Behandlung. Dieser durch THC ausgelöste ,anti-AbetaEffekt" blieb ohne Zeichen einer möglichen Zelltoxizität und suggerierte daher einen sicheren Umgang mit THC im Tiermodell (Cao et al. 2014). Zu beachten ist allerdings die im Vergleich mit unserer Studie um den Faktor 1000 verringerte THC-Dosis. Außerdem konnte bereits festgestellt werden, dass THC die Beta-Amyloid Aggregation verringert, indem es die AChE kompetetiv hemmt und damit einen bedeutenderen Effekt erzeugte als die bereits zugelassenen Medikamente mit gleicher Wirkweise wie Donepezil und Tacrine (Eubanks et al. 2006).

In der vorliegenden Arbeit konnte ein signifikant geringerer Abeta Plaqueload im Cortex von weiblichen THC-behandelten 5XFAD-Mäusen detektiert werden. Die gezeigten Ergebnisse konnten von unserer Arbeitsgruppe in vivo mittels ${ }^{18} \mathrm{~F}$-Florbetaben im AmyloidPET-MRT bestätigt werden (unveröffentlichte Daten der Arbeitsgruppe). In Zusammenschau mit den Ergebnissen der Verhaltenstests bezüglich eines verbesserten räumlichen Bezugsgedächtnisses und eines normalisierten Angstverhaltens nach THCBehandlung, deutet dies auf eine THC-induzierte Verringerung der schädlichen Wirkung von Beta-Amyloid hin (Chen et al. 2013; Aso et al. 2015). Unter den Mechanismen, die mit den positiven kognitiven Effekten zusammenhängen, spielen vermutlich auch die entzündungsmodulierenden Eigenschaften von THC eine Rolle (Absatz 4.3.2).

Wie THC die Pathologie von Amyloid-Plaques beeinflusst, ist Gegenstand aktueller Forschung. Cao et al. (2014) erklärten sich die Effekte über eine mögliche CB1-Rezeptor vermittelte Suppression von Mikroglia und anderen Entzündungszellen. Insbesondere der Zusammenhang von Neuroinflammation und die Reduktion von Amyloid-Plaques sollte weiterhin erforscht werden, da bislang noch nicht geklärt werden konnte, ob die Neuroprotektion von Cannabinoiden durch die antientzündliche Wirkung oder dem Eingriff in die Beta-Amyloid-Synthese zustande kommt. Eine Behandlung mit dem potenten synthetischen Cannabinoid HU210, welches die 100fache Potenz von THC aufweist und im Gegensatz zu THC als voller Agonist am CB1-Rezeptor wirkt, zeigte interessanterweise keinen Effekt auf die Beta-Amyloid-Synthese im APP23/PS45Mausmodell (Chen et al. 2010). Unabhängig von einer induzierten Hemmung der 
Cyclooxygenase-2 (COX-2), die an der CB1-rezeptorvermittelten Signaltransduktion beteiligt sein soll, ergab eine vierwöchige Behandlung von viermonatigen 5XFAD-Mäusen mit $3 \mathrm{mg} / \mathrm{kg} \mathrm{KG}$ eine signifikante Reduktion von Amyloid-Plaques im Cortex und Hippocampus (Chen et al. 2013). Dies legt nahe, dass neben einem CB1-Rezeptor vermittelten Mechanismus auch andere molekulare Abläufe in zukünftigen Studien untersucht werden sollten.

Die Datenlage hinsichtlich des Einflusses von CBD auf die Plaquepathologie ist ebenfalls noch sehr gering. In vitro Studien beschrieben einen neuroprotektiven Effekt von CBD gegen Beta-Amyloid-Toxizität, Schutz vor oxidativem Stress und damit ein verlängertes Zellüberleben in PC12-Zellen (Iuvone et al. 2004). Auch in SH-SY5Y-Zellen, einem menschlichen in vitro Neuronenmodell, zeigte sich nach CBD-Behandlung eine verminderte Apoptoserate und ein Schutz gegen toxisches Beta-Amyloid (Janefjord et al. 2014; Scuderi et al. 2014). Neben einem positiven Effekt von $50 \mathrm{mg} / \mathrm{kg} \mathrm{KG} \mathrm{CBD}$ auf das Lern- und Sozialverhalten von Mäusen des Alzheimermausmodells APPswe/PS1E9 zeigte sich nach einer Behandlung mit CBD ein moderat reduziertes Level von unlöslichem $A \beta_{40}$ im Hippocampus der Mäuse. Die Neuroinflammation, Neurodegeneration und der PPAR $\gamma$ Marker blieb von der Behandlung unbeeinträchtigt (Watt et al. 2020). Diese Erkenntnisse stehen im Einklang mit einem unbeeinträchtigtem und somit intaktem Lern- und Angstverhalten sowie einer signifikanten Reduktion des Abeta Plaqueloads im Hippocampus aber nicht im Cortex von CBD-behandelten männlichen 5XFAD-Mäusen in der hier vorgelegten Arbeit.

\subsubsection{Auswirkungen von THC und CBD auf die Neuroinflammation von 5XFAD- Mäusen}

Der anti-inflammatorische Effekt von Cannabinoiden ist von großem Interesse, da Neuroinflammation ein wichtiges Charakteristikum der Alzheimer-Krankheit darstellt und somit einen therapeutischer Ansatzpunkt bieten könnte. Ein erhöhtes Vorkommen von Mikroglia und Astrozyten zeigte sich in unmittelbarer Nähe von Amyloid-Plaques (CastroGomez et al. 2019). Diese Mikrogliaproliferation konnte auf die Aktivierung von Zytokinen, Akute-Phase-Proteinen oder Komplementfaktoren zurückgeführt werden, anstatt auf aggregiertes Beta-Amyloid als Auslöser (Itagaki et al. 1989; Edison et al. 2008; Fuger et al. 2017). Welchen Effekt Cannabinoide auf die Expression von GFAP als Korrelat zur Astrozytenaktivierung sowie IBA1 als Marker für Mikroglia hatte, konnte mittels immunhistochemischer Färbung in dieser Arbeit gezeigt werden. Die Studienlage hinsichtlich des Einflusses von THC oder CBD auf die Neuroinflammation in der Alzheimer-Krankheit ist bis zum jetzigen Zeitpunkt unzureichend. Trotz dieser Tatsache haben einige Studien eine höhere Wirksamkeit des gesamten Cannabis-Phytokomplexes gegenüber der Verwendung seiner einzelnen Komponenten gezeigt, was einen synergistischen Effekt der Wirkstoffe suggeriert (Borgonetti et al. 2019). 
Kürzlich konnte die Kombination von THC und CBD in der Dosis von $10 \mathrm{mg} / \mathrm{kg} \mathrm{KG}$ in einem Tiermodell der neurodegenerativen Erkrankung Multiple Sklerose eine verminderte Ausschüttung von proinflammatorischen Zytokinen und außerdem die Zahl antiinflammatorischer Moleküle signifikant erhöhen (Al-Ghezi et al. 2019). Die gleiche Kombination von pflanzlichen Cannabinoiden bewirkte auch in diversen Tiermodellen eine geringere Expression von GFAP und IBA1. Die 1:1 Kombination mit einer Gesamtdosis von $3 \mathrm{mg} / \mathrm{kg} \mathrm{KG}$ reduzierte in einem Huntington Mausmodell die durch Malonat ausgelöste reaktive Gliose und Astrozytose, was sich in einer signifikanten Verringerung der GFAP und IBA1 Expression mittels Immunfluoreszenz zeigen ließ (Valdeolivas et al. 2012). Die gleiche Forschungsgruppe beschäftigte sich anschließend auch mit dem nicht-psychoaktiven pflanzlichen Cannabisbestandteil Cannabigernol (CBG), dem auch eine neuroprotektive Wirkung zugeschrieben wurde. CBG schwächte die reaktive Mikrogliose in zwei Mausmodellen der neurodegenerativen Erkrankung Chorea Huntington (Valdeolivas et al. 2015).

In der hier durchgeführten Arbeit konnte eine gesteigerte Astrozystose im Rahmen der THC-Behandlung von weiblichen 5XFAD-Mäusen detektiert werden. Signifikant war der Effekt der GFAP-Färbung jedoch wie beim Abeta Plaqueload nur im Cortex, im Hippocampus hingegen nicht.

Diverse Studien evaluierten die Schlüsselwirkung von Mikroglia auf die Alzheimerpathogenese (Castro-Gomez et al. 2019). In der hier gezeigten Arbeit konnte eine signifikant verringerte Expression von IBA1 im Cortex von 5XFAD-Mäusen nach der Behandlung mit THC beobachtet werden.

Bislang konnte die neuroprotektive Wirkung von Cannabinoiden durch eine verminderte Aktivierung von Mikroglia durch den CB2-Rezeptor-Agonist JWH-133 nachgewiesen werden. In elfmonatigen Tg-APP-Mäusen beobachtete man nach vier Monaten oraler Therapie eine reduzierte IBA1 Expression. Interessanterweise blieb der Effekt auf die GFAP Expression aus (Martín-Moreno et al. 2012). Es wird angenommen, dass der CB2Rezeptor durch inflammatorische Reize heraufreguliert wird und nach CB2-RezeptorAgonisten-Gabe mittels eines negativen Feedback-Mechanismus schließlich herunterreguliert werden kann (Chen et al. 2013; Sun et al. 2017).

Tatsächlich scheint die CB1-Rezeptoraktivität in früheren Stadien der Alzheimer-Krankheit höher zu sein, was darauf hindeuten könnte, dass hier eine neuroprotektive Wirkung vorliegt, die über das ECS als Reaktion auf beginnende neuronale Schädigung vermittelt wird. Der CB1-Rezeptor wurde bislang nicht als ursächlich für die Neuroprotektion angesehen, da in Zusammenhang mit neurodegenerativen Erkrankungen eher eine Abnahme der Rezeptorexpression beschrieben wurde (Rodríguez-Cueto et al. 2014).

CBD zeigt eine dosisabhängige Inhibition von GFAP (Esposito et al. 2007). Mäuse, denen intrahippocampal menschliches $A \beta_{42}$ injiziert wurde, zeigten anti-inflammatorische Effekte in Form einer verminderten Expression von GFAP-mRNA und Proteinexpression, 
nachdem sie an sieben aufeinanderfolgenden Tagen täglich mit 2,5 oder $10 \mathrm{mg} / \mathrm{kg} \mathrm{KG}$ CBD intraperitoneal behandelt wurden (Esposito et al. 2007). Die Fähigkeit von CBD reaktive Gliose zu reduzieren wird aber vor allem auf die CB2-Rezeptorbindung als inverser Agonist zurückgeführt, welche als Teil der reaktiven Gliose diskutiert wird (Walter und Stella 2004; Thomas et al. 2007). Gegensätzliche in vitro Ergebnisse zeigten jedoch, dass CBD eine Aktivierung von Mikrogliazellen förderte (Walter und Stella 2004; Thomas et al. 2007; Martín-Moreno et al. 2011).

Die beschriebenen Studien stehen im Einklang mit den in dieser Arbeit gezeigten Ergebnissen. Diese ergaben eine Signifikanz hinsichtlich einer gesteigerten Expression von GFAP bei männlichen CBD-behandelten Mäusen im Hippocampus. Die Expression von IBA1 verringerte sich signifikant im Cortex der 5XFAD-Mäuse. Letzteres ließe sich im Rahmen einer abgeschwächten Entzündungsreaktion interpretieren.

Weitere Studien werden benötigt, um den Zusammenhang des hier gezeigten Effektes molekularbiologisch nachzuvollziehen. Der genaue Mechanismus, mit dem CBD den Einfluss auf die Neuroinflammation ausübt, ist bislang noch ungeklärt. Die Involvierung des PPAR $\gamma$, der nach Aktivierung ebenfalls antiinflammatorische Effekte zeigt, wurde bereits erforscht (Esposito et al. 2011). Die bisherige Datenlage legt nahe, dass der CB2Rezeptor in gesunden Gehirnen nur minimal exprimiert wird und erst unter inflammatorischen Bedingungen und infolge von CB2-Rezeptor-exprimierenden Zellen wie Mikroglia und Astrozyten hochreguliert wird (Maresz et al. 2007). Weiterführende Experimente mit geeigneten CB2-Antikörpern werden benötigt, um die molekularen Mechanismen der hier gezeigten Ergebnisse zu verifizieren.

Sofern die anti-inflammatorischen Wirkungen von Cannabis nicht auf einen einzelnen Bestandteil zurückzuführen ist, wäre es von großem Interesse, das Wissen über das gesamte Potential der Pflanze bei neuroinflammatorischen Erkrankungen wie der AlzheimerKrankheit zu vertiefen.

\subsection{Ausblick}

Im Lichte der nicht suffizienten gängigen Therapieoptionen erlangte die Erforschung alternativer Therapieformen in den letzten Jahren vermehrt Prominenz. Insbesondere das Wiederverwerten von bereits zugelassenen Medikamenten, das so genannte „Drug Repurposing“, bildet eine Basis für neue klinische Forschungen und führt zu einer schnellen Anwendung der Wirkstoffe in klinischen Studien. Auch die Anwendung von Cannabis bildete hierbei keine Ausnahme. Es sollte angemerkt werden, dass eine politische Entscheidung die Zulassung für Cannabis in der Pharmakotherapie beschleunigte und dadurch übliche Zulassungsverfahren umgangen werden konnten (Müller-Vahl und Grotenhermen 2017). Diese bestehen aus einem festgelegten aufwendigem Prozedere, das neben dem Ausschluss von Toxizität, der Evaluation von pharmakodynamischen 
Eigenschaften, auch die Wirksamkeit der Substanz nachweist und schlussendlich in einer langfristigen Überwachung resultiert, um seltene Nebenwirkungen zu entdecken. Gerade deshalb wächst die Zahl an Lifestyleprodukten, in denen insbesondere das freiverkäufliche CBD als Wundermittel proklamiert wird (Bergamaschi et al. 2011). In einem von uns veröffentlichten Paper konnte erstmals die Wirkung von CBD auf das Verhalten gesunder C57BL/6J-Mäuse beschrieben werden (Schleicher et al. 2019). Dies bildet die Grundlage für weitere Forschungen an Menschen, um die Sicherheit und Effektivität dieser Produkte zu garantieren.

Die vorliegende Arbeit beschreibt die Auswirkungen von THC und CBD auf die Alzheimer-Pathologie im 5XFAD-Mausmodell. Eine Aussage, in welchem Zusammenhang die histopathologischen Veränderungen durch die Behandlung von 5XFAD-Mäusen mit THC oder CBD mit einem veränderten Lern- und Angstverhalten in den tierexperimentellen Versuchen stehen, kann nach derzeitigem Stand nicht getroffen werden. Die zu Grunde liegenden molekularen Mechanismen sind bisher nicht ausreichend verstanden und bergen großes Potential hinsichtlich ihrer Erforschung.

Unter Berücksichtigung der geschlechts- und altersabhängigen Ausbildung der PlaquePathologie von 5XFAD-Mäusen sollte in zukünftigen Studien der Einfluss von CBD auf weibliche 5XFAD-Mäuse sowie die Auswirkungen einer THC-Behandlung auf männliche 5XFAD-Mäuse untersucht werden. Dies dient der Identifizierung eines Geschlechtereffekts hinsichtlich einer möglichen unterschiedlichen Sensitivität der 5XFAD-Mäuse gegenüber Cannabinoiden (Marusich et al. 2015). Des Weiteren sollten Untersuchungen bezüglich des Effektes der genannten Substanzen auf unterschiedlichen Altersabschnitten von 5XFAD-Mäusen folgen, um zu evaluieren, ab welchem Zeitpunkt eine Neuromodulation bewirkt werden kann. Interessant wären außerdem Studien, die die Auswirkungen der Kombination aus THC+CBD auf 5XFAD-Mäuse geschlechterspezifisch und altersabhängig untersuchen, um mögliche synergistische oder antagonistische Effekte zu erforschen. Bislang herrschte große Einigkeit darüber, dass CBD durch THC ausgelöste psychotische Symptome abschwächte, was durch empirische Evidenz unterstützt wurde (Bhattacharyya et al. 2010; Morgan et al. 2012; Englund et al. 2013). Dennoch konnte kürzlich gezeigt werden, dass CBD alleine ebenfalls eine berauschende Wirkung und psychotische Zustände auslösen kann. Dies war in Menschen jedoch abhängig vom bisherigen individuellen Cannabiskonsum (Morgan et al. 2018; Solowij et al. 2019).

Unter Berücksichtigung der zahlreichen Mechanismen, die an der Entstehung und dem Fortschreiten der Alzheimer-Krankheit beteiligt sind, bieten Behandlungen, die nur einzelne dieser Mechanismen angreifen, einen geringen Nutzen. Jedoch greifen Cannabinoide als Modulatoren des ECS mehrere dieser Mechanismen parallel gezielt an. $\mathrm{Da}$ das ECS an zahlreichen physiologischen Funktionen beteiligt ist, muss beachtet 
werden, dass Stoffwechselveränderungen, die durch Krankheiten wie dem Morbus Alzheimer ausgelöst werden, eine Manipulation des Systems bewirken könnten.

Klinische Studien, die die Wirksamkeit von Cannabinoiden bei Demenzerkrankungen untersuchen, sind bislang von geringer Evidenz und zeigen außerdem eine große Heterogenität der Befunde. So beschrieben Forschende rund um die Gruppe von Volicer et al. 1997) einen Effekt von $2 \times 2,5 \mathrm{mg}$ THC pro Tag auf eine Reduktion von Verhaltensauffälligkeiten (negativer Affekt mit Wut, Angst, Traurigkeit) bei an Alzheimer erkrankten Personen. Andere beobachteten eine Zunahme von unerwünschtem Verhalten aufgrund einer THC-Gabe und einer dadurch entstandenen Belastung der Pflegenden (Van der Elsen et al. 2015). Metaanalysen bestätigten die hohe Variabilität der Studien und offenbarten damit eine gering allgemeingültige Aussagekraft (Hillen et al. 2019; Bahji et al. 2019).

Die Meinung, dass der höchste Effekt einer Therapie erzielt werden kann, wenn diese bereits in frühen Phasen der Alzheimer-Krankheit eingesetzt wird, wird von den meisten Forschungsgruppen vertreten. Dazu wird eine adäquate Diagnostik zur Früherkennung der Krankheit benötigt. Biomarker sind deshalb von großer Bedeutung, da sie sich bereits in einer frühen Phase der Krankheit feststellen lassen (Hampel et al. 2010; Bateman et al. 2012; Vos et al. 2013). In Kombination mit einem bildgebenden Verfahren wie der PET könnte ein PET-Tracer, der an die Strukturen des ECS bindet, die in Alzheimergehirnen verändert sind, eine zusätzliche diagnostische Möglichkeit bieten. Zusätzlich könnte somit der Effekt von Cannabinoiden auf die Alzheimer-Pathologie weiterführend untersucht werden. Insbesondere Erkenntnisse über den CB2-Rezeptor Mechanismus könnten dadurch gewonnen werden.

Insgesamt werden also weitere kontrollierte Studien benötigt, um die Wirksamkeit von Cannabinoiden als eine alternative Therapie zu derzeitigen Behandlungsmöglichkeiten der Alzheimer-Krankheit zu erforschen. 


\section{$5 \quad$ Zusammenfassung}

Zielsetzung der vorliegenden Arbeit war es, den therapeutischen Einfluss von THC und CBD hinsichtlich Verhaltensänderungen, Amyloid-Plaque-Pathologie, Neuroinflammation und CB1-Rezeptorexpression anhand eines Mausmodells der familiären Form des Morbus Alzheimer zu untersuchen.

$\mathrm{Zu}$ diesem Zweck wurden adulte, fünf Monate alte 5XFAD-Mäuse einer sechswöchigen täglichen Behandlung mit THC, CBD oder eine Vehikelsubstanz mit der Dosierung von $20 \mathrm{mg} / \mathrm{kg} \mathrm{KG}$ unterzogen. Da beide Geschlechter unterschiedlich schnell die alzheimertypischen Pathologien ausbildeten, wurden die männlichen Tiere mit CBD behandelt und mit einer männlichen vehikelbehandelten Kontrollgruppe verglichen, während die mit THC behandelten weiblichen Tiere im Vergleich mit einer weiblichen vehikelbehandelten Kontrollgruppe untersucht wurden. Mithilfe von etablierten Verhaltenstests wurden die Motorik und das Angst- und Lernverhalten der Tiere erforscht. Außerdem wurde das Gewicht überwacht. Dies zeigte sich in allen Behandlungsgruppen konstant. Das Verhalten der männlichen 5XFAD-Mäuse wurde von CBD nicht beeinflusst, sodass unabhängig von der Behandlung ein intaktes Lern- und Angstverhalten vorlag. Eine THC-Behandlung von weiblichen 5XFAD-Mäusen rief diverse Verhaltensänderungen hervor. Neben einem funktionierenden räumlichen Bezugsgedächtnis der weiblichen 5XFAD-Mäusen im MWM nach THC-Behandlung, offenbarten die Tiere ein normalisiertes Angstverhalten im EPM, das dem Niveau gesunder WT-Mäuse glich.

Mithilfe von GFAP, dem Markerproteins für Astrozyten und IBA1, einem Marker für Mikroglia, wurden neuroinflammatorische Effekte der Substanzen untersucht. Es zeigte sich eine signfikante Reduktion von IBA1 im Cortex weiblicher 5XFAD-Mäuse nach THC-Gabe sowie im Hippocampus männlicher 5XFAD-Mäuse nach CBD-Gabe. Die Expression des Astrozytenmarkers GFAP war im Cortex von weiblichen THCbehandelten 5XFAD-Mäusen erhöht. Eine gesteigerte Astrozytose bestand ebenfalls im Hippocampus von männlichen CBD-behandelten Tieren. Inwieweit die beschriebenen Effekte im Zusammenhang mit dem beobachteten reduzierten Abeta Plaqueload im Hippocampus und Cortex nach THC- und CBD-Gabe stehen, bleibt aufgrund ungeklärter molekularer Mechanismen offen. Dennoch verspricht deren Erforschung großes Potential.

Des Weiteren wurde die CB1-Rezeptorexpression im Bereich von Hippocampus und Cortex untersucht. Hierbei zeigte sich eindrücklich die Herabregulation des CB1-Rezeptors in beiden Hirnregionen von weiblichen THC-behandelten 5XFAD-Mäusen. Nach CBDGabe blieb die Expression des CB1-Rezeptors unverändert. Die Veränderungen in der Expression des CB1-Rezeptors sowie der Inflammationsmarker GFAP und IBA1 weisen darauf hin, dass sich das Gehirn der an Alzheimer erkrankten Mäuse durch die Behandlung mit THC und CBD funktionell verändert. 
In der Zusammenschau aller durchgeführten Versuche konnte gezeigt werden, dass insbesondere THC einen modulierenden Einfluss auf das Verhalten und auf molekulare Veränderungen im 5XFAD-Mausmodell hatte.

Das ECS dient als physiologisches Regulationssystem der Erhaltung der Homöostase des Nervensystems und spielt eine bedeutende Rolle in der Entstehung neurodegenerativer Erkrankungen wie der Alzheimer-Krankheit. Insgesamt konnte in dieser Arbeit gezeigt werden, dass die Modulation des ECS durch Cannabinoide eine vielversprechende Therapie der Alzheimer-Krankheit darstellen könnte. Die genaue Wirkungsweise von Cannabinoiden ist noch nicht erforscht, dennoch bestätigt sich aufgrund der vorgelegten Arbeit die Eignung von THC und CBD an die Zielstrukturen des ECS anzubinden. Somit könnten die Wirkstoffe als ein vielversprechendes Therapeutikum dienen. 


\section{$6 \quad$ Literaturverzeichnis}

Adams R, Hunt M, Clark JH (1940): Structure of cannabidiol, a product isolated from the marihuana extract of minnesota wild hemp. I. J Am Chem Soc 62, 196-200

Aguilar S, Gutiérrez V, Sánchez L, Nougier M (2018): Medicinal cannabis policies and practices around the world. International Drug Policy Consortium 2018, 1-32

Ahmad R, Goffin K, van den Stock J, De Winter FL, Cleeren E, Bormans G, Tournoy J, Persoons P, van Laere K, Vandenbulcke M (2014): In vivo type 1 cannabinoid receptor availability in Alzheimer's disease. Eur Neuropsychopharmacol 24, 242-250

Akiyama H, Barger S, Barnum S, Bradt B, Bauer J, Cole GM, Cooper NR, Eikelenboom P, Emmerling M, Fiebich BL et al. (2000): Inflammation and Alzheimer's disease. Neurobiol Aging 21, 383-421

Albert MS, DeKosky ST, Dickson D, Dubois B, Feldman HH, Fox NC, Gamst A, Holtzman DM, Jagust WJ, Petersen RC et al. (2011): The diagnosis of mild cognitive impairment due to Alzheimer's disease: Recommendations from the National Institute on Aging-Alzheimer's Association workgroups on diagnostic guidelines for Alzheimer's disease. Alzheimers Dement 7, $270-279$

Al-Ghezi ZZ, Miranda K, Nagarkatti M, Nagarkatti PS (2019): Combination of cannabinoids, $\Delta$ 9Tetrahydrocannabinol and cannabidiol, ameliorates experimental multiple sclerosis by suppressing neuroinflammation through regulation of miRNA-mediated signaling pathways. Front Immunol 10, $19-21$

Alonso AD, Cohen LS, Corbo C, Morozova V, Elldrissi A, Phillips G, Kleiman FE (2018): Hyperphosphorylation of tau associates with changes in its function beyond microtubule stability. Front Cell Neurosci 12, 1090

Alzheimer A (1907): Über eine eigenartige Erkankung der Hirnrinde. Allg Z Psychiatr 64, 146-148

Alzheimer A, Stelzmann RA, Schnitzlein HN, Murtagh FR (1995): An english translation of Alzheimer's 1907 paper, "Über eine eigenartige Erkrankung der Hirnrinde". Clin Anat $\underline{8}$, 429_ 431

Alzheimer's Association (2019): 2019 Alzheimer's disease facts and figures. Alzheimers Dement $\underline{15}$, $321-387$

Andersen K, Launer LJ, Dewey ME, Letenneur L, Ott A, Copeland JRM, Dartigues JF, KraghSorensen P, Baldereschi M, Brayne C et al. (1999): Gender differences in the incidence of AD and vascular dementia: The EURODEM Studies. Neurology $\underline{\text { 53, }} 1992$

Antunes M, Biala G (2012): The novel object recognition memory: Neurobiology, test procedure, and its modifications. Cogn Process $\underline{13}$, 93-110 
Aso E, Sánchez-Pla A, Vegas-Lozano E, Maldonado R, Ferrer I (2015): Cannabis-based medicine reduces multiple pathological processes in AßPP/PS1 mice. J Alzheimers Dis 43, 977-991

Atwood BK, Mackie K (2010): CB2: A cannabinoid receptor with an identity crisis. Br J Pharmacol 160, 467-479

Bahji A, Meyyappan AC, Hawken ER (2019): Cannabinoids for the neuropsychiatric symptoms of dementia: A systematic review and meta-analysis. Can J Psychiatry 17, 1-12

Barbieri M, Ossato A, Canazza I, Trapella C, Borelli AC, Beggiato S, Rimondo C, Serpelloni G, Ferraro L, Marti M (2016): Synthetic cannabinoid JWH-018 and its halogenated derivatives JWH-018-Cl and JWH-018-Br impair novel object recognition in mice: Behavioral, electrophysiological and neurochemical evidence. Neuropharmacology 109, 254-269

Barnes LL, Wilson RS, Bienias JL, Schneider JA, Evans DA, Bennett DA (2005): Sex differences in the clinical manifestations of Alzheimer disease pathology. Arch Gen Psychiatry $\underline{62}$, 685-691

Bateman RJ, Xiong C, Benzinger TLS, Fagan AM, Goate A, Fox NC, Marcus DS, Cairns NJ, Xie X, Blazey TM et al. (2012): Clinical and biomarker changes in dominantly inherited Alzheimer's disease. N Engl J Med $\underline{367}, 795-804$

Bayer TA, Wirths O (2010): Intracellular accumulation of amyloid-beta - a predictor for synaptic dysfunction and neuron loss in Alzheimer's disease. Front Aging Neurosci 2 , 1-10

Benito C, Núñez E, Tolón RM, Carrier EJ, Rábano A, Hillard CJ, Romero J (2003): Cannabinoid CB 2 receptors and fatty acid amide hydrolase are selectively overexpressed in neuritic plaqueassociated glia in Alzheimer's disease brains. J Neurosci $\underline{23}, 11136-11141$

Bennett DA, Schneider JA, Arvanitakis Z, Kelly JF, Aggarwal NT, Shah RC, Wilson RS (2006): Neuropathology of older persons without cognitive impairment from two community-based studies. Neurology 66, 1837-1844

Bergamaschi MM, Costa Queiroz RH, Zuardi AW, Crippa JAS (2011): Safety and side effects of cannabidiol, a cannabis sativa constituent. Curr Drug Saf $\underline{6}, 237-249$

Bhattacharyya S, Morrison PD, Fusar-Poli P, Martin-Santos R, Borgwardt S, Winton-Brown T, Nosarti C, O' Carroll CM, Seal M, Allen P et al. (2010): Opposite effects of delta-9tetrahydrocannabinol and cannabidiol on human brain function and psychopathology. Neuropsychopharmacology $\underline{35}, 764-774$

Biddle KD, Jacobs HIL, d'Oleire UF, Zide BS, Kirn, Properzi, Rentz DM, Johnson KA, Sperling RA, Donovan NJ (2020): Associations of widowhood and $\beta$-Amyloid with cognitive decline in cognitively unimpaired older adults. JAMA Netw Open $\underline{3}$, e200121

Bilkei-Gorzo A, Albayram O, Draffehn A, Michel K, Piyanova A, Oppenheimer H, Dvir-Ginzberg M, Rácz I, Ulas T, Imbeault $\mathrm{S}$ et al. (2017): A chronic low dose of $\Delta$ 9-tetrahydrocannabinol (THC) restores cognitive function in old mice. Nat Med $\underline{23}, 782-787$

Billings LM, Oddo S, Green KN, McGaugh JL, LaFerla FM (2005): Intraneuronal abeta causes the onset of early Alzheimer's disease-related cognitive deficits in transgenic mice. Neuron $\underline{45}$, 675-688

Blennow K, De Leon MJ, Zetterberg H (2006): Alzheimer's disease. Lancet $\underline{368}$, 387-403 
Blessing EM, Steenkamp MM, Manzanares J, Marmar CR (2015): Cannabidiol as a potential treatment for anxiety disorders. Neurotherapeutics $\underline{12}, 825-836$

Bolognini D, Cascio MG, Parolaro D, Pertwee RG (2012): AM630 behaves as a protean ligand at the human cannabinoid CB2 receptor. Br J Pharmacol 165, 2561-2574

Borgonetti V, Governa P, Montopoli M, Biagi M (2019): Cannabis sativa L. constituents and their role in neuroinflammation. CBC $\underline{15}, 147-158$

Bouaboula M, Hilairet S, Marchand J, Fajas L, Le Fur G, Casellas P (2005): Anandamide induced PPARgamma transcriptional activation and 3T3-L1 preadipocyte differentiation. Eur J Pharmacol 517, 174-181

Bourin M, Hascoët M (2003): The mouse light/dark box test. Eur J Pharmacol $\underline{463}$, 55-65

Boychuk DG, Goddard G, Mauro G, Orellana MF (2015): The effectiveness of cannabinoids in the management of chronic nonmalignant neuropathic pain: A systematic review. J Oral Facial Pain Headache $\underline{29}, 7-14$

Brooks SP, Trueman RC, Dunnett SB (2012): Assessment of motor coordination and balance in mice using the rotarod, elevated bridge, and footprint tests. Curr Protoc Mouse Biol 2, 37-53

Buchman AS, Bennett DA (2014): Loss of motor function in preclinical Alzheimer's disease. Expert Rev Neurother 11, 665-676

Busquets-Garcia A, Bains J, Marsicano G (2018a): CB1 receptor signaling in the brain: Extracting specificity from ubiquity. Neuropsychopharmacology $\underline{43}, 4-20$

Busquets-Garcia A, Gomis-González M, Salgado-Mendialdúa V, Galera-López L, Puighermanal E, Martín-García E, Maldonado R, Ozaita A (2018b): Hippocampal protein kinase c signaling mediates the short-term memory impairment induced by delta9-Tetrahydrocannabinol. Neuropsychopharmacology $\underline{43}, 1021-1031$

Campos AC, Ortega Z, Palazuelos J, Fogaça MV, Aguiar DC, Díaz-Alonso J, Ortega-Gutiérrez S, Vázquez-Villa H, Moreira FA, Guzmán M et al. (2013): The anxiolytic effect of cannabidiol on chronically stressed mice depends on hippocampal neurogenesis: Involvement of the endocannabinoid system. Int J Neuropsychopharmacol 16, 1407-1419

Cao C, Li Y, Liu H, Bai G, Mayl J, Lin X, Sutherland K, Nabar N, Cai J (2014): The potential therapeutic effects of THC on Alzheimer's disease. J Alzheimers Dis $\underline{42}$, 973-984

Casas C, Sergeant N, Itier J-M, Blanchard V, Wirths O, van der Kolk N, Vingtdeux V, van de Steeg E, Ret G, Canton T et al. (2004): Massive CA1/2 neuronal loss with intraneuronal and Nterminal truncated Abeta42 accumulation in a novel Alzheimer transgenic model. Am J Pathol $\underline{165}, 1289-1300$

Castellani RJ, Lee HG, Zhu X, Perry G, Smith MA (2008): Alzheimer disease pathology as a host response. J Neuropathol Exp Neurol 67, 523-531

Castro-Gomez S, Binder J, Heneka MT (2019): Neuroinflammation as motor of Alzheimer's disease. Nervenarzt $\underline{90}, 898-906$ 
Chen B, Bromley-Brits K, He G, Cai F, Zhang X, Song W (2010): Effect of synthetic cannabinoid HU210 on memory deficits and neuropathology in Alzheimer's disease mouse model. Curr Alzheimer Res 7, 255-261

Chen R, Zhang J, Fan N, Teng ZQ, Wu Y, Yang H, Tang YP, Sun H, Song Y, Chen C (2013): $\Delta$ 9THC-caused synaptic and memory impairments are mediated through COX-2 signaling. Cell $\underline{155}, 1154-1165$

Chêne G, Beiser A, Au R, Preis SR, Wolf PA, Dufouil C, Seshadri S (2015): Gender and incidence of dementia in the Framingham Heart Study from mid-adult life. Alzheimers Dement 11, 310 320

Cheng D, Low JK, Logge W, Garner B, Karl T (2014a): Chronic cannabidiol treatment improves social and object recognition in double transgenic APPswe/PS1 $\Delta \mathrm{E} 9$ mice. Psychopharmacology (Berl) 231, 3009-3017

Cheng D, Spiro AS, Jenner AM, Garner B, Karl T (2014b): Long-term cannabidiol treatment prevents the development of social recognition memory deficits in Alzheimer's disease transgenic mice. J Alzheimers Dis $\underline{42}, 1383-1396$

Ciccocioppo R, Antonelli L, Biondini M, Perfumi M, Pompei P, Massi M (2002): Memory impairment following combined exposure to $\Delta 9$-tetrahydrocannabinol and ethanol in rats. Eur J Pharmacol $\underline{449}$, 245-252

Colacurcio DJ, Pensalfini A, Jiang Y, Nixon RA (2018): Dysfunction of autophagy and endosomallysosomal pathways: Roles in pathogenesis of Down syndrome and Alzheimer's disease. Free Radic Biol Med 114, 40-51

Craft RM, Wakley AA, Tsutsui KT, Laggart JD (2012): Sex differences in cannabinoid 1 vs. cannabinoid 2 receptor-selective antagonism of antinociception produced by delta9tetrahydrocannabinol and CP55,940 in the rat. J Pharmacol Exp Ther $\underline{340}$, 787-800

Cunha JM, Carlini EA, Pereira AE, Ramos OL, Pimentel C, Gagliardi R, Sanvito WL, Lander N, Mechoulam R (1980): Chronic administration of cannabidiol to healthy volunteers and epileptic patients. Pharmacology 21, 175-185

Currais A, Quehenberger O, M Armando A, Daugherty D, Maher P, Schubert D (2016): Amyloid proteotoxicity initiates an inflammatory response blocked by cannabinoids. NPJ Aging Mech Dis 2,503

D'Hooge R, De Deyn PP (2001): Applications of the Morris water maze in the study of learning and memory. Brain Res Rev $\underline{36}, 60-90$

Da Silva GE, Takahashi RN (2002): SR 141716A prevents $\Delta$ 9-tetrahydrocannabinol-induced spatial learning deficit in a Morris-type water maze in mice. Prog Neuropsychopharmacol Biol Psychiatry 26, 321-325

De Oliveira Lanna ME, Pimentel MLV, Novis SAP (2014): Diabetes effects in Alzheimer disease: The interactive role of insulin and $A \beta$ peptide. J Alzheimers Dis Parkinsonism 4,151

Deacon RMJ (2013): Measuring Motor Coordination in Mice. J Vis Exp 75, e2609 
Denenberg VH (1969): Open-Field behavior in the rat: What does this mean? Ann NY Acad Sci $\underline{159}, 852-859$

Devane WA, Dysarz FA, Johnson MR, Melvin LS, Howlett AC (1988): Determination and characterization of a cannabinoid receptor in rat brain. Mol Pharmacol $\underline{34}$, 605-613

Devi L, Alldred MJ, Ginsberg SD, Ohno M (2010): Sex- and brain region-specific acceleration of $\beta$ amyloidogenesis following behavioral stress in a mouse model of Alzheimer's disease. Mol Brain $\underline{3}, 34$

Di Marzo V, Goparaju SK, Wang L, Liu J, Bátkai S, Járai Z, Fezza F, Miura GI, Palmiter RD, Sugiura $T$ et al. (2001): Leptin-regulated endocannabinoids are involved in maintaining food intake. Nature $\underline{410}, 822-825$

Dickson DW, Farlo J, Davies P, Crystal H, Fuld P, Yen SH (1988): Alzheimer's disease. A doublelabeling immunohistochemical study of senile plaques. Am J Pathol 132, 86-101

Donovan NJ, Wu Q, Rentz DM, Sperling RA, Marshall GA, Glymour MM (2017): Loneliness, depression and cognitive function in older U.S. adults. Int J Geriatr Psychiatry $\underline{32}, 564-573$

Duff K, Eckman C, Zehr C, Yu X, Prada C-M, Perez-tur J, Hutton M, Buee L, Harigaya Y, Yager $\mathrm{D}$ et al. (1996): Increased amyloid- $\beta 42(43)$ in brains of mice expressing mutant presenilin 1. Nature $\underline{383}, 710-713$

Duncombe J, Kitamura A, Hase Y, Thara M, Kalaria RN, Horsburgh K (2017): Chronic cerebral hypoperfusion: A key mechanism leading to vascular cognitive impairment and dementia. Closing the translational gap between rodent models and human vascular cognitive impairment and dementia. Clin Sci (Lond) 131, 2451-2468

Dysken MW, Sano M, Asthana S, Vertrees JE, Pallaki M, Llorente M, Love S, Schellenberg GD, McCarten JR, Malphurs J et al. (2014): Effect of vitamin E and memantine on functional decline in Alzheimer disease: The TEAM-AD VA cooperative randomized trial. JAMA Netw Open $\underline{311}, 33-44$

Edison P, Archer HA, Gerhard A, Hinz R, Pavese N, Turkheimer FE, Hammers A, Tai YF, Fox N, Kennedy A et al. (2008): Microglia, amyloid, and cognition in Alzheimer's disease: An 11C(R)PK11195-PET and 11CPIB-PET study. Neurobiol Dis $\underline{32}$, 412-419

Edison P, Donat CK, Sastre M (2018): In vivo imaging of glial activation in Alzheimer's disease. Front Neurol $\underline{9}, 625$

Eimer WA, Vassar R (2013): Neuron loss in the 5XFAD mouse model of Alzheimer's disease correlates with intraneuronal A $\beta 42$ accumulation and Caspase-3 activation. Mol Neurodegener $\underline{8}, 1-12$

Englund A, Morrison PD, Nottage J, Hague D, Kane F, Bonaccorso S, Stone JM, Reichenberg A, Brenneisen R, Holt D et al. (2013): Cannabidiol inhibits THC-elicited paranoid symptoms and hippocampal-dependent memory impairment. J Psychopharmacol 27, 19-27

Ennaceur A (2014): Tests of unconditioned anxiety - pitfalls and disappointments. Physiol Behav $\underline{135}, 55-71$ 
Esposito G, Scuderi C, Savani C, Steardo L, De Filippis D, Cottone P, Iuvone T, Cuomo V (2007): Cannabidiol in vivo blunts beta-amyloid induced neuroinflammation by suppressing IL-1beta and iNOS expression. Br J Pharmacol 151, 1272-1279

Esposito G, Scuderi C, Valenza M, Togna GI, Latina V, De Filippis D, Cipriano M, Carratù MR, Iuvone T, Steardo L et al. (2011): Cannabidiol reduces A $\beta$-induced neuroinflammation and promotes hippocampal neurogenesis through PPAR $\gamma$ involvement. PLoS One $\underline{6}$, e28668

Esquerda-Canals G, Montoliu-Gaya L, Güell-Bosch J, Villegas S (2017): Mouse models of Alzheimer's disease. J Alzheimers Dis $\underline{57}, 1171-1183$

Eubanks LM, Rogers CJ, Beuscher AE, Koob GF, Olson AJ, Dickerson TJ, Janda KD (2006): A molecular link between the active component of marijuana and Alzheimer's disease pathology. Mol Pharm $\underline{3}, 773-777$

Fadda P, Robinson L, Fratta W, Pertwee RG, Riedel G (2004): Differential effects of THC- or CBD-rich cannabis extracts on working memory in rats. Neuropharmacology $\underline{47}, 1170-1179$

Fagherazzi EV, Garcia VA, Maurmann N, Bervanger T, Halmenschlager LH, Busato SB, Hallak JE, Zuardi AW, Crippa JA, Schröder N (2012): Memory-rescuing effects of cannabidiol in an animal model of cognitive impairment relevant to neurodegenerative disorders. Psychopharmacology (Berl) 219, 1133-1140

Fan Z, Brooks DJ, Okello A, Edison P (2017): An early and late peak in microglial activation in Alzheimer's disease trajectory. Brain $\underline{140}, 792-803$

Farquhar CE, Breivogel CS, Gamage TF, Gay EA, Thomas BF, Craft RM, Wiley JL (2019): Sex, THC, and hormones: Effects on density and sensitivity of CB1 cannabinoid receptors in rats. Drug Alcohol Depend 194, 20-27

Farrimond JA, Whalley BJ, Williams CM (2012): Cannabinol and cannabidiol exert opposing effects on rat feeding patterns. Psychopharmacology (Berl) $\underline{223}, 117-129$

Feingold D, Weiser M, Rehm J, Lev-Ran S (2016): The association between cannabis use and anxiety disorders: Results from a population-based representative sample. Eur Neuropsychopharmacol 26, $493-505$

Fratiglioni L, Launer LJ, Andersen K, Breteler MM, Copeland JR, Dartigues JF, Lobo A, MartinezLage J, Soininen H, Hofman A (2000): Incidence of dementia and major subtypes in europe: A collaborative study of population-based cohorts. Neurologic diseases in the elderly research group. Neurology $\underline{54}, 10-15$

Fride E, Feigin C, Ponde DE, Breuer A, Hanus L, Arshavsky N, Mechoulam R (2004): (+)Cannabidiol analogues which bind cannabinoid receptors but exert peripheral activity only. Eur J Pharmacol $\underline{506}, 179-188$

Friedman D, Sirven JI (2017): Historical perspective on the medical use of cannabis for epilepsy: Ancient times to the 1980s. Epilepsy Behav 70, 298-301

Fuger P, Hefendehl JK, Veeraraghavalu K, Wendeln AC, Schlosser C, Obermuller U, WegenastBraun BM, Neher JJ, Martus P, Kohsaka S et al. (2017): Microglia turnover with aging and in an Alzheimer's model via long-term in vivo single-cell imaging. Nat Neurosci 20, 1371-1376 
Games D, Adams D, Alessandrini R, Barbour R, Borthelette P, Blackwell C, Carr T, Clemens J, Donaldson T, Gillespie F et al. (1995): Alzheimer-type neuropathology in transgenic mice overexpressing V717F $\beta$-amyloid precursor protein. Nature $\underline{373}$, 523-527

Gaoni Y, Mechoulam R (1964): Isolation, structure, and partial synthesis of an active constituent of hashish. J Am Chem Soc 므, 1646-1647

Giacobini, E, Becker, RE: Alzheimer Disease: Therapeutic Strategies. Advances in Alzheimer Disease Therapy; Birkhäuser Boston, Boston, MA 1994

Gomes FV, Del Bel EA, Guimarães FS (2013): Cannabidiol attenuates catalepsy induced by distinct pharmacological mechanisms via 5-HT1A receptor activation in mice. Prog Neuropsychopharmacol Biol Psychiatry $\underline{46}$, 43-47

Gómez-Isla T, Growdon WB, McNamara MJ, Nochlin D, Bird TD, Arango JC, Lopera F, Kosik KS, Lantos PL, Cairns NJ et al. (1999): The impact of different presenilin 1 and presenilin 2 mutations on amyloid deposition, neurofibrillary changes and neuronal loss in the familial Alzheimer's disease brain: Evidence for other phenotype-modifying factors. Brain 122, 1709_ 1719

Graham BM, Langton JM, Richardson R (2011): Pharmacological enhancement of fear reduction: Preclinical models. Br J Pharmacol $\underline{164}, 1230-1247$

Gras LZ, Kanaan SF, McDowd JM, Colgrove YM, Burns J, Pohl PS (2015): Balance and gait of adults with very mild Alzheimer's disease. J Geriatr Phys Ther $\underline{38}, 1-7$

Grotenhermen F, Müller-Vahl K (2012): The therapeutic potential of cannabis and cannabinoids. Dtsch Arztebl Int 109, 495-501

Grotenhermen F, Häußermann K: Cannabis: Verordnungshilfe für Ärzte. 2. Auflage; Wissenschaftliche Verlagsgesellschaft, Stuttgart 2017

Hamelink C, Hampson A, Wink DA, Eiden LE, Eskay RL (2005): Comparison of cannabidiol, antioxidants, and diuretics in reversing binge ethanol-induced neurotoxicity. J Pharmacol Exp Ther $\underline{314}, 780-788$

Hampel H, Frank R, Broich K, Teipel SJ, Katz RG, Hardy J, Herholz K, Bokde ALW, Jessen F, Hoessler YC et al. (2010): Biomarkers for Alzheimer's disease: Academic, industry and regulatory perspectives. Nat Rev Drug Discov $\underline{9}, 560-574$

Haney M, Rabkin J, Gunderson E, Foltin RW (2005): Dronabinol and marijuana in $\operatorname{HIV}(+)$ marijuana smokers: Acute effects on caloric intake and mood. Psychopharmacology (Berl) $\underline{181}$, $170-178$

Hanger DP, Anderton BH, Noble W (2009): Tau phosphorylation: The therapeutic challenge for neurodegenerative disease. Trends Mol Med 15, 112-119

Harvey BS, Ohlsson KS, Mååg JLV, Musgrave IF, Smid SD (2012): Contrasting protective effects of cannabinoids against oxidative stress and amyloid- $\beta$ evoked neurotoxicity in vitro. Neurotoxicology $\underline{33}, 138-146$

Hebert LE, Weuve J, Scherr PA, Evans DA (2013): Alzheimer disease in the United States (20102050) estimated using the 2010 census. Neurology $\underline{80}, 1778-1783$ 
Hillen JB, Soulsby N, Alderman C, Caughey GE (2019): Safety and effectiveness of cannabinoids for the treatment of neuropsychiatric symptoms in dementia: A systematic review. Ther Adv Drug Saf $\underline{10}, 1-23$

Hirasawa T, Ohsawa K, Imai Y, Ondo Y, Akazawa C, Uchino S, Kohsaka S (2005): Visualization of microglia in living tissues using Iba1-EGFP transgenic mice. J Neurosci Res $\underline{81}, 357-362$

Holcomb L, Gordon MN, McGowan E, Yu X, Benkovic S, Jantzen P, Wright K, Saad I, Mueller R, Morgan D et al. (1998): Accelerated Alzheimer-type phenotype in transgenic mice carrying both mutant amyloid precursor protein and presenilin 1 transgenes. Nat Med 4, 97-100

Holtzman DM, Morris JC, Goate AM (2011): Alzheimer's disease: The challenge of the second century. Sci Transl Med $\underline{3}, 77 \mathrm{sr} 1$

Hsiao K, Chapman P, Nilsen S, Eckman C, Harigaya Y, Younkin S, Yang F, Cole G (1996): Correlative memory deficits, abeta elevation, and amyloid plaques in transgenic mice. Science $\underline{274}, 99-102$

Hughes B, Herron CE (2019): Cannabidiol reverses deficits in hippocampal LTP in a model of Alzheimer's disease. Neurochem Res $\underline{44}, 703-713$

Iba M, Guo JL, McBride JD, Zhang B, Trojanowski JQ, Lee VMY (2013): Synthetic tau fibrils mediate transmission of neurofibrillary tangles in a transgenic mouse model of Alzheimer'slike tauopathy. J Neurosci $\underline{33}, 1024-1037$

Ihl R, Tribanek M, Bachinskaya N (2012): Efficacy and tolerability of a once daily formulation of Ginkgo biloba extract EGb $761{ }^{\circledR}$ in Alzheimer's disease and vascular dementia: Results from a randomised controlled trial. Pharmacopsychiatry $\underline{45}, 41-46$

Itagaki S, McGeer PL, Akiyama H, Zhu S, Selkoe D (1989): Relationship of microglia and astrocytes to amyloid deposits of Alzheimer disease. J Neuroimmunol 24, 173-182

Ito D, Imai Y, Ohsawa K, Nakajima K, Fukuuchi Y, Kohsaka S (1998): Microglia-specific localisation of a novel calcium binding protein, Iba1. Molecular Brain Research $\underline{57}, 1-9$

Iuvone T, Esposito G, Esposito R, Santamaria R, Di Rosa M, Izzo AA (2004): Neuroprotective effect of cannabidiol, a non-psychoactive component from cannabis sativa, on beta-amyloidinduced toxicity in PC12 cells. J Neurochem $\underline{89}, 134-141$

Jack CR, Bennett DA, Blennow K, Carrillo MC, Dunn B, Haeberlein SB, Holtzman DM, Jagust W, Jessen F, Karlawish J et al. (2018): NIA-AA Research Framework: Toward a biological definition of Alzheimer's disease. Alzheimers Dement 14, 535-562

Janefjord E, Mååg JLV, Harvey BS, Smid SD (2014): Cannabinoid effects on $\beta$ amyloid fibril and aggregate formation, neuronal and microglial-activated neurotoxicity in vitro. Cell Mol Neurobiol 34, 31-42

Jawhar S, Trawicka A, Jenneckens C, Bayer TA, Wirths O (2012): Motor deficits, neuron loss, and reduced anxiety coinciding with axonal degeneration and intraneuronal $A \beta$ aggregation in the 5XFAD mouse model of Alzheimer's disease. Neurobiol Aging $\underline{33}$, 196.e29-40 
Jiang Q, Lee CYD, Mandrekar S, Wilkinson B, Cramer P, Zelcer N, Mann K, Lamb B, Willson TM, Collins JL et al. (2008): ApoE promotes the proteolytic degradation of Abeta. Neuron $\underline{58}$, 681-693

Kaduszkiewicz H, Zimmermann T, Beck-Bornholdt H-P, van den Bussche H (2005): Cholinesterase inhibitors for patients with Alzheimer's disease: Systematic review of randomised clinical trials. BMJ $\underline{331}, 321-327$

Kang J, Lemaire HG, Unterbeck A, Salbaum JM, Masters CL, Grzeschik KH, Multhaup G, Beyreuther K, Müller-Hill B (1987): The precursor of Alzheimer's disease amyloid A4 protein resembles a cell-surface receptor. Nature $\underline{325}, 733-736$

Kano M, Ohno-Shosaku T, Hashimotodani Y, Uchigashima M, Watanabe M (2009):

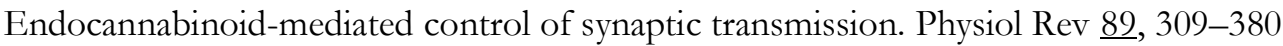

Kasten CR, Zhang Y, Boehm SL (2017): Acute and long-term effects of $\Delta$-tetrahydrocannabinol on object recognition and anxiety-like activity are age- and strain-dependent in mice. Pharmacol Biochem Behav 163, 9-19

Kasten CR, Zhang Y, Boehm SL (2019): Acute cannabinoids produce robust anxiety-like and locomotor effects in mice, but long-term consequences are age- and sex-dependent. Front Behav Neurosci 13,32

Katona I, Freund TF (2012): Multiple functions of endocannabinoid signaling in the brain. Annu Rev Neurosci 35, 529-558

Kedzior KK, Laeber LT (2014): A positive association between anxiety disorders and cannabis use or cannabis use disorders in the general population--a meta-analysis of 31 studies. BMC Psychiatry $\underline{14}, 136$

Kimura R, Ohno M (2009): Impairments in remote memory stabilization precede hippocampal synaptic and cognitive failures in 5XFAD Alzheimer mouse model. Neurobiol Dis $\underline{33}, 229$ 235

Knopman DS, Parisi JE, Salviati A, Floriach-Robert M, Boeve BF, Ivnik RJ, Smith GE, Dickson DW, Johnson KA, Petersen LE et al. (2003): Neuropathology of cognitively normal elderly. J Neuropathol Exp Neurol 62, 1087-1095

Koppel J, Davies P (2008): Targeting the endocannabinoid system in Alzheimer's disease. J Alzheimers Dis $\underline{15}$, 495-504

Kucerova J, Tabiova K, Drago F, Micale V (2014): Therapeutic potential of cannabinoids in schizophrenia. RPCN 2, 13-25

Larson EB, Wang L, Bowen JD, McCormick WC, Teri L, Crane P, Kukull W (2006): Exercise is associated with reduced risk for incident dementia among persons 65 years of age and older. Ann Intern Med 144, 73

Lee JH, Agacinski G, Williams JH, Wilcock GK, Esiri MM, Francis PT, Wong PTH, Chen CP, Lai MKP (2010): Intact cannabinoid CB1 receptors in the Alzheimer's disease cortex. Neurochem Int $\underline{57}, 985-989$ 
Lev-Ran S, Roerecke M, Le Foll B, George TP, McKenzie K, Rehm J (2014): The association between cannabis use and depression: A systematic review and meta-analysis of longitudinal studies. Psychol Med $\underline{44}, 797-810$

Lichtman AH, Dimen KR, Martin BR (1995): Systemic or intrahippocampal cannabinoid administration impairs spatial memory in rats. Psychopharmacology $\underline{119}$, 282-290

Long LE, Chesworth R, Arnold JC, Karl T (2010a): A follow-up study: Acute behavioural effects of $\triangle 9$-THC in female heterozygous Neuregulin 1 transmembrane domain mutant mice. Psychopharmacology (Berl) 211, 277-289

Long LE, Chesworth R, Huang X-F, McGregor IS, Arnold JC, Karl T (2010b): A behavioural comparison of acute and chronic Delta9-tetrahydrocannabinol and cannabidiol in C57BL/6JArc mice. Int J Neuropsychopharmacol 13, 861-876

Lu HC, Mackie K (2016): An introduction to the endogenous cannabinoid system. Biol Psychiatry $\underline{79}, 516-525$

Lutz B, Marsicano G, Maldonado R, Hillard CJ (2015): The endocannabinoid system in guarding against fear, anxiety and stress. Nat Rev Neurosci $\underline{16}, 705-718$

Maarouf CL, Kokjohn TA, Whiteside CM, Macias MP, Kalback WM, Sabbagh MN, Beach TG, Vassar R, Roher AE (2013): Molecular differences and similarities between Alzheimer's disease and the 5XFAD transgenic mouse model of amyloidosis. Biochem Insights $\underline{6}, 1-10$

Mantzavinos V, Alexiou A (2017): Biomarkers for Alzheimer's disease diagnosis. Curr Alzheimer Res $\underline{14}, 1149-1154$

Marchalant Y, Brownjohn PW, Bonnet A, Kleffmann T, Ashton JC (2014): Validating antibodies to the cannabinoid CB2 receptor: Antibody sensitivity is not evidence of antibody specificity. J Histochem Cytochem 62, 395-404

Maresz K, Pryce G, Ponomarev ED, Marsicano G, Croxford JL, Shriver LP, Ledent C, Cheng X, Carrier EJ, Mann MK et al. (2007): Direct suppression of CNS autoimmune inflammation via the cannabinoid receptor CB1 on neurons and CB2 on autoreactive T cells. Nat Med $\underline{13}, 492-$ 497

Martin BK, Szekely C, Brandt J, Piantadosi S, Breitner JCS, Craft S, Evans D, Green R, Mullan M (2008): Cognitive function over time in the Alzheimer's disease anti-inflammatory prevention trial (ADAPT): Results of a randomized, controlled trial of naproxen and celecoxib. Arch Neurol 65, 896-905

Martín-Moreno AM, Reigada D, Ramírez BG, Mechoulam R, Innamorato N, Cuadrado A, De Ceballos ML (2011): Cannabidiol and other cannabinoids reduce microglial activation in vitro and in vivo: Relevance to Alzheimer's disease. Mol Pharmacol 79, 964-973

Martín-Moreno AM, Brera B, Spuch C, Carro E, García-García L, Delgado M, Pozo MA, Innamorato NG, Cuadrado A, De Ceballos ML (2012): Prolonged oral cannabinoid administration prevents neuroinflammation, lowers $\beta$-amyloid levels and improves cognitive performance in Tg APP 2576 mice. J Neuroinflammation 2,8 
Marusich JA, Lefever TW, Antonazzo KR, Craft RM, Wiley JL (2014): Evaluation of sex differences in cannabinoid dependence. Drug Alcohol Depend 137, 20-28

Marusich JA, Craft RM, Lefever TW, Wiley JL (2015): The impact of gonadal hormones on cannabinoid dependence. Exp Clin Psychopharmacol 23, 206-216

Masters CL, Bateman R, Blennow K, Rowe CC, Sperling RA, Cummings JL (2015): Alzheimer's disease. Nat Rev Dis Primers 1, 515

Mayeux R, Stern Y (2012): Epidemiology of Alzheimer disease. Cold Spring Harb Perspect Med 2 , a006239

McKhann GM, Knopman DS, Chertkow H, Hyman BT, Jack CR, Kawas CH, Klunk WE, Koroshetz WJ, Manly JJ, Mayeux R et al. (2011): The diagnosis of dementia due to Alzheimer's disease: Recommendations from the National Institute on Aging-Alzheimer's Association workgroups on diagnostic guidelines for Alzheimer's disease. Alzheimers Dement ㄱ, 263-269

Mecha M, Feliú A, Iñigo PM, Mestre L, Carrillo-Salinas FJ, Guaza C (2013): Cannabidiol provides long-lasting protection against the deleterious effects of inflammation in a viral model of multiple sclerosis: A role for A2A receptors. Neurobiol Dis $\underline{59}$, 141-150

Mechoulam R, Hanuš L (2001): The cannabinoids: An overview. Therapeutic implications in vomiting and nausea after cancer chemotherapy, in appetite promotion, in multiple sclerosis and in neuroprotection. Pain Res Manag $\underline{6}, 67-73$

Mechoulam R, Parker LA, Gallily R (2002): Cannabidiol: An overview of some pharmacological aspects. J Clin Pharmacol $\underline{42}, 11-19$

Mechoulam R, Peters M, Murillo-Rodriguez E, Hanus LO (2007): Cannabidiol-recent advances. Chem Biodivers $\underline{4}, 1678-1692$

Mechoulam R, Parker LA (2013): The endocannabinoid system and the brain. Annu Rev Psychol 64, 21-47

Mechoulam R, Hanuš LO, Pertwee R, Howlett AC (2014): Early phytocannabinoid chemistry to endocannabinoids and beyond. Nat Rev Neurosci $\underline{15}, 757-764$

Melnikova T, Park D, Becker L, Lee D, Cho E, Sayyida N, Tian J, Bandeen-Roche K, Borchelt DR, Savonenko AV (2016): Sex-related dimorphism in dentate gyrus atrophy and behavioral phenotypes in an inducible tTa:APPsi transgenic model of Alzheimer's disease. Neurobiol Dis 96, 171-185

Micale V, Di Marzo V, Sulcova A, Wotjak CT, Drago F (2013): Endocannabinoid system and mood disorders: Priming a target for new therapies. Pharmacol Ther 138, 18-37

Millan MJ, Agid Y, Brüne M, Bullmore ET, Carter CS, Clayton NS, Connor R, Davis S, Deakin B, De Rubeis RJ et al. (2012): Cognitive dysfunction in psychiatric disorders: Characteristics, causes and the quest for improved therapy. Nat Rev Drug Discov 11, 141-168

Miller BR, Dorner JL, Shou M, Sari Y, Barton SJ, Sengelaub DR, Kennedy RT, Rebec GV (2008): Up-regulation of GLT1 expression increases glutamate uptake and attenuates the Huntington's disease phenotype in the R6/2 mouse. Neuroscience $\underline{153}$, 329-337 
Mohammad F, Ho J, Woo JH, Lim CL, Poon DJJ, Lamba B, Claridge-Chang A (2016): Concordance and incongruence in preclinical anxiety models: Systematic review and metaanalyses. Neurosci Biobehav Rev $\underline{68}, 504-529$

Montine TJ, Phelps CH, Beach TG, Bigio EH, Cairns NJ, Dickson DW, Duyckaerts C, Frosch MP, Masliah E, Mirra SS et al. (2012): National Institute on Aging-Alzheimer's Association guidelines for the neuropathologic assessment of Alzheimer's disease: A practical approach. Acta Neuropathol 123, 1-11

Morales P, Hurst DP, Reggio PH (2017): Molecular targets of the phytocannabinoids: A complex picture. Prog Chem Org Nat Prod 103, 103-131

Morgan CJA, Freeman TP, Hindocha C, Schafer G, Gardner C, Curran HV (2018): Individual and combined effects of acute delta-9-tetrahydrocannabinol and cannabidiol on psychotomimetic symptoms and memory function. Transl Psychiatry $\underline{8}, 181$

Morgan CJA, Gardener C, Schafer G, Swan S, Demarchi C, Freeman TP, Warrington P, Rupasinghe I, Ramoutar A, Tan N et al. (2012): Sub-chronic impact of cannabinoids in street cannabis on cognition, psychotic-like symptoms and psychological well-being. Psychol Med $\underline{42}, 391-400$

Mori MA, Meyer E, Soares LM, Milani H, Guimarães FS, De Oliveira RMW (2017): Cannabidiol reduces neuroinflammation and promotes neuroplasticity and functional recovery after brain ischemia. Prog Neuropsychopharmacol Biol Psychiatry $\underline{75}, 94-105$

Morris R (1984): Developments of a water-maze procedure for studying spatial learning in the rat. J Neurosci Methods 11, 47-60

Mücke M, Carter C, Cuhls H, Prüß M, Radbruch L, Häuser W (2016): Cannabinoide in der palliativen Versorgung: Systematische Übersicht und Metaanalyse der Wirksamkeit, Verträglichkeit und Sicherheit. Schmerz $\underline{30}, 25-36$

Mukhopadhyay P, Rajesh M, Horváth B, Bátkai S, Park O, Tanchian G, Gao RY, Patel V, Wink DA, Liaudet L et al. (2011): Cannabidiol protects against hepatic ischemia/reperfusion injury by attenuating inflammatory signaling and response, oxidative/nitrative stress, and cell death. Free Radic Biol Med 무, 1368-1381

Mulder J, Zilberter M, Pasquaré SJ, Alpár A, Schulte G, Ferreira SG, Köfalvi A, Martín-Moreno AM, Keimpema E, Tanila H et al. (2011): Molecular reorganization of endocannabinoid signalling in Alzheimer's disease. Brain 134, 1041-1060

Müller-Vahl K, Schneider U, Prevedel H, Theloe K, Kolbe H, Daldrup T, Emrich HM (2003): Delta 9-tetrahydrocannabinol (THC) is effective in the treatment of tics in Tourette syndrome: A 6-week randomized trial. J Clin Psychiatry 64, 459-465

Müller-Vahl K, Grotenhermen F (2017): Medizinisches Cannabis: Die wichtigsten Änderungen. Dtsch Arztebl 114, 352-356

Munro S, Thomas KL, Abu-Shaar M (1993): Molecular characterization of a peripheral receptor for cannabinoids. Nature $\underline{365}, 61-65$ 
Nelson PT, Head E, Schmitt FA, Davis PR, Neltner JH, Jicha GA, Abner EL, Smith CD, van Eldik LJ, Kryscio RJ et al. (2011): Alzheimer's disease is not "brain aging": Neuropathological, genetic, and epidemiological human studies. Acta Neuropathol 121, 571-587

Oakley H, Cole SL, Logan S, Maus E, Shao P, Craft J, Guillozet-Bongaarts A, Ohno M, Disterhoft J, van Eldik L et al. (2006): Intraneuronal beta-amyloid aggregates, neurodegeneration, and neuron loss in transgenic mice with five familial Alzheimer's disease mutations: Potential factors in amyloid plaque formation. J Neurosci $\underline{26}$, 10129-10140

Oddo S, Caccamo A, Shepherd JD, Murphy MP, Golde TE, Kayed R, Metherate R, Mattson MP, Akbari Y, LaFerla FM (2003): Triple-transgenic model of Alzheimer's disease with plaques and tangles: Intracellular Abeta and synaptic dysfunction. Neuron 39, 409-421

O'Keefe ST, Kazeem H, Philpott RM, Playfer JR, Gosney M, Lye M (1996): Gait disturbance in Alzheimer's disease: A clinical study. Age Ageing 25, 313-316

Onaivi ES, Green MR, Martin BR (1990): Pharmacological characterization of cannabinoids in the elevated plus maze. J Pharmacol Exp Ther 253, 1002-1009

O'Sullivan SE (2007): Cannabinoids go nuclear: Evidence for activation of peroxisome proliferatoractivated receptors. Br J Pharmacol 152, 576-582

Oveisgharan S, Arvanitakis Z, Yu L, Farfel J, Schneider JA, Bennett DA (2018): Sex differences in Alzheimer's disease and common neuropathologies of aging. Acta Neuropathol 136, 887-900

Patra PH, Barker-Haliski M, White HS, Whalley BJ, Glyn S, Sandhu H, Jones N, Bazelot M, Williams CM, McNeish AJ (2019): Cannabidiol reduces seizures and associated behavioral comorbidities in a range of animal seizure and epilepsy models. Epilepsia $\underline{60}, 303-314$

Paxinos G, Franklin KBJ: Paxinos and Franklin's the mouse brain in stereotaxic coordinates, 4. Auflage; Elsevier Academic Press, Amsterdam, Boston, Heidelberg 2013

Pellow S, Chopin P, File SE, Briley M (1985): Validation of open closed arm entries in an elevated plus-maze as a measure of anxiety in the rat. J Neurosci Methods $\underline{14}, 149-167$

Pellow S, File SE (1986): Anxiolytic and anxiogenic drug effects on exploratory activity in an elevated plus-maze: A novel test of anxiety in the rat. Pharmacol Biochem Behav 24, 525-529

Petersen RC, Lopez O, Armstrong MJ, Getchius TSD, Ganguli M, Gloss D, Gronseth GS, Marson D, Pringsheim T, Day GS et al. (2018): Practice guideline update summary: Mild cognitive impairment: Report of the guideline development, dissemination, and implementation subcommittee of the American Academy of Neurology. Neurology $\underline{90}, 126-135$

Petrocellis L, Di Marzo V (2010): Non-CB1, non-CB2 receptors for endocannabinoids, plant cannabinoids, and synthetic cannabimimetics: Focus on G-protein-coupled receptors and transient receptor potential channels. J Neuroimmune Pharmacol $\underline{5}$, 103-121

Petrocellis L, Ligresti A, Moriello AS, Allarà M, Bisogno T, Petrosino S, Stott CG, Di Marzo V (2011): Effects of cannabinoids and cannabinoid-enriched Cannabis extracts on TRP channels and endocannabinoid metabolic enzymes. Br J Pharmacol 163, 1479-1494

Pettersson AF, Engardt M, Wahlund LO (2002): Activity level and balance in subjects with mild Alzheimer's disease. Dement Geriatr Cogn Disord 13, 213-216 
Pittà M, Brunel N, Volterra A (2016): Astrocytes: Orchestrating synaptic plasticity? Neuroscience $\underline{323}, 43-61$

Raber J, Huang Y, Ashford JW (2004): ApoE genotype accounts for the vast majority of AD risk and AD pathology. Neurobiol Aging 25, 641-650

Ramírez BG, Blázquez C, Gómez del Pulgar T, Guzmán M, De Ceballos ML (2005): Prevention of Alzheimer's disease pathology by cannabinoids: Neuroprotection mediated by blockade of microglial activation. J Neurosci $\underline{25}$, 1904-1913

Richard BC, Kurdakova A, Baches S, Bayer TA, Weggen S, Wirths O (2015): Gene dosage dependent aggravation of the neurological phenotype in the 5XFAD mouse model of Alzheimer's disease. J Alzheimers Dis $\underline{45}, 1223-1236$

Riedel G, Fadda P, McKillop-Smith S, Pertwee RG, Platt B, Robinson L (2009): Synthetic and plant-derived cannabinoid receptor antagonists show hypophagic properties in fasted and nonfasted mice. Br J Pharmacol 156, 1154-1166

Rodríguez-Cueto C, Benito C, Fernández-Ruiz J, Romero J, Hernández-Gálvez M, Gómez-Ruiz M (2014): Changes in $\mathrm{CB}(1)$ and $\mathrm{CB}(2)$ receptors in the post-mortem cerebellum of humans affected by spinocerebellar ataxias. Br J Pharmacol 171, 1472-1489

Roher AE, Tyas SL, Maarouf CL, Daugs ID, Kokjohn TA, Emmerling MR, Garami Z, Belohlavek M, Sabbagh MN, Sue LI et al. (2011): Intracranial atherosclerosis as a contributing factor to Alzheimer's disease dementia. Alzheimers Dement $7,436-444$

Ruehle S, Rey AA, Remmers F, Lutz B (2012): The endocannabinoid system in anxiety, fear memory and habituation. J Psychopharmacol 26, 23-39

Russo EB, Burnett A, Hall B, Parker KK (2005): Agonistic properties of cannabidiol at 5-HT1a receptors. Neurochem Res $\underline{30}, 1037-1043$

Russo EB (2007): History of cannabis and its preparations in saga, science, and sobriquet. Chem Biodivers $\underline{4}, 1614-1648$

Ruthirakuhan M, Lanctôt KL, Vieira D, Herrmann N (2019): Natural and synthetic cannabinoids for agitation and aggression in Alzheimer's disease: A meta-analysis. J Clin Psychiatry $\underline{80}, 2$

Ryberg E, Larsson N, Sjögren S, Hjorth S, Hermansson NO, Leonova J, Elebring T, Nilsson K, Drmota T, Greasley PJ (2007): The orphan receptor GPR55 is a novel cannabinoid receptor. Br J Pharmacol 152, 1092-1101

Schaeffer EL, Figueiro M, Gattaz WF (2011): Insights into Alzheimer disease pathogenesis from studies in transgenic animal models. Clinics $\underline{66}, 45-54$

Schiavon AP, Soares LM, Bonato JM, Milani H, Guimarães FS, Weffort de Oliveira RM (2014): Protective effects of cannabidiol against hippocampal cell death and cognitive impairment induced by bilateral common carotid artery occlusion in mice. Neurotox Res $\underline{26}, 307-316$

Schleicher EM, Ott FW, Müller M, Silcher B, Sichler ME, Löw MJ, Wagner JM, Bouter Y (2019): Prolonged cannabidiol treatment lacks on detrimental effects on memory, motor performance and anxiety in C57BL/6J mice. Front Behav Neurosci $\underline{13}, 196$ 
Schmitz C, Rutten BPF, Pielen A, Schäfer S, Wirths O, Tremp G, Czech C, Blanchard V, Multhaup G, Rezaie P et al. (2004): Hippocampal neuron loss exceeds amyloid plaque load in a transgenic mouse model of Alzheimer's disease. Am J Pathol 164, 1495-1502

Schneider M, Kasanetz F, Lynch DL, Friemel CM, Lassalle O, Hurst DP, Steindel F, Monory K, Schafer C, Miederer I et al. (2015): Enhanced functional activity of the cannabinoid type-1 receptor mediates adolescent behavior. J Neurosci $\underline{35}$, 13975-13988

Schramm-Sapyta NL, Cha YM, Chaudhry S, Wilson WA, Swartzwelder HS, Kuhn CM (2007): Differential anxiogenic, aversive, and locomotor effects of THC in adolescent and adult rats. Psychopharmacology (Berl) 191, 867-877

Scopinho AA, Guimarães FS, Corrêa FMA, Resstel LBM (2011): Cannabidiol inhibits the hyperphagia induced by cannabinoid-1 or serotonin-1A receptor agonists. Pharmacol Biochem Behav 98, 268-272

Scuderi C, Steardo L, Esposito G (2014): Cannabidiol promotes amyloid precursor protein ubiquitination and reduction of beta amyloid expression in SHSY5YAPP+ cells through PPAR $\gamma$ involvement. Phytother Res $\underline{28}, 1007-1013$

Selkoe DJ (2011): Resolving controversies on the path to Alzheimer's therapeutics. Nat Med 17, 1060-1065

Serrano-Pozo A, Frosch MP, Masliah E, Hyman BT (2011): Neuropathological alterations in Alzheimer disease. Cold Spring Harb Perspect Med 1, a006189

Shelef A, Barak Y, Berger U, Paleacu D, Tadger S, Plopsky I, Baruch Y (2016): Safety and efficacy of medical cannabis oil for behavioral and psychological symptoms of dementia: An-open label, add-on, pilot study. J Alzheimers Dis $\underline{51}, 15-19$

Shiotsuki H, Yoshimi K, Shimo Y, Funayama M, Takamatsu Y, Ikeda K, Takahashi R, Kitazawa S, Hattori N (2010): A rotarod test for evaluation of motor skill learning. J Neurosci Methods $\underline{189}, 180-185$

Silva L, Black R, Michaelides M, Hurd YL, Dow-Edwards D (2016): Sex and age specific effects of delta-9-tetrahydrocannabinol during the periadolescent period in the rat: The unique susceptibility of the prepubescent animal. Neurotoxicol Teratol $\underline{58}, 88-100$

Sim-Selley LJ (2003): Regulation of cannabinoid CB1 receptors in the central nervous system by chronic cannabinoids. Crit Rev Neurobiol $\underline{15}$, 91-119

Smoker MP, Hernandez M, Zhang Y, Boehm SL (2019): Assessment of acute motor effects and tolerance following self-administration of alcohol and edible $\Delta 9$-Tetrahydrocannabinol in adolescent male mice. Alcohol Clin Exp Res 43, 2446-2457

Sneider JT, Gruber SA, Rogowska J, Silveri MM, Yurgelun-Todd DA (2013): A preliminary study of functional brain activation among marijuana users during performance of a virtual water maze task. J Addict 2013, 1-12

Solas M, Francis PT, Franco R, Ramirez MJ (2013): CB2 receptor and amyloid pathology in frontal cortex of Alzheimer's disease patients. Neurobiol Aging $\underline{34}$, 805-808 
Solowij N, Broyd S, Greenwood LM, van Hell H, Martelozzo D, Rueb K, Todd J, Liu Z, Galettis P, Martin J et al. (2019): A randomised controlled trial of vaporised $\Delta$ 9-tetrahydrocannabinol and cannabidiol alone and in combination in frequent and infrequent cannabis users: Acute intoxication effects. Eur Arch Psychiatry Clin Neurosci 269, 17-35

Spires TL, Hyman BT (2005): Transgenic models of Alzheimer's disease: Learning from animals. NeuroRx $\underline{2}, 423-437$

Stark T, Ruda-Kucerova J, Iannotti FA, D'Addario C, Di Marco R, Pekarik V, Drazanova E, Piscitelli F, Bari M, Babinska Z et al. (2019): Peripubertal cannabidiol treatment rescues behavioral and neurochemical abnormalities in the MAM model of schizophrenia. Neuropharmacology 146, 212-221

Stempel AV, Stumpf A, Zhang HY, Özdoğan T, Pannasch U, Theis AK, Otte DM, Wojtalla A, Rácz I, Ponomarenko A et al. (2016): Cannabinoid type 2 receptors mediate a cell type-specific plasticity in the hippocampus. Neuron $\underline{90}, 795-809$

Strittmatter WJ, Huang DY, Saunders A, Schmechel D, Pericak-Vance M, Roses AD, Weisgraber KH, Goedert M: Apolipoprotein E and Alzheimer's Disease: Therapeutic Implications. In: Giacobini E, Becker RE (Hrsg.): Alzheimer Disease: Therapeutic Strategies. Advances in Alzheimer Disease Therapy. Birkhäuser Boston, Boston, MA 1994, 65-71

Sun L, Dong R, Xu X, Yang X, Peng M (2017): Activation of cannabinoid receptor type 2 attenuates surgery-induced cognitive impairment in mice through anti-inflammatory activity. $\mathrm{J}$ Neuroinflammation 14, 138

Taffe MA, Creehan KM, Vandewater SA (2015): Cannabidiol fails to reverse hypothermia or locomotor suppression induced by $\Delta(9)$-tetrahydrocannabinol in Sprague-Dawley rats. Br J Pharmacol 172, 1783-1791

Tekirian TL, Cole GM, Russell MJ, Yang F, Wekstein DR, Patel E, Snowdon DA, Markesbery WR, Geddes JW (1996): Carboxy terminal of beta-amyloid deposits in aged human, canine, and polar bear brains. Neurobiol Aging 17, 249-257

Teuscher E, Lindequist U: Biogene Gifte: Biologie - Chemie - Pharmakologie mit 178 Abbildungen und 57 Tabellen. Akademischer Verlag, Berlin 1988

Thomas A, Baillie GL, Phillips AM, Razdan RK, Ross RA, Pertwee RG (2007): Cannabidiol displays unexpectedly high potency as an antagonist of CB1 and CB2 receptor agonists in vitro. Br J Pharmacol 150, 613-623

Todd SM, Arnold JC (2016): Neural correlates of interactions between cannabidiol and $\Delta(9)$ tetrahydrocannabinol in mice: Implications for medical cannabis. Br J Pharmacol $\underline{173}$, 53-65

Toledo JB, Arnold SE, Raible K, Brettschneider J, Xie SX, Grossman M, Monsell SE, Kukull WA, Trojanowski JQ (2013): Contribution of cerebrovascular disease in autopsy confirmed neurodegenerative disease cases in the National Alzheimer's Coordinating Centre. Brain 136, $2697-2706$

Tolppanen AM, Taipale H, Hartikainen S (2017): Head or brain injuries and Alzheimer's disease: A nested case-control register study. Alzheimers Dement $\underline{13}, 1371-1379$ 
Underwood W, Anthony R (2013): AVMA Guidelines for the Euthanasia of Animals: 2020 Edition. https://www.avma.org/resources-tools/avma-policies/avma-guidelines-euthanasiaanimals; abgerufen am: 20.01.2021

Valdeolivas S, Satta V, Pertwee RG, Fernández-Ruiz J, Sagredo O (2012): Sativex-like combination of phytocannabinoids is neuroprotective in malonate-lesioned rats, an inflammatory model of Huntington's disease: Role of CB1 and CB2 receptors. ACS Chem Neurosci $\underline{3}, 400-406$

Valdeolivas S, Navarrete C, Cantarero I, Bellido ML, Muñoz E, Sagredo O (2015): Neuroprotective properties of cannabigerol in Huntington's disease: Studies in R6/2 mice and 3nitropropionate-lesioned mice. Neurotherapeutics 12, 185-199

Van der Elsen GAH, Ahmed AIA, Verkes RJ, Feuth T, Van der Marck MA, Olde Rikkert MGM (2015): Tetrahydrocannabinol in behavioral disturbances in dementia: A crossover randomized controlled trial. Am J Geriatr Psychiatry 23, 1214-1224

Vázquez C, Tolón RM, Grande MT, Caraza M, Moreno M, Koester EC, Villaescusa B, RuizValdepeñas L, Fernández-Sánchez FJ, Cravatt BF et al. (2015): Endocannabinoid regulation of amyloid-induced neuroinflammation. Neurobiol Aging $\underline{36}$, 3008-3019

Villemagne VL, Pike KE, Chételat G, Ellis KA, Mulligan RS, Bourgeat P, Ackermann U, Jones G, Szoeke C, Salvado O et al. (2011): Longitudinal assessment of $A \beta$ and cognition in aging and Alzheimer disease. Ann Neurol 69, 181-192

Viudez-Martínez A, García-Gutiérrez MS, Medrano-Relinque J, Navarrón CM, Navarrete F, Manzanares J (2019): Cannabidiol does not display drug abuse potential in mice behavior. Acta Pharmacol Sin 40, 358-364

Viveros MP, Marco EM, File SE (2005): Endocannabinoid system and stress and anxiety responses.

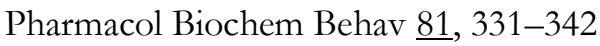

Volicer L, Stelly M, Morris J, McLaughlin J, Volicer BJ (1997): Effects of dronabinol on anorexia and disturbed behavior in patients with Alzheimer's disease. Int J Geriatr Psychiatry 12, 913 919

Vorhees CV, Williams MT (2006): Morris water maze: Procedures for assessing spatial and related forms of learning and memory. Nat Protoc $1,848-858$

Vos SJB, Xiong C, Visser PJ, Jasielec MS, Hassenstab J, Grant EA, Cairns NJ, Morris JC, Holtzman DM, Fagan AM (2013): Preclinical Alzheimer's disease and its outcome: A longitudinal cohort study. Lancet Neurol $\underline{12}, 957-965$

Wada H, Nakajoh K, Satoh-Nakagawa T, Suzuki T, Ohrui T, Arai H, Sasaki H (2001): Risk factors of aspiration pneumonia in Alzheimer's disease patients. Gerontology 47, 271-276

Wagner JM, Sichler ME, Schleicher EM, Franke TN, Irwin C, Löw MJ, Beindorff N, Bouter C, Bayer TA, Bouter Y (2019): Analysis of motor function in the Tg4-42 mouse model of Alzheimer's disease. Front Behav Neurosci 13, 107

Wallace MJ, Blair RE, Falenski KW, Martin BR, DeLorenzo RJ (2003): The endogenous cannabinoid system regulates seizure frequency and duration in a model of temporal lobe epilepsy. J Pharmacol Exp Ther $\underline{307}$, 129-137 
Walsh RN, Cummins RA (1976): The Open-Field Test: A critical review. Psychol Bull $\underline{83}$, 482-504

Walter L, Stella N (2004): Cannabinoids and neuroinflammation. Br J Pharmacol 141, 775-785

Watt G, Shang K, Zieba J, Olaya J, Li H, Garner B, Karl T (2020): Chronic treatment with 50 $\mathrm{mg} / \mathrm{kg}$ cannabidiol improves cognition and moderately reduces A $\beta 40$ levels in 12-month-old male A $\beta P P s w e / P S 1 \Delta E 9$ transgenic mice. J Alzheimers Dis $\underline{74}$, 937-950

Weiner MW, Crane PK, Montine TJ, Bennett DA, Veitch DP (2017): Traumatic brain injury may

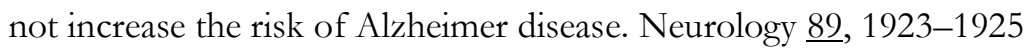

Weingarten MD, Lockwood AH, Hwo SY, Kirschner MW (1975): A protein factor essential for microtubule assembly. Proc Natl Acad Sci U S A $\underline{72}, 1858-1862$

Weinstein A, Livny A, Weizman A (2017): Brain imaging studies on the cognitive, pharmacological and neurobiological effects of cannabis in humans: Evidence from studies of adult users. CPD 22, 6366-6379

Weller J, Budson A (2018): Current understanding of Alzheimer's disease diagnosis and treatment. F1000Res ㄱ, 1161

Westlake TM, Howlett AC, Bonner TI, Matsuda LA, Herkenham M (1994): Cannabinoid receptor binding and messenger RNA expression in human brain: An in vitro receptor autoradiography and in situ hybridization histochemistry study of normal aged and Alzheimer's brains. Neuroscience $\underline{63}, 637-652$

Whiting PF, Wolff RF, Deshpande S, Di Nisio M, Duffy S, Hernandez AV, Keurentjes JC, Lang S, Misso K, Ryder S et al. (2015): Cannabinoids for medical use: A systematic review and metaanalysis. JAMA $\underline{313}, 2456-2473$

WHO (2017): Dementia. https://www.who.int/news-room/fact-sheets/detail/dementia; abgerufen am: 12.03.2019

Wietrzych M, Meziane H, Sutter A, Ghyselinck N, Chapman PF, Chambon P, Krezel W (2005): Working memory deficits in retinoid X receptor gamma-deficient mice. Learn Mem 12, 318326

Winblad B, Wimo A, Engedal K, Soininen H, Verhey F, Waldemar G, Wetterholm AL, Haglund A, Zhang R, Schindler R (2006): 3-year study of donepezil therapy in Alzheimer's disease: effects of early and continuous therapy. Dement Geriatr Cogn Disord 21, 353-363

Wirths O, Bayer TA (2008): Motor impairment in Alzheimer's disease and transgenic Alzheimer's disease mouse models. Genes Brain Behav $\underline{7}, 1-5$

Zhang HY, Gao M, Liu QR, Bi GH, Li X, Yang HJ, Gardner EL, Wu J, Xi ZX (2014): Cannabinoid CB2 receptors modulate midbrain dopamine neuronal activity and dopaminerelated behavior in mice. Proc Natl Acad Sci U S A 111, E5007-15

Zis P, Strydom A (2018): Clinical aspects and biomarkers of Alzheimer's disease in Down syndrome. Free Radic Biol Med 114, 3-9 
Zygmunt PM, Petersson J, Andersson DA, Chuang H, Sørgård M, Di Marzo V, Julius D, Högestätt ED (1999): Vanilloid receptors on sensory nerves mediate the vasodilator action of anandamide. Nature $\underline{400}, 452-457$ 


\section{Danksagung}

An erster Stelle möchte ich mich herzlich bei Frau PD Dr. Yvonne Bouter für die hervorragende Betreuung bedanken. Vielen Dank für die wertvollen Einblicke in die naturwissenschaftliche Grundlagenforschung, die sorgfältige methodische Einarbeitung, die Begleitung zu Kongressen und die Unterstützung bei Problemen jeder Art.

Herrn Prof. Dresbach, der sich als Zweitbetreuer zur Verfügung gestellt hat, danke ich für die Zusammenarbeit und für die Einblicke ins Mover-Projekt.

Des Weiteren möchte ich mich bei Herrn Prof. Bayer bedanken, der bei Fragen gerne und kompetent mit fachlichen Denkanstößen weitergeholfen hat.

Nicht zuletzt gilt mein Dank allen Mitarbeitenden der Arbeitsgruppe für molekulare Psychiatrie, die eine herzliche und freundschaftliche Arbeitsatmosphäre schafften.

Vielen Dank an Frederik Ott und Marius Sichler für die vielen gemeinsamen Laborstunden, die produktiven Gespräche, die gegenseitige Unterstützung und die aus dieser Zeit entstandene Freundschaft. 